
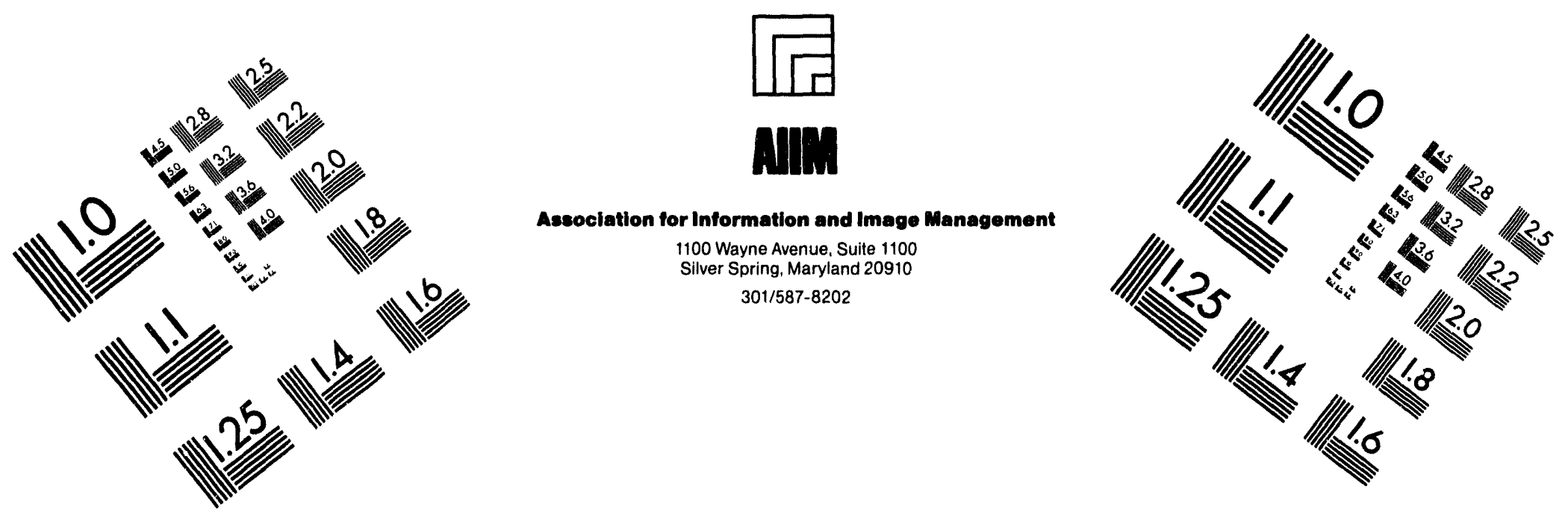

Centimeter

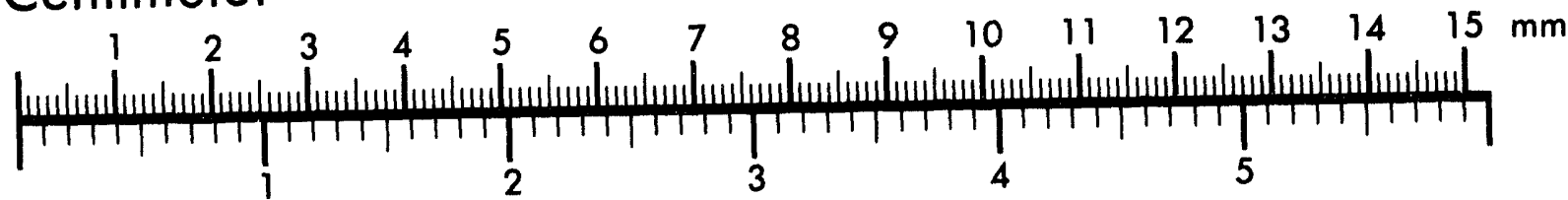
Inches
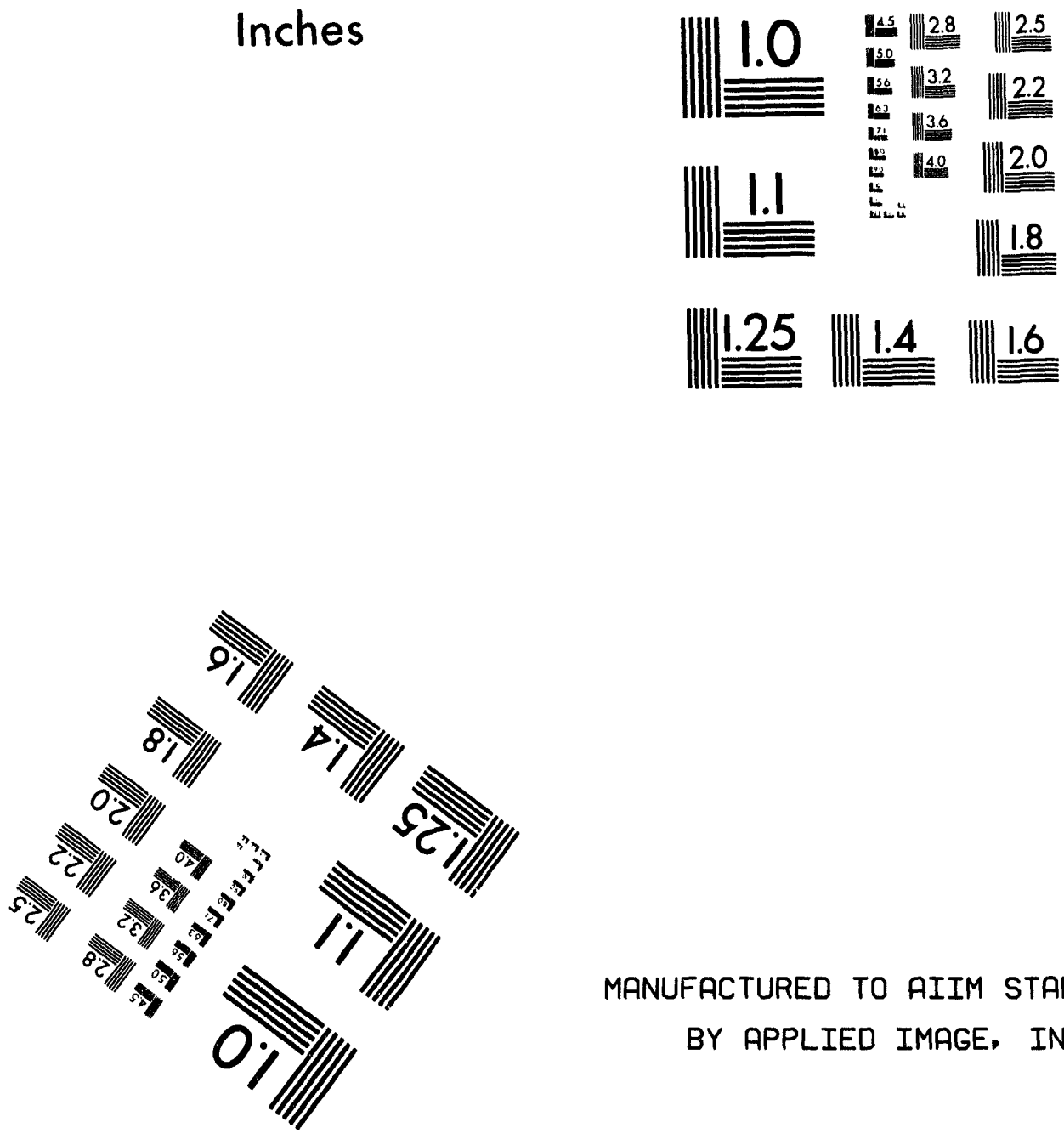

MANUFACTURED TO AIIM STANDARDS

BY APPLIED IMAGE, INC.

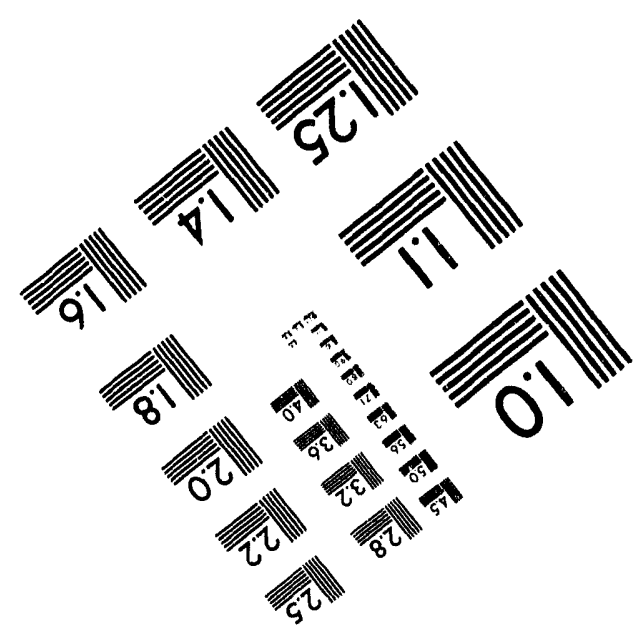



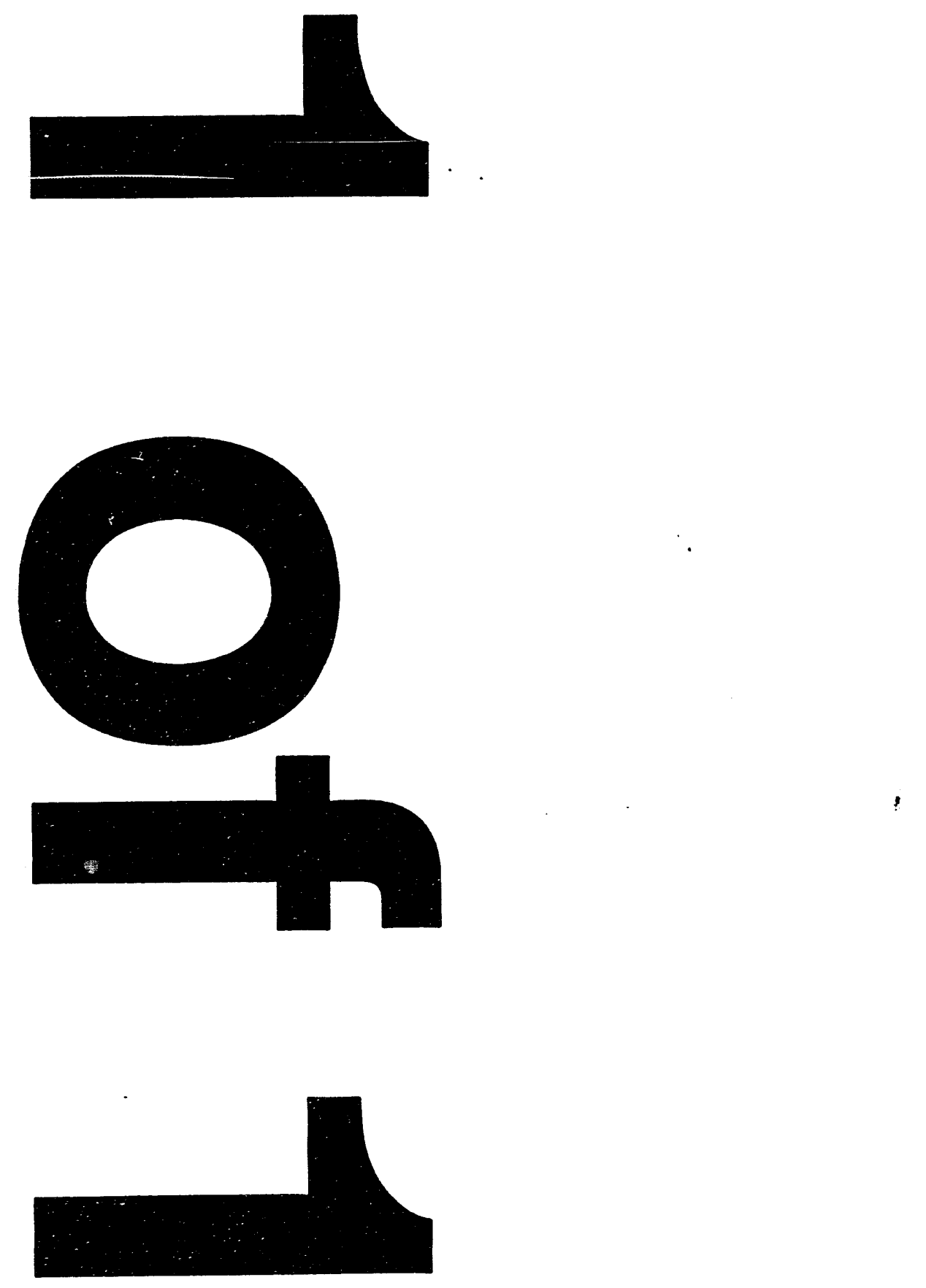


\title{
VORTEX DIODE JET PERFORMANCE AND THEORY
}

\author{
E. D. Houck
}

December 1993

\section{Westinghouse Idaho}

\author{
PREPARED FOR THE \\ DEPARTMENT OF ENERGY \\ IDAHO OPERATIONS OFFICE \\ UNDER CONTRACT DE-AC07-84ID12435
}




\section{ABSTRACT}

Fluidics is the technology dealing with the use of a flowing liquid or gas in various devices for controls and fluid transfers. Existing fluidic technology transfers fluid at approximately the same rate as air lifts and jets. A vortex diode combined in parallel with a jet (vortex diode jet) produces significantly higher transfer rates and retains the fluidic system advantages. This paper presents the proof of concept research and gives design parameters for the vortex diode jet. The goal of this research was to develop a vortex diode jet that would improve fluidic system transfer rates, and to develop and verify the design equations. Proven design equations could then be used to design, and model vortex diode jet systems. This research has shown that vortex diode jets improve fluidic system transfer rate by up to 60 percent and can be modelled with the design equations. 


\section{Summary}

In the nuclear industry steam jets, air jets, and air lifts have been the standard fluid transfer methods. These methods of fluid transfer have several disadvantages such as: evaporation or dilution of the fluid, jet plugging or overheating, and severe transfer height limitations (typically $<20 \mathrm{ft}$.).

Fluidic transfer systems, those that use the fluid to transfer itself, eliminate the diuadvantages of other transfer systems. However, existing fluidic systems have one disadvantage, slow overall transfer rate. The vortex diode jet which produces a synergistic combination of a vortex diode and a jet that increases the transfer rate of existing fluidic systems by $57 \%$ - $73 \%$ over a large range of motive pressure. The vortex diode is combined with the jet such that the vortex diode high pressure drop flow path inlet is coupled with the jet motive fluid inlet. The vortex diode outlet (low pressure drop flow path inlet) is coupled with the jet plenum (suction) line. With this configuration most of the flow during pumping is through the jet to take advantage of the jet's inductive pumping action, and during refill most of the flow is through the low pressure drop flow path of the vortex diode. Thus the vortex diode jet which pumps principally as a jet and refills better than a vortex diode to produce a synergistic combination that nearly doubles the fluidic transfer rates producing a significant improvement over air jets, steam jets, and air lifts.

The vortex diode jet invention, on which DOE has filed a patent application, produces a fluidic transfer system that does not evaporate or dilute the transfer fluid, can transfer with a lift of over $60 \mathrm{ft}$ in one stage, allows unbiased samples to be taken, reduces sample scatter, and eliminates mist plugging of HEPA filters that nonfluidic systems produce. The Vortex Diode Jet significantly improves and advances fluidic technology by producing higher quality transfers and samples. Vortex diode jets improve productivity and reduce transfer and sampling costs by reducing 
fluid biasing, sample scatter, and transfer failures, eliminating multistage lifts, and reducing HEPA filter usage. The elimination of the mist generated by steam and air jets and air lifts is a significant environmental improvement. 
Abstract

Summary

1.0 Introduction

2.0 Background

3.0 Theory

3.1 Design Equations

4.0 Design Test Conditions

5.0 Experimental Equipment

6.0 Experimental Procedure $\quad 21$

7.0 Results and Discussion 23

7.1 Inlet Flow 23

7.2 Outlet Flow 30

7.3 Inlet and Outlet Pressure Relationship 32

$\begin{array}{ll}7.4 \text { Refill Flow } & 34\end{array}$

7.5 Overall Flow Rate 38

7.6 Construction Effects $\quad 41$

7.7 Use With Sampler $\quad 42$

8.0 Conclusions 43

9.0 Recommendations $\quad 45$

10.0 References $\quad 46$

11.0 Nomenclature $\quad 47$

12.0 Appendix 49

\section{FIGURES}

Figure 1. Vortex Diode 2

Figure 2. Basic Fluidic Transfer System 4

Figure 3. Fluidic Transfer System with Vortex Diode 5

Figure 4. Fluidic Transfer System with Jet 6

Figure 5. Fluidic System with Series Combinations of VDs and Jet 8

Figure 6. Fluidic Transfer System with Vortex Diode Jet 9 
Figure 7. Fluidic Mock-Up

Figure 8. Vortex Diode Jet Dimensions 20

Figure 9. 1/2" Fox Jet Inlet Flow 25

Figure 10. 1/2" Penberthy Jet Inlet Flow 26

Figure 11. 1/4" VD(t) - 1/2" Fox Vortex Diode Jet Inlet Flow 27

Figure 12. Vortex Diode Turbulent $C_{\text {ivd }}$ versus Vortex Diode I.D. 29

Figure 13. 1/4" VD - 1/2" Penberthy Vortex Diode Jet Outlet Flow 31

Figure 14. 1/8" VD - 1/2" Fox VDJ $P_{0}$ versus $P_{1}$ Relationship 33

Figure 15. 1/8" VD - 1/2" Fox $P_{0}$ versus $P_{1}$ Relationship 33

Figure 16. 1/4" $V D(t) \cdot 1 / 2$ " Fox Vortex Diode Jet Refill Time 35

Figure 17. Overal1 Pumping Rate for the 1/2" Fox Jet and the 1/8"

VD. $1 / 2$ " Fox VDJ versus $P_{1}$

Figure 18. Overal1 Pumping Rate for the 1/2" Fox Jet and the 1/8" VD

\section{- 1/2" Fox VDJ versus Transfer Height}

Figure 19. 1/2" Fox Jet Inlet Flow

Figure 20. 1/8" VD - 1/2" Fox Vortex Diode Jet Inlet Flow

Figure 21. 1/4" VD(t) - 1/2" Fox Vortex Diode Jet Inlet Flow

Figure 22. 1/4" VD(s) - 1/2" Fox Vortex Diode Jet Inlet Flow

Figure 23. 1/2" Penberthy Jet Inlet Flow

Figure 24. 1/4" VD - 1/2" Pen. Vortex Diode Jet Inlet Flow

Figure 25. 3/8" VD - 1/2" Pen. Vortex Diode Jet Inlet Flow

Figure 26. 1/2" VD - 1/2" Pen. Vortex Diode Jet Inlet Flow

52

Figure 27. 1/2" Fox Jet Outlet Flow

53

Figure 28. 1/8" VD - 1/2" Fox Vortex Diode Jet Outlet Flow

Figure 29. 1/4" VD(t) - 1/2" Fox Vortex Diode Jet Outlet Flow

Figure 30. 1/4" VD(s) - 1/2" Fox VDJ Outlet Flow

54

Figure 31. 1/2" Penberthy Jet Outlet Flow

55

Figure 32. 1/4" VD - 1/2" Pen. Vortex Diode Jet Outlet Flow 55

Figure 33. 3/8" VD - 1/2" Pen. Vortex Diode Jet Outlet Flow 56

Figure 34. 1/2" VD - 1/2" Pen. Vortex Diode Jet Outlet Flow 56

Figure 35. 1/2" Fox Jet Refill Flow

57

Figure 36. 1/8" VD - 1/2" Fox Vortex Diode Jet Refill Flow

Figure 37. 1/4" VD(t) - 1/2" Fox Vortex Diode Jet Refill Flow 58

Figure 38. 1/4" VD(s) - 1/2" Fox Vortex Diode Jet Refill Flow 58

Figure 39. 1/2" Penberthy Jet Refill Flow 59

Figure 40. 1/4" VD - 1/2" Pen. Vortex Diode Jet Refill Flow 
Figure 41. 3/8" VD - 1/2" Pen. Vortex Diode Jet Refill Flow 60

Figure 42. 1/2" VD - 1/2" Pen. Vortex Diode Jet Refil1 Flow 61

Figure 43. Jetless Refill Flow 61

\section{TABLES}

Table 1. Vortex Diode Jet Dimensions 20

Table 2. Test Configurations $\quad 24$

Table 3. 1/2" Fox Jet Inlet Flow Coefficients 25

Table 4. 1/2" Penberthy Jet Inlet Flow Coefficients 26

Table 5. Transition Point Data 28

Table 6. Observed Transition Reynolds Number 28

Table 7. Vortex Diode Iniet. Flow Coefficients $\left(C_{i v d}=C_{i}-C_{i f}\right) \quad 29$

Table 8. Outlet Flow Coefficients 31

Table 9. $P_{h}$ Intercept and 95\% Confidence Interval 32

Table 10. 1/2" Fox Refill Flow Coefficients 35

Table 11. 1/2" Penberthy Refill Flow Coefficients 36

Table 12. Refill Laminar-Transition Flow Transition Point 37

Table 13. Overall Pumping Rates for a Typical Case $\left(P_{f}=62 \mathrm{psig}\right) \quad 38$

Table 14. Overall Pumping Rates for a Typical Case $\left(P_{f}=84\right.$ psig) 39

Table 15. Overall Pumping Rates for a Typical Case $\left(P_{f}=96\right.$ psig $) \quad 39$ 


\subsection{Introduction}

In the nuclear industry it is very desirable to have fluid transfer systems that do not require direct maintenance in the radiation zone. The radiation fields and chemistry of the solutions quickly destroy most plastics, seals, and moving parts. Moving parts are undesirable due to the required seals and the part motion causes additional frictional wear and increased corrosion rates. Technologies that meet this criterion are jets, air lifts, and fluidics. Fluidics is the technology dealing with the use of a flowing liquid or gas in various devices for controls and fluid transfers. In transfer applications a small pumping chamber is pressurized with a gas driving the solution out of the pumping chamber to the desired destination. Then the pumping chamber is vented and refilled with solution from the feed vessel. The use of the small pumping chamber allows the feed and receiving vessels to be built to low pressure standards, which is a major cost, operations, and safety benefit.

In the nuclear industry, it is also very desirable to produce unbiased samples and to transfer solution without dilution or concentration. Typically, air lifts or jet eductors are used for sampling and solution trailsfers, but air lifts and air jets concentrate and steam jets dilute the solutions they transfer. A third option that is used primarily in Europe and Japan is fluidic pumping of the solution. Unlike gas jet, steam jet, or gas lift transfers, fluidic transfer does not concentrate or dilute the solution being transferred. Other fluidic transfer and fluidic sampling advantages are: (a) very high lift capability. (b) low sample scatter. (c) lower off-gas production with the attendant reduction in HEPA filter consumption and environmental emissions, (d) dependability, and (e) very low maintenance. However, existing fluidic technology transfers fluid at approximately the same rate as air lifts and jets. The problem that prevents fluidic jet pumping from being significantly faster than air lifts is that the jet causes low backfill rate. The low backfill rate limits the overall system performance.

This paper examines the use of an innovative technology to increase fluidic jet pump performance using fluid flow check valves called vortex diodes 
(Figure 1, Reference 1). Vortex diode jets are the parallel combination of a vortex diode and a jet. This combination provides near jet pumping rates with the high vortex diode refill rates. Vortex diode jets produce significantly higher transfer rates and retain the fluidic system advantages by retaining near jet pumping performance, while obtaining high back fill rates characteristic of the vortex diode. This research had six objectives, these were: 1 ) determine the effective jet coefficients and generated curves of the effective jet coefficient for both jets. 2) Evaluate the vortex diode jet theory of a synergistic effect from the two parallel flow paths and technology in this application. 3) Develop a set of operating curves for each variation of the vortex diode jet.

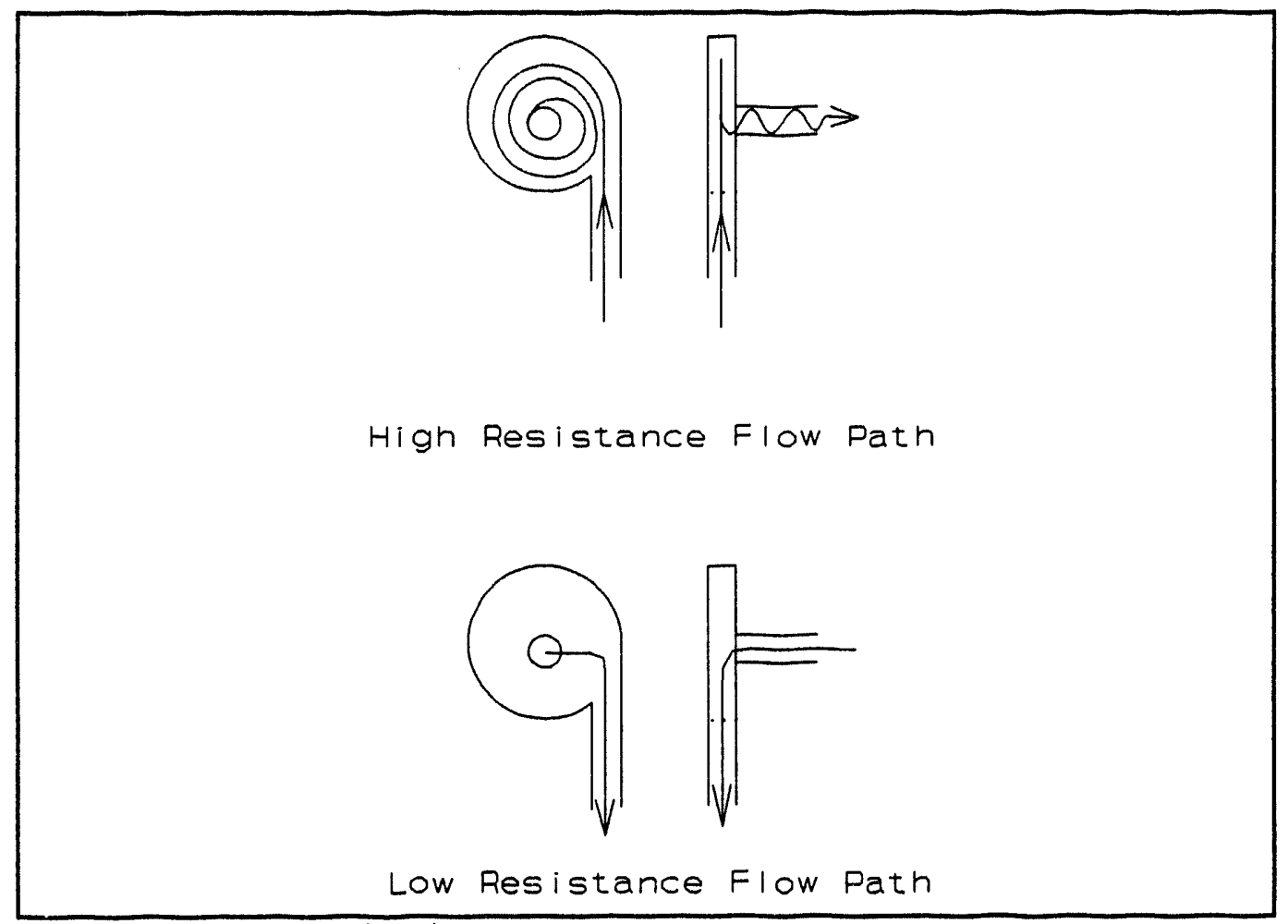

Figure 1. Vortex Diode

4). Evaluate the effect of vortex diode size on performance to develop some understanding of and the design coefficient range for the effect of the vortex diode size on the vortex diode jet (VDJ). 5) Analyze the experimental data and correlate it to the design equations. And 6) determine if the design equations are applicable and usable as vortex diode jet design equations. 


\subsection{Background}

The basic fluidic transfer systems (Figure 2) use gas to pump solution out of a pumping chamber, forcing most of the solution from the pumping chamber into the feed tank, and the rest into the receiving tank. The pumping chamber is then vented and gravity-refilled from the feed tank.

Limitations of this process include: 1) the pumping chamber must refill after each pumpout as the large tanks cannot be pressurized due to structural 1 imitations. And 2) the leakage into the feed tank during pumping limits the overall pumping rate.

The first major improvement on the fluidic transfer system was the installation of a vortex diode (VD), in the outlet line of the feed tank (Figure 3, Reference 2). A vortex diode is a no-moving-parts check valve which consists of a tarigential entry into a cylinder with the exit port located in the center of the cylinder (Figure 1). Vortex diodes are designed to have a higher resistance to flow in one direction (spiral entry) than in the opposite direction (elbow-like flow path). This means the pressure drop flowing through a vortex diode at the same flow rate in one direction is much less than the pressure drop of the fluid flowing through the vortex diode in the opposite direction. Typical pressure turn down ratios are $100 \cdot 150$, flow turn down ratios are thus $10 \cdot 12$ for the same pressure differential. The vortex diode eliminates most of the back flow into the feed tank.

The refill resistance of a vortex diode is essentially equivalent to a tee of the same inlet and outlet diameter. As the vortex diode has a low refill resistance, the pumping chamber refills almost as fast as the basic system, hence the overall pumping rate is greatly increased.

The next major improvement was the use of a jet (Figure 4). The solution from the pumping chamber passes through a jet eductor. entraining the solution from a feed tank, then transferring the combined solution streams to the transfer destination. Since the air is not passed through the jet. the fluidic system essentially uses the solution to be transferred to pump 


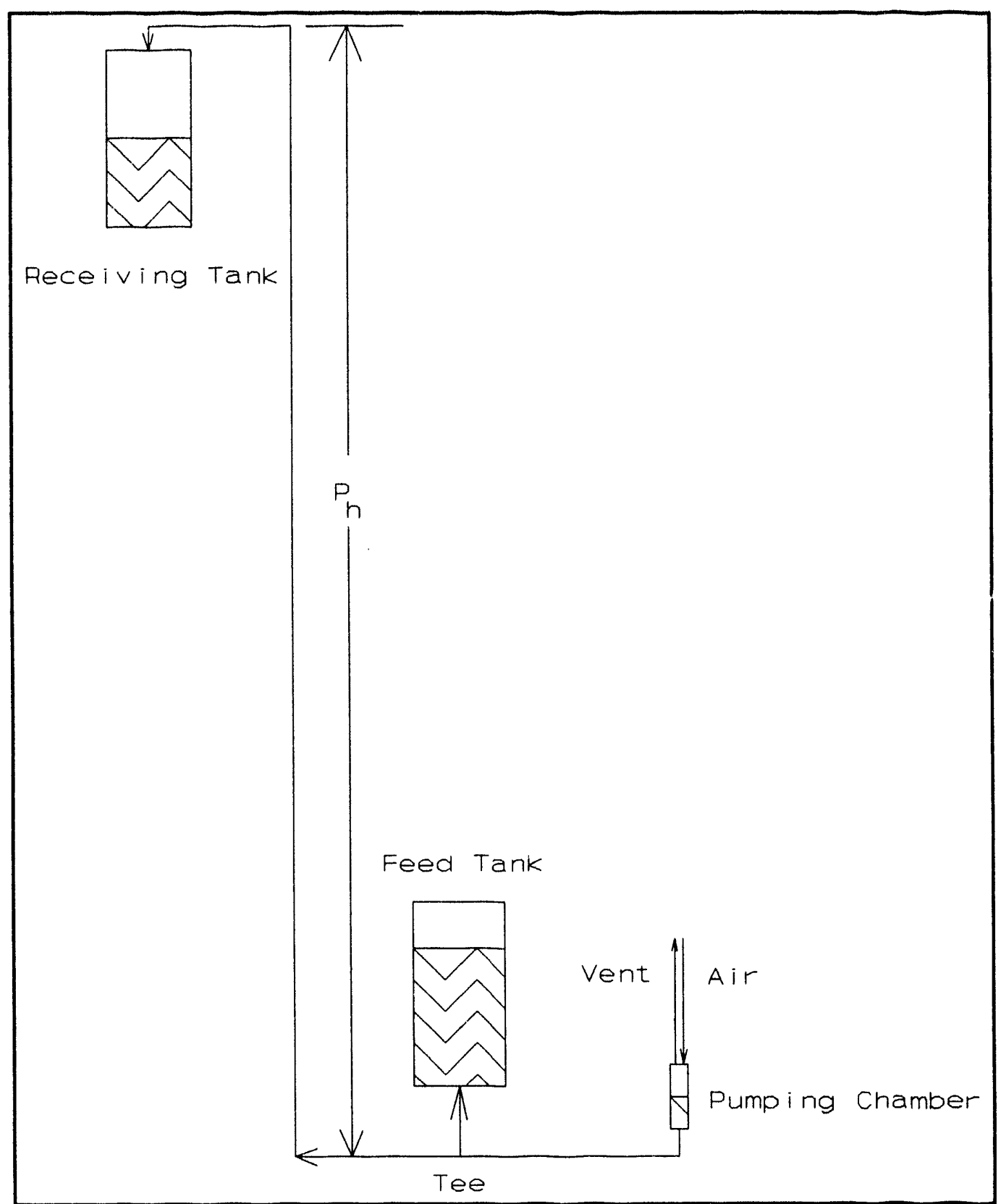

Figure 2. Basic Fluidic Transfer System

4

I 


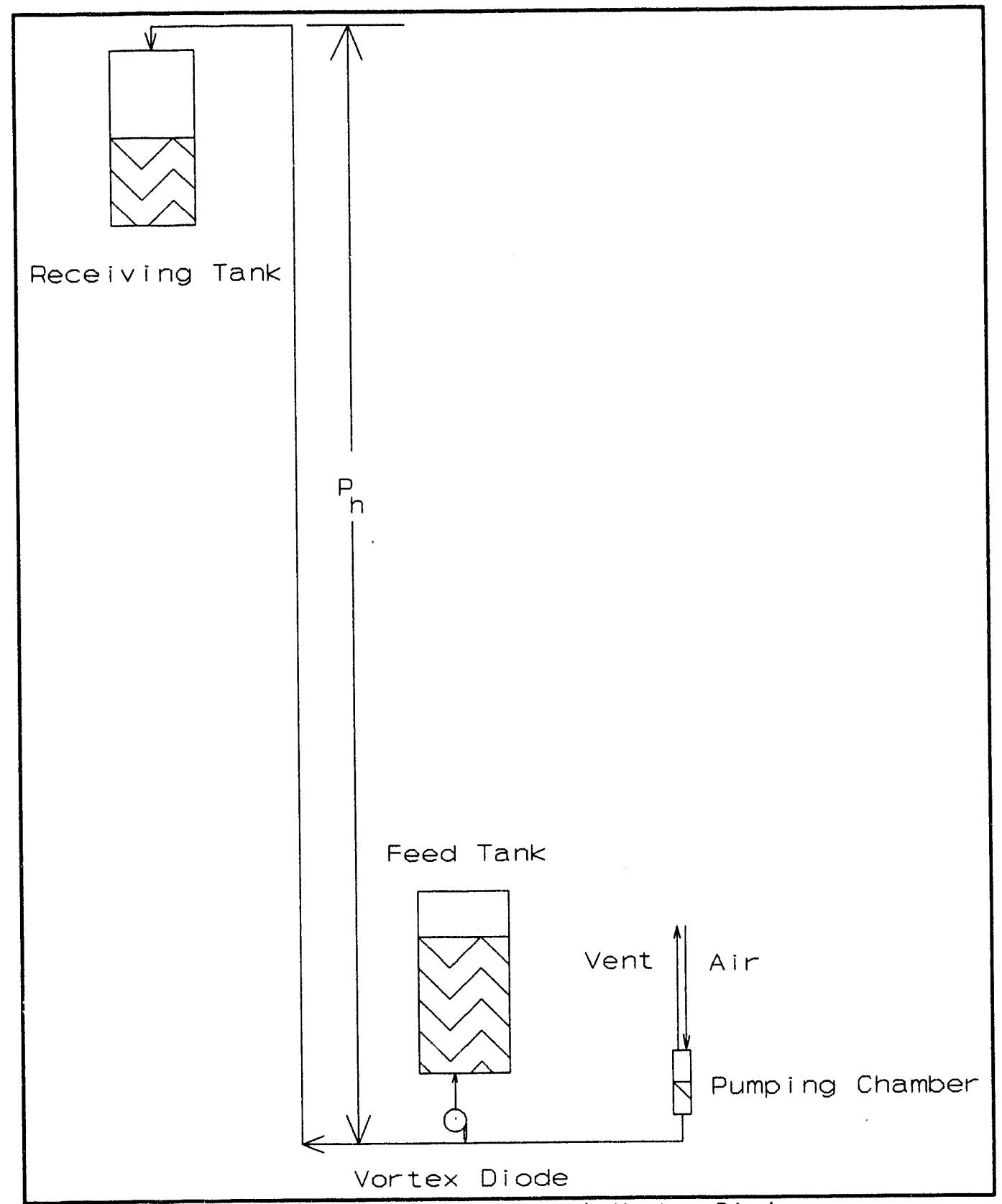

Figure 3. Fluidic Transfer System with Vortex Diode

5 


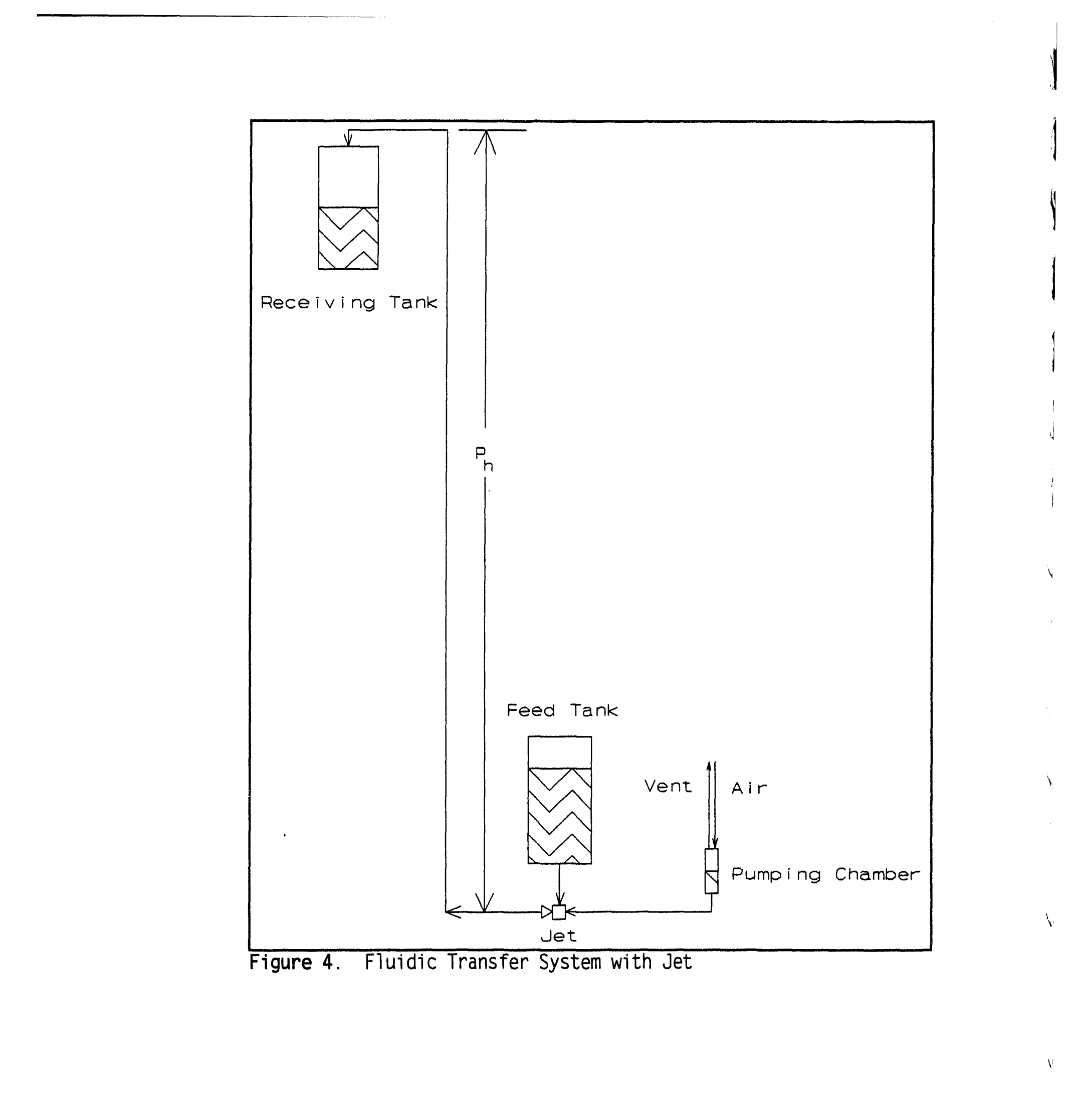


itself. This combination refills very slowly, but pumps much faster: therefore the overall pumping rate for the jet system is better than the vortex diode. Fluidic jet transfer also has a much greater lift capability than air lifts or vortex diode transfer systems.

Vortex diodes in series combination with jets (in the jet plenum and outlet lines) have been tried (Figure 5, Reference 3 ). The vortex diode jet is different from these combinations, because the vortex diode is in parallel combination with the jet. These other combinations are a smal1 improvement over single element systems; however, they do not have the key principle of the synergistic effect that is produced in a vortex diode jet by the bypassing of the jet with the vortex diode to provide two pumping flow paths and two refill flow paths. These combinations only reduced flow in directions that are undesirable, i.e., flow into the feed tank during noninductive pumping. Hence, the simple combinations of vortex diodes and jets do not produce the performance of a vortex diode jet. The vortex diode jet, with two inlet flow paths and two refill flow paths, produces a significant increase in overall fluidic system transfer rate and thus represents a major improvement in fluidic system design. The limiting factor for application of fluidics systems is that the overall transfer rate is no greater than gas jets and/or gas lifts. Since jet and air lift systems are simpler and have approximately the same transfer rates as fluidic system jets, they are usually used. Fluidic systems are generally only used for high lift systems since they are more complex and costly than air lifts. An increase in the fluidic system overal1 transfer rates would increase fluidic system applications by increasing their advantages. The major limiting factor in the pumping rate of a jet fluidic system is the refill rate of the pumping chamber. The jet is essentially the entire resistance in this path; any reduction in the refill time should be accomplished by reducing the refill resistance of the jet.

The vortex diode jet (Figure 6 ) is a new and unique combination (patent applied for) that uses a synergistic effect to produce a pumping device that is better than a vortex diode, an eductor jet, or any combinations of the two that have been tried in the past. This unique combination purposely bypasses the jet with a vortex diode, connecting the jet inlet 


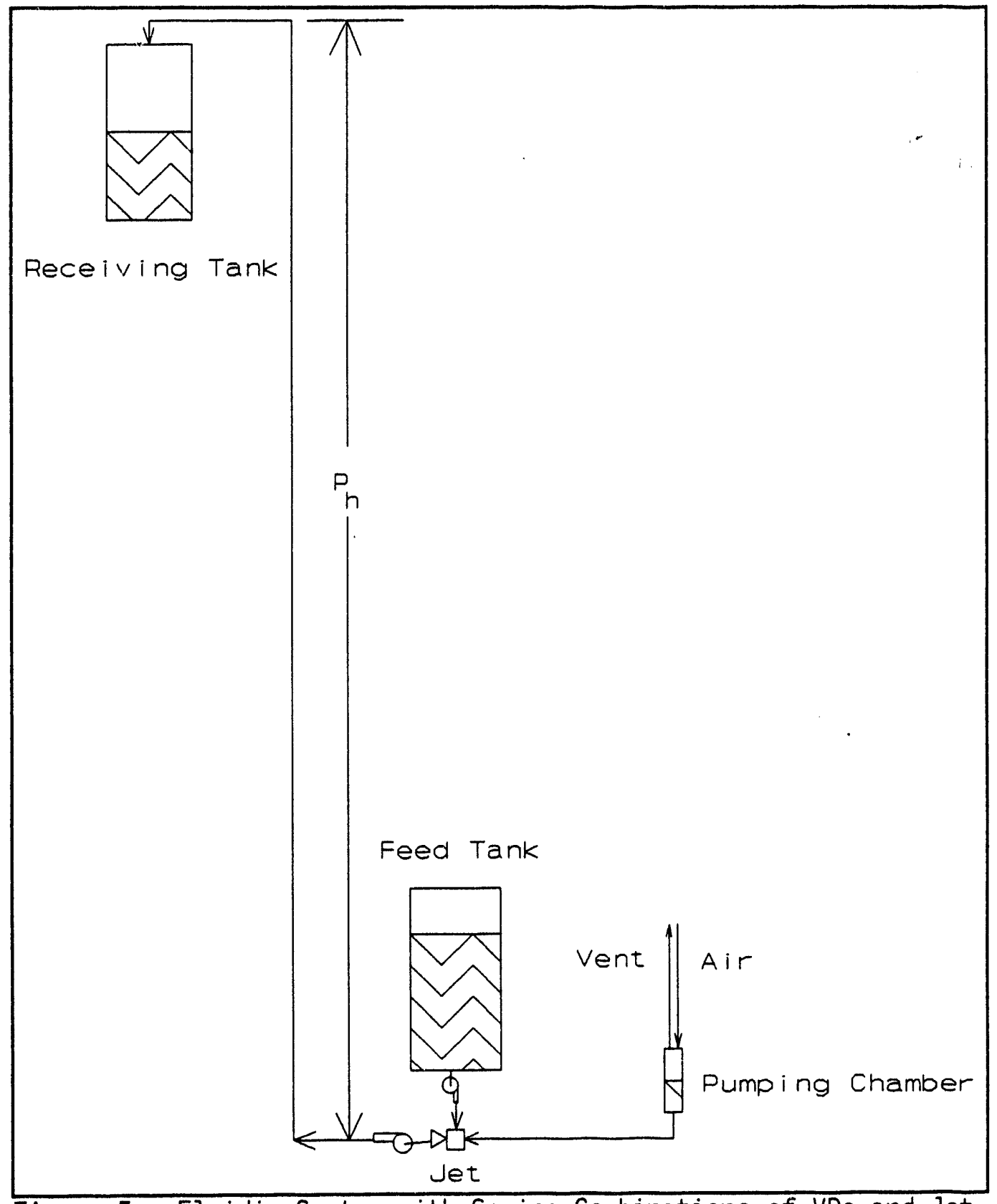

Figure 5. Fluidic System with Series Combinations of GDs and Jet

8 


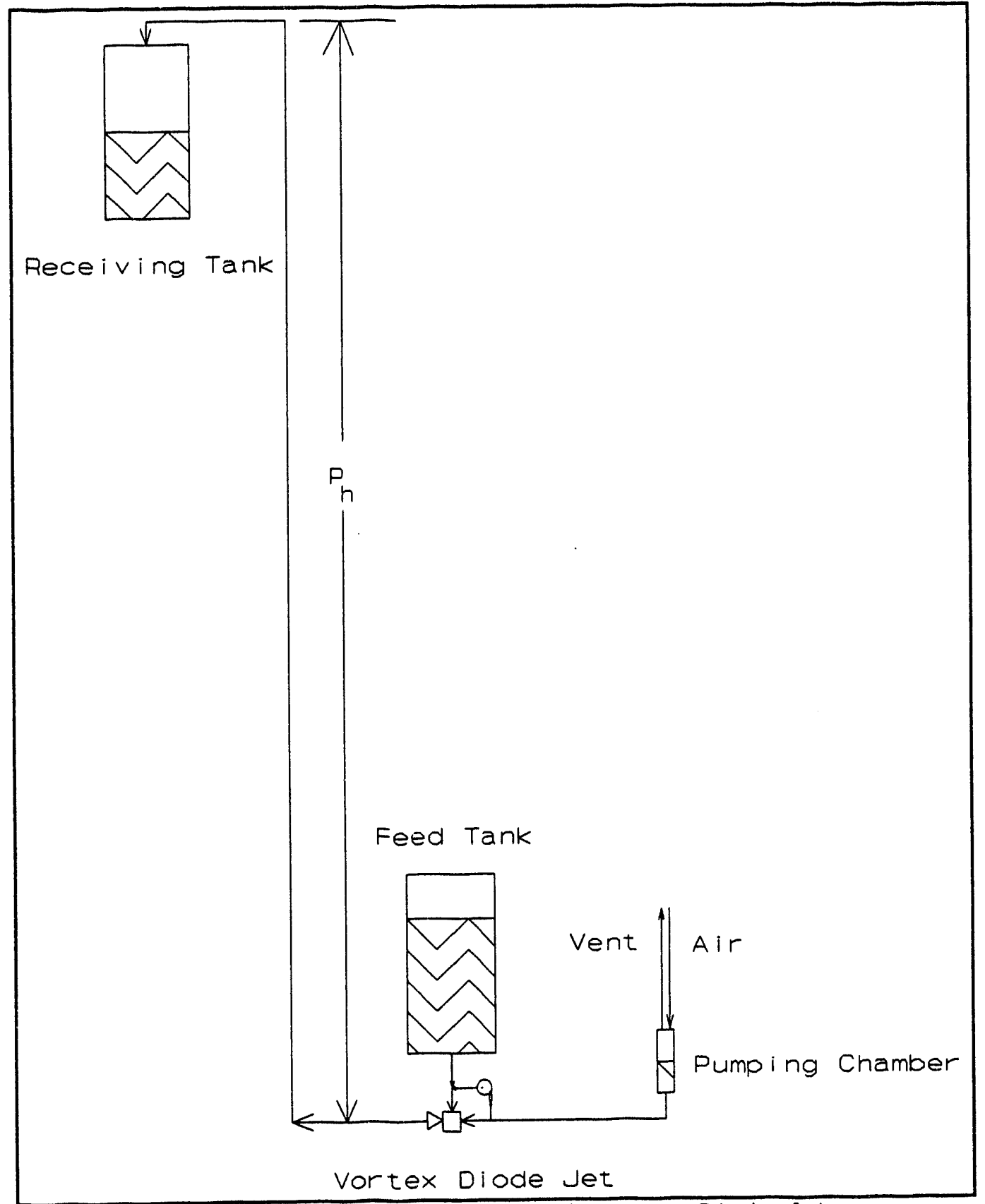

Figure 6. Fluidic Transfer System with Vortex Diode Jet 
line with the jet suction line through the vortex diode. The combination of a jet with an vortex diode in this manner produces a vortex diode jet which leaks some of the motive fluid through the vortex diode (high resistance path) during pumping. This combination refills very fast (primarily through the vortex diode, through the vortex diode's low resistance path). By sacrificing some of the pumping cycle efficiency, the vortex diode jet significantly improves the overall pumping rate. Vortex diode jet fluidic systems overall transfer rate is higher in pumping or sampling applications than existing technology (air lifts, jets, or any other single eductor with vortex diode(s) fluidic systems) and stil1 produce high outlet heads. A vortex diode can transfer only a fraction of the solution fed into it from a pumping chamber to the desired destination; the rest leaks into the feed vessel. Therefore, a vortex diode jet is a significant improvement over a pure vortex diode. Jets are highly resistant to back flow through them during refill, therefore, the actual pumping time can be a twentieth of the total pumping cycle time. A vortex diode jet has a shorter total pumping cycle because of its fast refill and pumping rate, and therefore, higher throughput. The lower inlet flow rate to the jet caused by flow through the vortex diode is more than compensated for by the faster refill time providing more pumping cycles for a given duration at the lower pumping rate. Therefore, the overall pumping rate of the vortex diode jet is greater than that of a jet. 


\subsection{Theory}

The goal of this research was to develop a vortex diode jet system that would improve overall fluidic system transfer rates, and to develop and verify the design equations. These design equations could then be used to design, and model vortex diode jet systems.

Jets use the Bernoulli Effect (Reference 4) to entrain more solution than is fed to the motive inlet to the jet. In a fluidic application this greatly increases the pumping rate of the jet. Not only is more solution pumped than is emptied out of the pumping chamber, but the refill time is much less because only a fraction of the solution transferred has to refill the pumping chamber through the very high resistance path through the jet. The disadvantage is the lower outlet pressure for the same pumping pressure due to the pressure drop across the jet.

A vortex diode provides a high resistance to flow path by tangentially directing fluid into a cylindrical chamber and out the centered exit. High shearing action of flow in spiral paths give high pressure differentiais and low flow rate through the vortex diode. The large frictional losses are due to: (a) the long spiral flow path, and (b) the viscous flow losses between flow streams flowing at different velocities and radii. In the reverse flow direction the vortex diode friction losses are roughly equivalent to a $90^{\circ}$ elbow. Turndown ratios of 150:1 are achievable with vortex diodes (Reference 1 ).

\subsection{Design Equations}

The following sections present the design equations for vortex diode jet performance. With these equations vortex diode jet performance can be modeled, predicted, and vortex diode jets designed. These equations were verified as part of this work. 


\section{Jet Flow Rates and Pressure Drops During Pumping}

The flow rate through a jet inlet orifice is dependent on the inlet and plenum pressures, the solution density and the physical characteristics of the jet. The design equation for the flow rate into the jet is (Figure 7 , Reference 3):

$$
Q_{1 j}=C_{d A_{n}} \sqrt{\left(\frac{2\left(P_{1}-P_{p}\right)}{\rho\left(1-\frac{A_{n}^{2}}{A_{1}^{2}}\right)}\right)}
$$

The flow rate through a jet outlet orifice is dependent on the outlet and plenum pressures, the solution density and the physical characteristics of the jet. For a fixed jet and solution this simplifies following:

$$
Q_{1 y}=C_{d A_{p}} \sqrt{\left(\frac{2\left(P_{1}-P_{p}\right)}{\rho\left(1-\frac{A_{n}^{2}}{A_{1}^{2}}\right)}\right)}=C_{1 y} \sqrt{P_{1}-P_{p}}
$$

The design equation for the flow rate out of the jet with no outlet line resistance is (Reference 3 ):

$$
Q_{0}=A_{n} \sqrt{\left(\frac{2\left(P_{0}-P_{p}\right)}{\rho C_{p}}\right)}=C_{o f} \sqrt{P_{0}-P_{p}}
$$

With an outlet line, Bernoulli and continuity equations are used again to determine flow rate with significant outlet head or resistance.

The Bernoulli equation for the outlet line with a outlet height differential produces the general outlet line flow equation (4).

$$
Q_{0}=C_{0} \sqrt{P_{0}-P_{b}}
$$




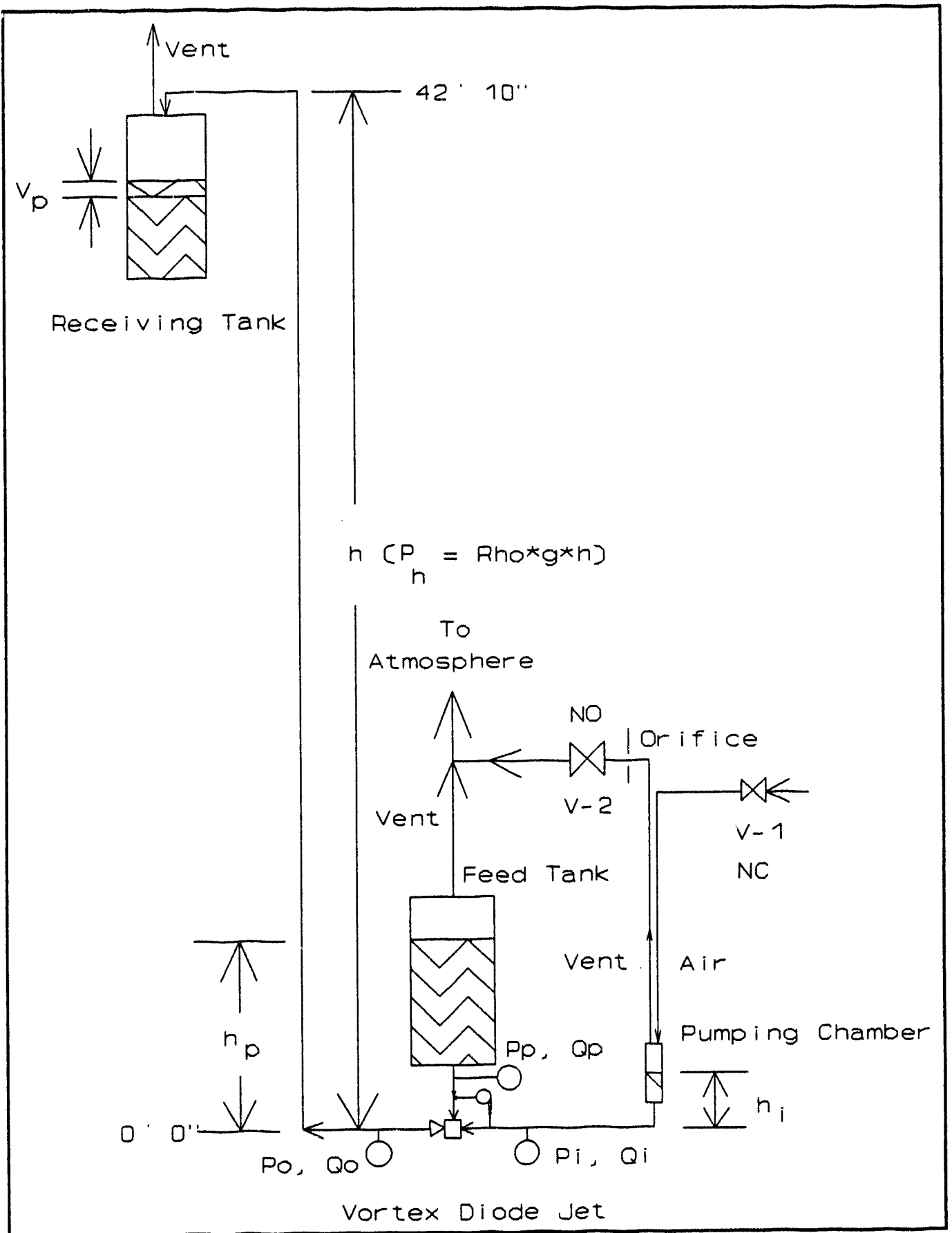

Figure 7. Fluidic Mock-Up

The term for the lift height difference in the outlet line is $P_{h}$. Flow occurs when $P_{0}$ is greater than the $P_{h}$. 
The continuity equation gives the flow rate into the jet from the feed tank (induced flow):

$$
Q_{p}=Q_{0}-Q_{1 y}
$$

\section{Vortex Diode Pumping Flow Rate Equation}

The design equation for the flow rate through the vortex diode in the spiral (pumping) flow path is (References 1 and 2 (with $\left.1 / K_{f}=A_{0} C_{o v}(2)^{1 / 2}\right)$ ):

$$
Q_{f}=\sqrt{\left(\frac{P_{1}-P_{p}}{K_{t} p}\right)}=C_{1 v a d} \sqrt{P_{1}-P_{p}}
$$

\section{Vortex Diode Jet Pumping Flow Rate Equation}

Combining equations 1 and 6 produces the vortex diode jet inlet flow equation:

(7)

$$
Q_{1}=\left(C_{1 j}+C_{1 v d}\right) \sqrt{P_{1}-P_{p}}=C_{1} \sqrt{P_{1}-P_{p}}
$$

\section{Pumping Chamber Refill Flow Rate}

As the levels in vessels are typically measured by solution column heights and not pressures, as was the case with this research, the refill equations are given as a function of the solution heights. The design equation for the pumping chamber refill flow rate through the jet is:

(8)

$$
Q_{x y}=\frac{\sqrt{2 g\left(h_{p}-h_{1}\right)}}{\left(\frac{f_{p, a}+f_{p, 1}}{D_{p}}+\frac{1}{\left.\left(C d_{a, a}^{2}+C d_{a, 1}^{2}\right) A_{a}^{2}+R_{f, 1} * f_{y, 1}\right)}\right)}
$$


Or over a smal1 velocity range where $f_{p, 0}, f_{p, 1}, D_{p}, C d_{0,0}, C_{0,1}, K_{j, 1}$ and $f_{j, 1}$ are relatively constant (Reference 5 ):

$$
Q_{x y}=C_{1} \sqrt{\left(h_{p}-h_{1}\right)}
$$

The design equation (Reference 1) for the pumping chamber refill flow rate through the vortex diode is:

$$
Q_{x v}=\sqrt{\left(\frac{P_{p}-P_{1}}{K_{x} \rho}\right)}
$$

Substituting $\left(h_{p} \cdot h_{1}\right)=\left(P_{p} \cdot P_{1}\right) /\left(\rho^{*} g\right)$ and letting $C_{2}=\left(g / K_{r}\right)^{1 / 2}$

$$
Q_{x v}=C_{2} \sqrt{\left(h_{p}-h_{1}\right)}
$$

Combining Equations 9 and 11 gives:

$$
Q_{x q}=Q_{x y}+Q_{x v}=\left(C_{1}+C_{2}\right) \sqrt{\left(h_{p}-h_{1}\right)}=C_{3} \sqrt{h_{p}-h_{1}}
$$

\section{Total Cycle Time}

Total pumping time is the time required to empty the pumping chamber to the desired level and then to refill it. Total cycle time is dependent on outlet line pressure drop, motive pressure, the refill coefficient of the jet or vortex diode jet, and the differential pressure head between the feed tank and the pumping chamber. The total cycle time equation is:

$$
\text { Total cycle tine }=\frac{V_{p}}{Q_{1}}+\frac{V_{p}}{Q_{x y}+Q_{x v}}
$$




\section{Average Refill Rate}

Integrating the refill equation (13) over the range on the initial and final pumping chamber levels produces the equation for the average refill flow rate (ARFR):

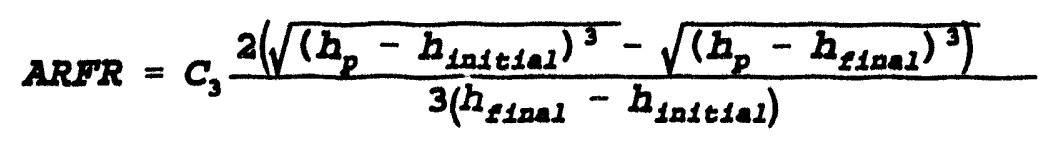

For a particular set of refill heights this equation reduces to:

$$
\text { Average Ref111 Flow Rate }=C_{3} * h_{\text {factor }}
$$

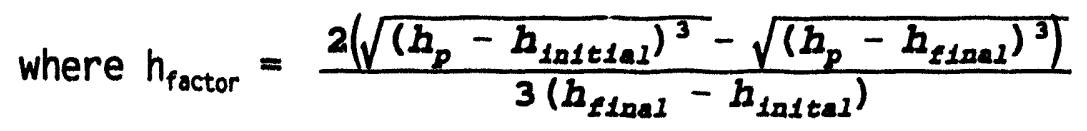

\section{Overall Pumping Rate}

Overall pumping rate is simply the volume pumped into the receiving tank divided by the total cycle time. Overall pumping rate is dependent on the outlet line pressure drop, motive pressure, refill coefficient of the jet/vortex diode jet, and differential pressure head between the jet or vortex diode jet outlet and the receiving tank $\left(P_{h}\right)$ inlet. The simple overall pumping rate equation is:

$$
\text { Overall Pumpling Rate }=\frac{\text { Total Volume Transferred }}{\text { Total Cycle Time }}
$$


Combining the refill and pumping equations with equation (16) produces the overall pumping rate equation:

(17)

$$
\text { Overall Pumping Rate (GPM) }=\frac{C_{0} \sqrt{P_{0}-P_{b}}}{1+\frac{C_{1} \sqrt{P_{1}-P_{p}}}{C_{3} * h_{\text {fuctor }}}}
$$




\subsection{Design Test Conditions}

The fluidic mock-up is shown in Figure 7. Two different jets were used (1/2" Fox and 1/2" Penberthy) each with various sizes of vortex diodes $\left(1 / 8^{\prime \prime}, 1 / 4^{\prime \prime}, 3 / 8^{\prime \prime}\right.$, and 1/2"). A11 of the jet and jet-diode configurations were tested both with and without a fluidic sampler installed in the outlet line. The net effect of a fluidic sampler was to increase the back pressure in the transfer systems. Water was used as the transfer medium. Air was used to drive the water from the pumping chamber through the jet. The jet entrained some liquid from the feed vessel and the combined flows emptied into the receiving tank. When the jet could not overcome the outlet line back pressure, solution flow was into the feed tank with a transient flow into the outlet line until the $P_{0}$ is balanced with a pressure head in the outlet line $\left(P_{h}\right)$. The large outlet line back pressure can be caused by a large lift height, a large pressure drop item in the outlet line (for these tests a fluidic sampler), or a combination of these items. The water level in the feed tank was varied to provide a range of lifts.

Air pressure to the pumping chamber was varied to provide a range of pumping rates so that the inlet and outlet flow coefficients for the jets could be determined. The vent line orifice size was also varied to provide a range of pumping and refill times for the Fox jet. 


\subsection{Experimental Equations}

Figure 7 shows the configurations of the fluidic mock-up. The following were stainless steel: drip pans, pumping chamber, pumping jet (vortex diode or base), tubing fittings, flow and pressure meters, and the tubing between the pumping chamber, pumping jet, feed tank, and the start of the vertical run of the pumping jet outlet line. Two versions of the vortex diode jets were constructed. The Fox jet and the Fox vortex diode jets used the Fox $1 / 2^{\prime \prime}$ - SS, P/N G12007 jet. The Penberthy jet and the Penberthy vortex diode jets used the stainless steel Penberthy 1/2" GL jet.

The two versions of the 1/4" VD - 1/2" Fox vortex diode jet were the twist $(t)$ and slant (s) that had essentially the same construction with different orientation (Figure 8, Table 1). The twist version had the inlet to the vortex diode parallei to the plenum (suction) line of the jet. This twisted the vortex diode out of line with the body of the jet. The slant version had the vortex diode in-line with the body of the jet, that is, the outlet line of the vortex diode was parallel to the body of the jet.

The flow gauges were RCM Series 700 FLO-GAUGE, with stainless steel bodies and cells, and calibrated for water. The inlet flowmeter was a $1 / 2^{n} \cdot 73 \cdot R$ $6 A D(0.5 \cdot 6.0 \mathrm{gpm})$, the plenum flowmeter was a $1 / 2 " \cdot 73 \cdot R \cdot 4 \cdot A D(0.5 \cdot 4.0$ $\mathrm{gpm})$, and the outlet flow meter was a 1/2" -7 3-R-10-AD (1.5 $10.0 \mathrm{gpm})$. Helicoid stainless steel pressure gauges were used. The gauges measured the pressures at the following positions: pumping chamber ( $0-160 \mathrm{psig})$. jet plenum $(0-30 \mathrm{psig})$, and the jet outlet ( $0 \cdot 60 \mathrm{psig})$.

The pumping chamber was an $8^{\prime \prime}$ schedule 80 stainless steel pipe. $3^{\prime} 9^{\prime \prime}$ tall. with an internal volume of 7.91 gallons. The feed tank was a $9^{\prime} 4^{\prime \prime} 5^{\prime \prime}$ tall fiberglass tank with a conical bottom. The receiving tank was a 50 gallon polypropylene tank. The line from the compressor to the pumping chamber. pumping jet outlet line, hold-up tank return line, and pumping chamber vent line were all polyethylene. 


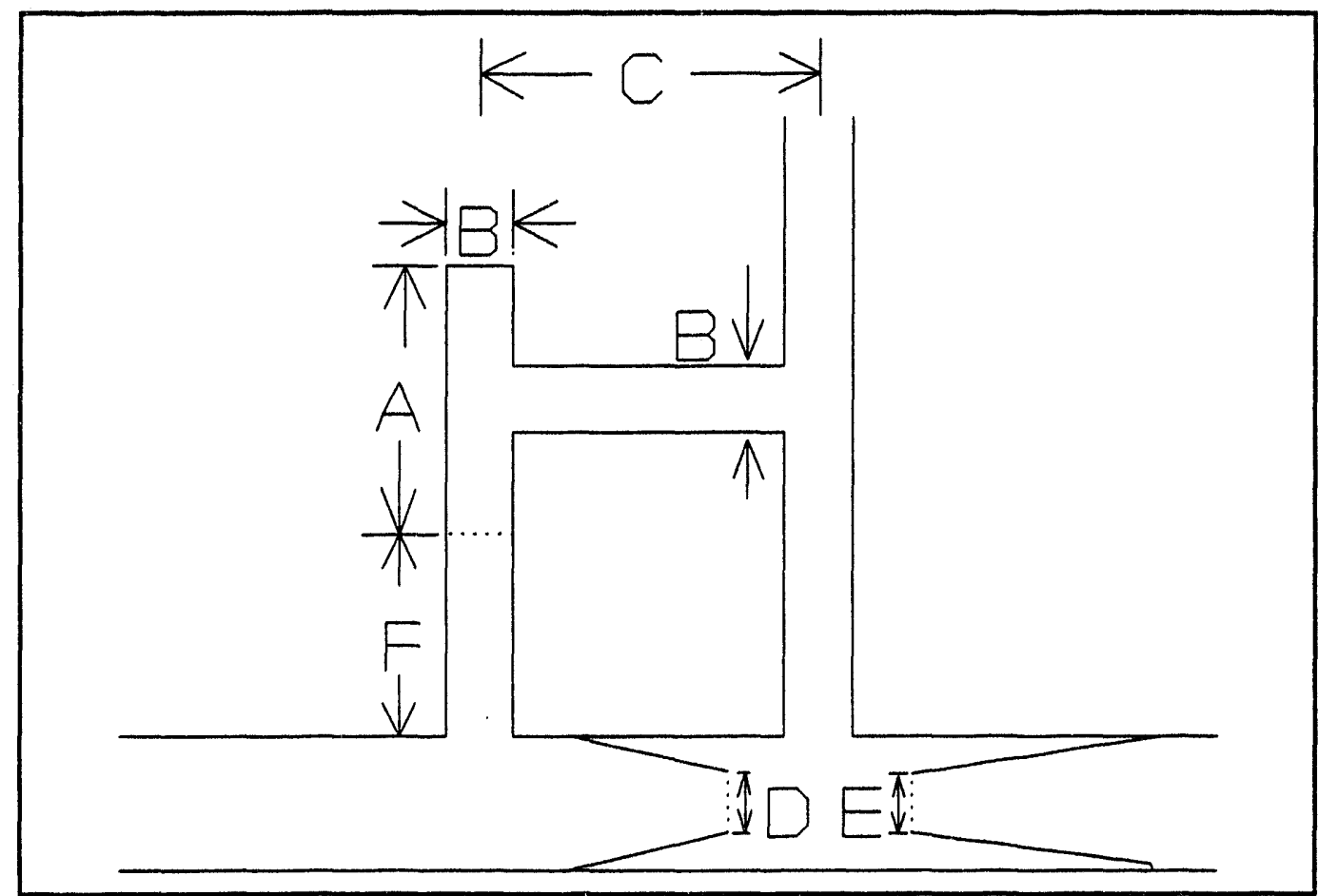

Figure 8. Vortex Diode Jet Dimensions

Table 1. Vortex Diode Jet Dimensions

\begin{tabular}{|c|c|c|c|c|c|c|}
\hline Configuration & $\begin{array}{c}A \\
\text { (in.) }\end{array}$ & $\begin{array}{c}B \\
\text { (in.) }\end{array}$ & $\begin{array}{c}C \\
\text { (in.) }\end{array}$ & $\begin{array}{c}D \\
\text { (in.) }\end{array}$ & $\begin{array}{c}E \\
\text { (in.) }\end{array}$ & $\begin{array}{c}F \\
\text { (in.) }\end{array}$ \\
\hline 1/2" Fox & N/A & N/A & N/A & 0.094 & 0.094 & N/A \\
\hline 1/8" VD - Fox & 1.35 & 0.269 & 2.63 & 0.094 & 0.094 & 1.75 \\
\hline $1 / 4^{\prime \prime}(t)$ VD - Fox & 1.82 & 0.364 & 2.88 & 0.094 & 0.094 & 1.38 \\
\hline $1 / 4^{\prime \prime}$ (s) VD - Fox & 1.82 & 0.364 & 2.13 & 0.094 & 0.094 & 1.5 \\
\hline 1/2" Penberthy & N/A & N/A & N/A & 0.066 & 0.234 & N/A \\
\hline 1/4" VD - Pen. & 1.82 & 0.364 & 2.88 & 0.066 & 0.234 & 0.63 \\
\hline 3/8" VD - Pen. & 2.47 & 0.493 & 2.75 & 0.066 & 0.234 & 2.13 \\
\hline 1/2" VD - Pen. & 3.11 & 0.622 & 2.63 & 0.066 & 0.234 & 1.63 \\
\hline
\end{tabular}




\subsection{Experimental Procedure}

The fluidic mock-up was operated by opening the pressurized air inlet valve to the pumping chamber. When the desired solution level in the pumping chamber was reached, the pressurized air inlet valve (V-1) was closed and the vent valve $(V-2)$ was opened, venting the pressurized pulping chamber air to the feed tank through the vent 1 ine. The pumping chamber was refilled by gravity with solution from the feed tank and with returning solution from the jet outlet line. These steps made up one pumping cycle. Additional pumping cycles were performed by repeating these steps. Valve V.2 was usually used to control the pumping chamber venting, however orifices in the vent line were also used. When orifices were used, they were placed in the upstream fitting of the valve. When using an orifice, valve V-2 was left open and was not operated. The orifices vented air during pumping as well as during refill and the reduced the refill rate, however, the use of orifices does eliminate one moving part in the system and increases system reliability.

The fluidic transfer mock-up was operated with a constant feed tank level and orifice size for each run. Pumping pressure was varied for the runs. The Fox jet was operated with a variety of orifice sizes, including a 1/2" Swagelok valve. The other configurations were operated with a 1/2" Swagelok valve as the vent line orifice. The pumping chamber could be partially or completely emptied of solution during a pumping cycle. Only the Fox jet runs were operated by fulling and partially emptying the pumping chamber. Using the Penberthy jet and all of the vortex diode jets. the pumping chamber was aiways emptied. Two methods were employed for emptying the pumping chamber: closing the inlet air valve so air did not pass through the pumping jet: and closing the inlet air valve just as air leaked through the jet (blowout operation). Blowout operation was used for most of the Fox jet runs and all of the runs for the other configurations, as it produced the most repeatable data. 
The pumping jet inlet $\left(P_{1}\right)$, plenum $\left(P_{p}\right)$, and outlet $\left(P_{0}\right)$ pressures and flow rates $\left(Q_{1}, Q_{p}\right.$, and $\left.Q_{0}\right)$ were measured and recorded. The total solution transferred during each pumping cycle was collected and measured. The time required to complete each pumping and refill cycle was recorded, as well as some times required for the system to come to steady state. 


\subsection{Results and Discussion}

Test configurations used in this work are listed in Table 2. Results showed vortex diode jet performance was predicted by the design equations. Performance coefficients were determined from flow and pressure measurements as described in the following sections.

\subsection{Inlet Flow}

The inlet flow rates during pumping showed a well behaved and reproducible behavior (Figure 9, and the Appendix for the other $Q_{f}$ graphs). A11 of the lines shown in Figures 9.43 are the results of 1 inear regression analysis fits with calculated intercepts of the data to the design equations. The well behaved and reproducible behavior was true of all eight jets (two base jets, and six VDJs). Figures 10 and 11 show a break from transition to turbulent flow. The composite, transition, and turbulent inlet flow coefficients are given in Tables 3 and 4 . The regression lines shown in Figures 10 and 11 represent the transition and turbulent inlet flow coefficients for the 1/2" Penberthy jet. The difference between the transition and turbulent flow coefficients is $0.30 \%$. However, an overall coefficient is accurate enough for most modeling purposes. To do the best modeling job, the two-regime inlet flow coefficients should be used with the linear regression calculated intercepts. The transition point is a function of the vortex diode, if one is present, and the jet. In all the cases the vortex diode of the vortex diode jets is essentially controlling the transition point of the transition-turbulent behavior and the pumping rate coefficient.

The transition flow rate for each configuration is given in Table 5. Also given is the jet flow rate at the transition point. This allows the flow through the vortex diode to be calculated at the transition point as well as the Reynolds Number $\left(\mathrm{N}_{\mathrm{Re}}\right)$. As can be seen in Table 6 , the observed transition point was in the transition zone. This proves that the break in 
Table 2. Test Configurations

\begin{tabular}{||l|c|c|c|c|c|c||}
\hline Config. & $\begin{array}{c}\text { Jet } \\
\text { Size }\end{array}$ & $\begin{array}{c}\text { Jet } \\
\text { Mfg. }\end{array}$ & $\begin{array}{c}\text { VD } \\
\text { Size }\end{array}$ & $\begin{array}{c}\text { VD } \\
\text { Config. }\end{array}$ & $\begin{array}{c}\text { Orifice } \\
\text { Size }\end{array}$ & $\begin{array}{c}\text { Number of Tests in } \\
\text { Config. }\end{array}$ \\
\hline$F(1)$ & $1 / 2^{\prime \prime}$ & Fox & N/A & N/A & $1 / 2^{\prime \prime}$ V. & 9 \\
\hline$F(2)$ & $1 / 2^{\prime \prime}$ & Fox & N/A & N/A & $0.0320^{\prime \prime}$ & 9 \\
\hline$F(3)$ & $1 / 2^{\prime \prime}$ & Fox & N/A & N/A & $0.0625^{\prime \prime}$ & 25 \\
\hline$F(4)$ & $1 / 2^{\prime \prime}$ & Fox & N/A & N/A & $0.125^{\prime \prime}$ & 2 \\
\hline$F 1 / 8$ & $1 / 2^{\prime \prime}$ & Fox & $1 / 8^{\prime \prime}$ & slant & $1 / 2^{\prime \prime} V$. & 16 \\
\hline$F 1 / 4 t$ & $1 / 2^{\prime \prime}$ & Fox & $1 / 4^{\prime \prime}$ & twist & $1 / 2^{\prime \prime} V$. & 34 \\
\hline$F 1 / 4 s$ & $1 / 2^{\prime \prime}$ & Fox & $1 / 4^{\prime \prime}$ & slant & $1 / 2^{\prime \prime} V$. & 20 \\
\hline$P$ & $1 / 2^{\prime \prime}$ & Pen. & N/A & N/A & $1 / 2^{\prime \prime} V$. & 17 \\
\hline$P 1 / 4$ & $1 / 2^{\prime \prime}$ & Pen. & $1 / 4^{\prime \prime}$ & slant & $1 / 2^{\prime \prime} V$. & 15 \\
\hline P3/8 & $1 / 2^{\prime \prime}$ & Pen. & $3 / 8^{\prime \prime}$ & slant & $1 / 2^{\prime \prime} V$. & 9 \\
\hline$P 1 / 2$ & $1 / 2^{\prime \prime}$ & Pen. & $1 / 2^{\prime \prime}$ & slant & $1 / 2^{\prime \prime} V$. & 9 \\
\hline
\end{tabular}

the flow versus pressure drop curves was due to the difference in transition and turbulent flow characteristics.

In four cases (F1/8, F1/4s, $P$, and $P 1 / 2)$ the magnitude of the transition turbulent inlet flow coefficient was significant to a $95 \%$ confidence interval leve1. The vortex diode jet characteristic diameter was the vortex diode inlet pipe diameter. For the Fox jet the characteristic diameter was the jet inlet orifice. The Penberthy jet characteristic diameter was the inlet nozzle's inlet diameter, because the outlet of the inlet nozzle was already turbulent for these flow ranges. For the Penberthy jet the first characteristic nozzle diameter $(0.066 ")$ goes fully turbulent and the secondary nozzle diameter $(0.27 ")$ provides the characteristic nozzle diameter given by these results. 


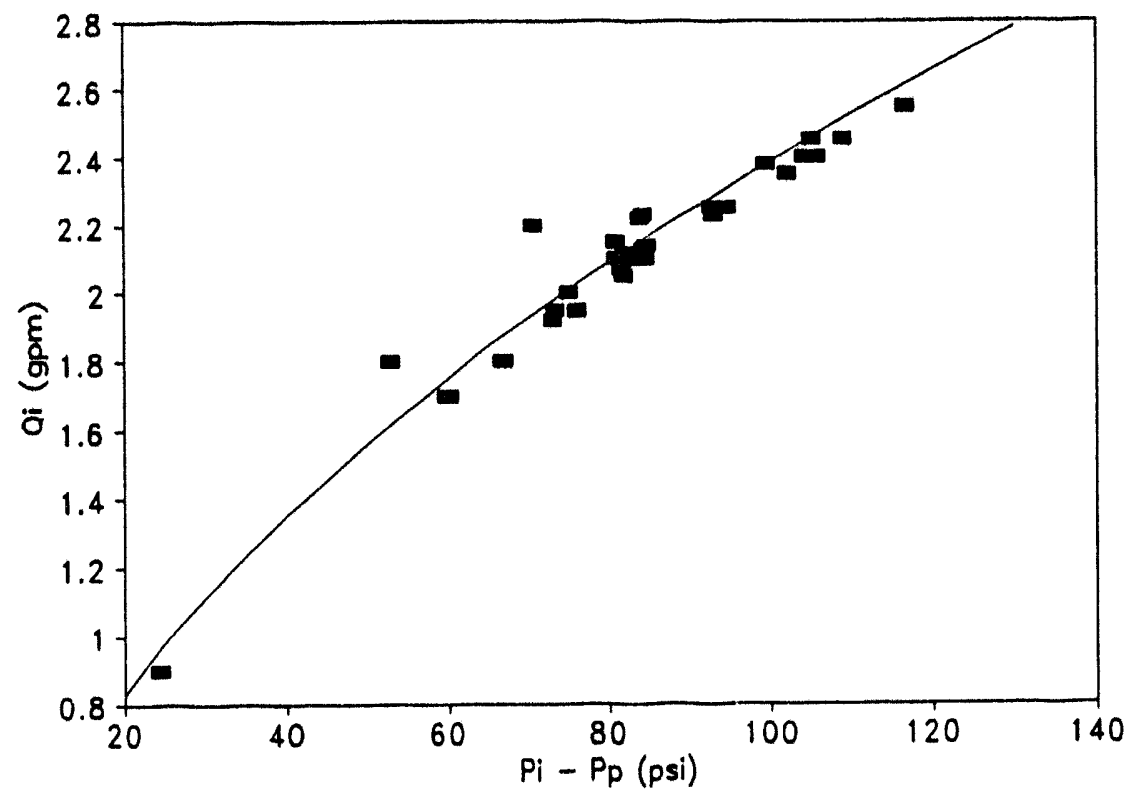

Figure 9. 1/2" Fox Jet Inlet Flow

Table 3. 1/2" Fox Inlet Flow Coefficients

\begin{tabular}{||l|c|c|c||}
\hline Configuration & $\begin{array}{c}\text { Composite Inlet } \\
\text { Flow } \\
\text { Coefficient }\end{array}$ & $\begin{array}{c}\text { Transition } \\
\text { Flow } \\
\text { Coefficient }\end{array}$ & $\begin{array}{c}\text { Turbulent } \\
\text { Flow } \\
\text { Coefficient }\end{array}$ \\
\hline \hline 1/2" Fox Jet & 0.269 & $\cdots$ & $\cdots$ \\
\hline $1 / 8^{\prime \prime}$ VD $-1 / 2^{\prime \prime}$ Fox & 0.564 & 0.462 & 0.613 \\
\hline $1 / 4^{\prime \prime} V(t) \cdot 1 / 2^{\prime \prime ~ F o x ~}$ & 0.800 & 0.608 & 0.805 \\
\hline $1 / 4^{\prime \prime} V(s) \cdot 1 / 2^{\prime \prime}$ Fox & 0.779 & 0.605 & 0.832 \\
\hline
\end{tabular}


Table 4. 1/2" Penberthy Inlet Flow Coefficients

\begin{tabular}{|c|c|c|c|}
\hline Configuration & $\begin{array}{c}\text { Composite Inlet } \\
\text { Flow } \\
\text { Coefficient }\end{array}$ & $\begin{array}{c}\text { Transition } \\
\text { Flow } \\
\text { Coefficient }\end{array}$ & $\begin{array}{c}\text { Turbulent Flow } \\
\text { Coefficient }\end{array}$ \\
\hline 1/2" Penberthy Jet & 0.212 & 0.163 & 0.220 \\
\hline $1 / 4 "$ VD $\cdot 1 / 2^{\prime \prime}$ Pen. & 0.766 & 0.698 & 0.729 \\
\hline 3/8" VD - 1/2" Pen. & 0.962 & 0.872 & 0.898 \\
\hline $1 / 2 "$ VD $\cdot 1 / 2 "$ Pen. & 1.04 & 0.820 & 1.201 \\
\hline
\end{tabular}

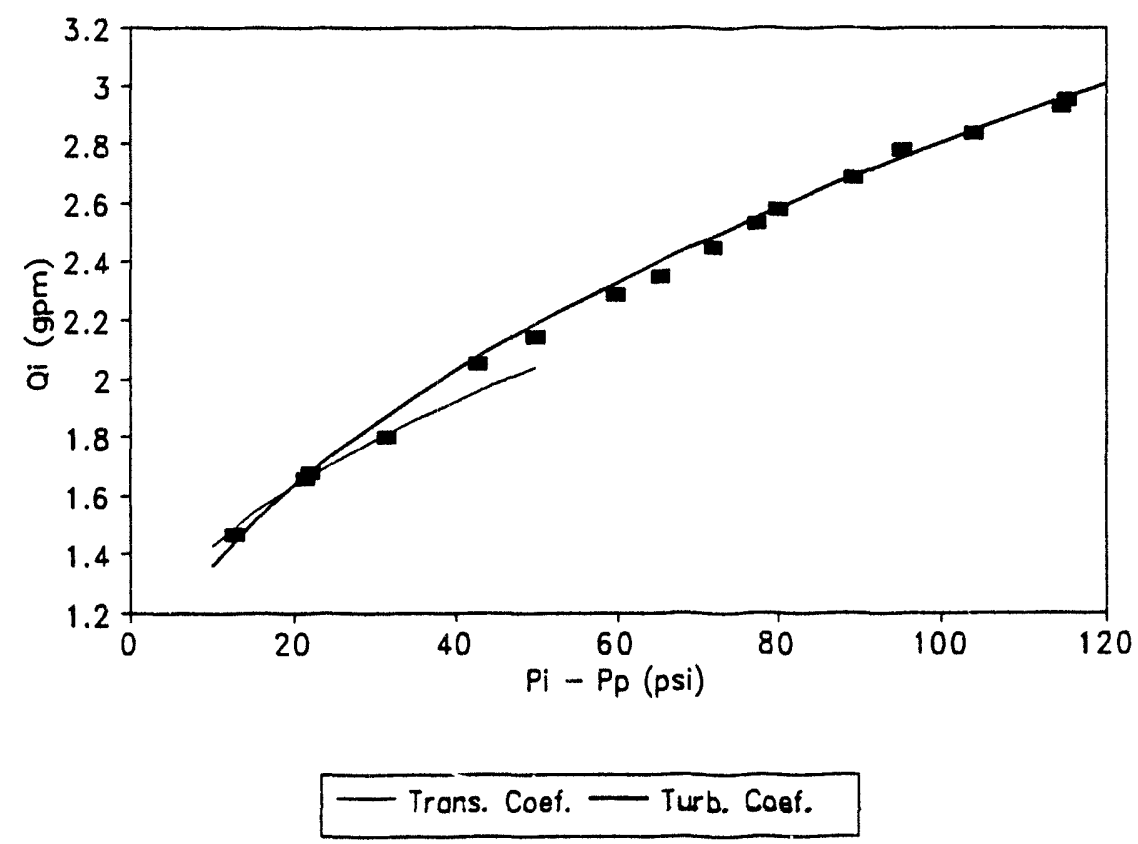

Figure 10. 1/2" Penberthy Jet Inlet Flow 


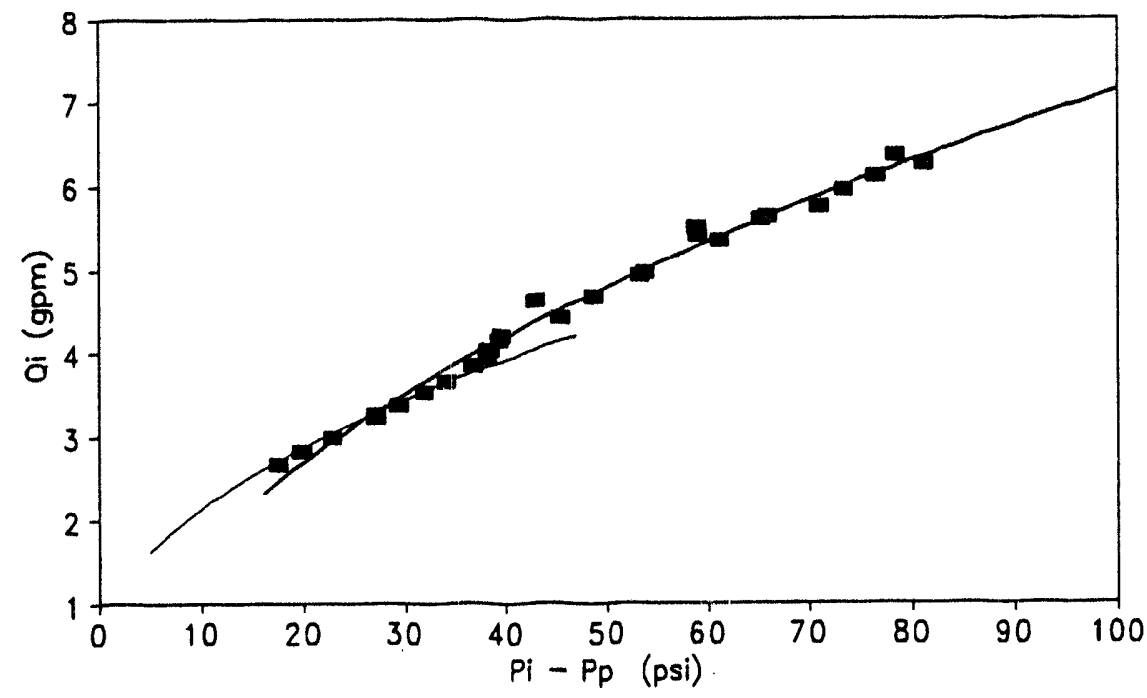

Trons. Coof. - Turb. Coef.

Figure 11. 1/4" VD(t) - 1/2" Fox Vortex Diode Jet Inlet Flow

As expected, the inlet flow coefficients for the vortex diode are related to the size of the vortex diode. As the vortex diode size increases, more flow is through the vortex diode for the same motive pressure. This should produce a larger inlet flow coefficient for an increase in the vortex diode size. As the results show in Tables 3, 4, and 7, this relationship does hold. The difference between $C_{i}$ (VDJ) and $C_{i j}$ (jet) is the vortex diode inlet flow coefficient $\left(C_{i v d}\right)$. The vortex diode composite, transition, and turbulent inlet coefficients are given in Table 7 . The relationship between the turbulent $C_{i v d}$ and the vortex diode inside diameter was linear over the range tested (Figure 12, $R^{2}=0.971$ ). Because of transition to turbulent flow characteristics the values of $C_{\text {ivd }}$ overall show slightly more variation. The inlet coefficients also show that a minimum of 32 percent of the inlet flow was through the vortex diode (VD flow fraction $=C_{i v d} / C_{1}$ ). 
Table 5. Transition Point Data

\begin{tabular}{|c|c|c|c|c|}
\hline Configuration & $\begin{array}{l}Q_{\text {trans. }} \\
\text { (gpm) }\end{array}$ & $\begin{array}{c}Q_{\text {jet }} \text { at } \\
\text { Transition } \\
\quad(\mathrm{gpm})\end{array}$ & $\begin{array}{c}a_{v o} \\
\left(a_{\text {trans }}-a_{\text {jet }}\right) \\
(\mathrm{gpm})\end{array}$ & $\begin{array}{c}\mathrm{N}_{\mathrm{Re}} \text { at transition } \\
\left(\mathrm{Q}_{\mathrm{VD}} \text {, or } \mathrm{Q}_{\mathrm{jet}} \text { as }\right. \\
\text { appropriate })\end{array}$ \\
\hline$F$ & $N / A$ & N/A & N/A & $N / A$ \\
\hline $\mathrm{F} 1 / 8$ & 3.3 & 1.4 & 1.9 & $2.2 * 10^{4}$ \\
\hline$F 1 / 4 t$ & 4.0 & 1.2 & 2.8 & $2.4 * 10^{4}$ \\
\hline $\mathrm{F} 1 / 4 \mathrm{~s}$ & 4.0 & 1.3 & 2.7 & $2.3 * 10^{4}$ \\
\hline$P$ & 1.7 & 1.7 & N/A & $8.1 * 10^{4}$ \\
\hline P1/4 & 4.0 & 1.8 & 2.2 & $1.9 * 10^{4}$ \\
\hline P3/8 & 4.0 & 1.7 & 2.3 & $1.5 * 10^{4}$ \\
\hline $\mathrm{P} 1 / 2$ & 4.3 & 1.7 & 2.6 & $1.5 * 10^{4}$ \\
\hline
\end{tabular}

Table 6. Observed Transition Reynolds Number

\begin{tabular}{|c|c|c|c|c|}
\hline Configuration & $\begin{array}{l}\mathrm{N}_{\mathrm{Re}} \text { at start } \\
\text { of trans. } \\
\text { zone }\end{array}$ & $\begin{array}{l}\mathrm{N}_{\mathrm{Re}} \text { at mid point } \\
\text { of transition } \\
\text { zone }\end{array}$ & $\begin{array}{l}\mathrm{N}_{\mathrm{Re}} \text { at end } \\
\text { of trans. } \\
\text { zone }\end{array}$ & $\begin{array}{l}\mathrm{N}_{\mathrm{Re}} \text { of } \\
\text { transition } \\
\text { (observed) }\end{array}$ \\
\hline$F$ & $3.3 * 10^{3}$ & $7.0 * 10^{3}$ & $4.5 * 10^{4}$ & N/A \\
\hline $\mathrm{F} 1 / 8$ & $3.4 * 10^{3}$ & $7.3 * 10^{3}$ & $1.5 * 10^{5}$ & $2.2 * 10^{4}$ \\
\hline$F 1 / 4 t$ & $3 * 10^{3}$ & $8.0 * 10^{3}$ & $2.3 * 10^{5}$ & $2.4 * 10^{4}$ \\
\hline $\mathrm{F} 1 / 4 \mathrm{~s}$ & $3 * 10^{3}$ & $8.0 * 10^{3}$ & $2.3 * 10^{5}$ & $2.3 * 10^{4}$ \\
\hline$P$ & $3 * 10^{3}$ & $8.0 * 10^{3}$ & $3.0 * 10^{4}$ & $8.1 * 10^{4}$ \\
\hline $\mathrm{P} 1 / 4$ & $3 * 10^{3}$ & $8.0 * 10^{3}$ & $2.3 * 10^{5}$ & $1.9 * 10^{4}$ \\
\hline P3/8 & $3 * 10^{3}$ & $8.5 * 10^{3}$ & $3.5 * 10^{5}$ & $1.5 * 10^{4}$ \\
\hline $\mathrm{P} 1 / 2$ & $3 * 10^{3}$ & $8.7 * 10^{3}$ & $3.7 * 10^{5}$ & $1.5 * 10^{4}$ \\
\hline
\end{tabular}


Table 7. Vortex Diode Inlet Flow Coefficient $\left(C_{i v d}=C_{1} \cdot C_{i j}\right)$

\begin{tabular}{|c|c|c|c|c||}
\hline $\begin{array}{c}\text { Vortex Diode } \\
\text { Size }\end{array}$ & Base Jet & $\begin{array}{c}\text { Composite } \\
\text { Inlet Flow } \\
\text { Coefficient }\end{array}$ & $\begin{array}{c}\text { Transition } \\
\text { Inlet Flow } \\
\text { Coefficient }\end{array}$ & $\begin{array}{c}\text { Turbulent } \\
\text { Inlet Flow } \\
\text { Coefficient }\end{array}$ \\
\hline \hline $1 / 8^{\prime \prime}$ & Fox & 0.295 & 0.193 & 0.344 \\
\hline $1 / 4^{\prime \prime}(t)$ & Fox & 0.531 & 0.339 & 0.536 \\
\hline $1 / 4^{\prime \prime}(s)$ & Fox & 0.501 & 0.336 & 0.563 \\
\hline $1 / 4^{\prime \prime}$ & Penberthy & 0.554 & 0.535 & 0.509 \\
\hline $3 / 8^{\prime \prime}$ & Penberthy & 0.750 & 0.709 & 0.678 \\
\hline $1 / 2^{\prime \prime}$ & Penberthy & 0.828 & 0.657 & 0.981 \\
\hline
\end{tabular}

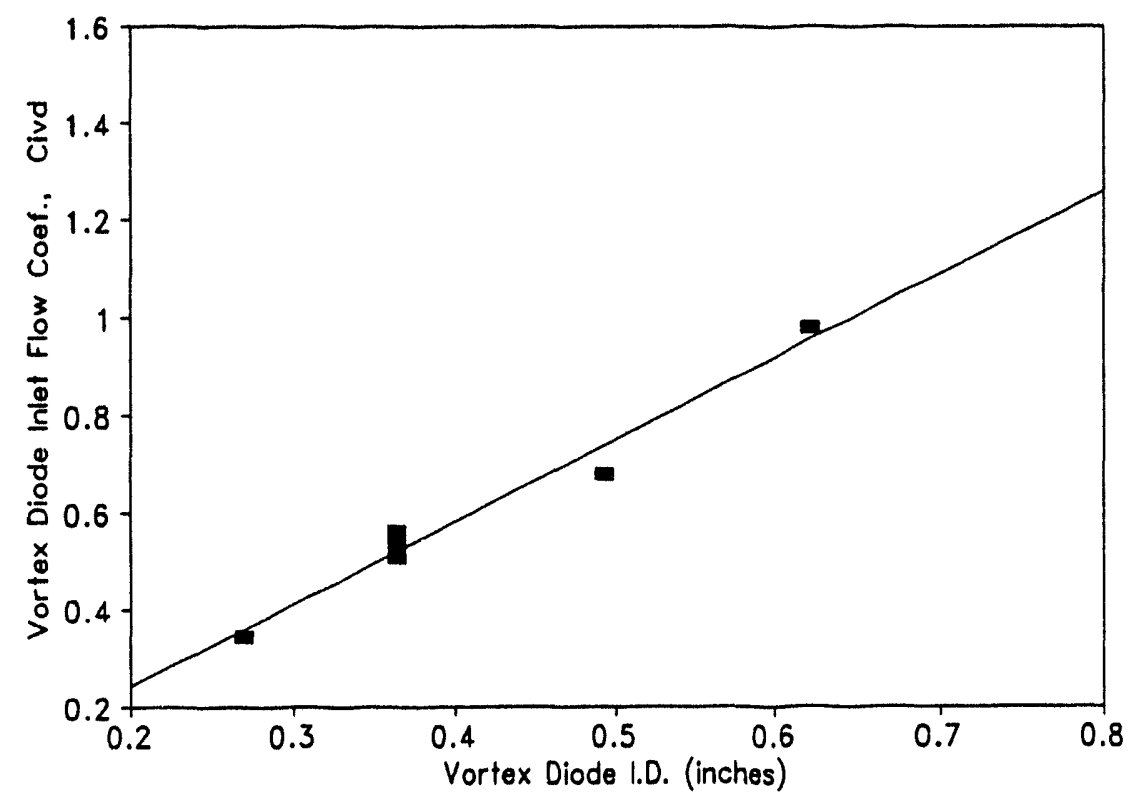

Figure 12. Vortex Diode Turbulent $C_{\text {ivd }}$ versus Vortex Diode I.D. 


\subsection{Outlet Flow}

Outlet flow rate (Figure 13, Table 8) was well predicted by equation (4). As predicted by equation (4), before flow is initiated the outlet differential pressure had to overcome the outlet head $\left(P_{h}\right)$. If the column height was less than the outlet differential pressure continuous flow occurred during the pumping cycle. If the differential outlet pressure was less than the column height of the solution in the outlet line required for transfer, the outlet line would fill to a steady-state height and the jet inlet flow would all go into the feed tank. Table 9 shows the intercepts and their 95\% confidence interval for the transfer systems. The transfer head was $42^{\circ} 10^{\prime \prime}$ for all cases. The deviation from the expected intercept and slope is in part caused by the inclusion of the transient start-up time in determining $C_{0}$. This caused less than a two percent error in the $Q_{0}$ flow rate and greatly simplified the overall pumping rate equation (17). As the results show. the break point for the transients have a significant effect on the measured coefficients for the 1/4" vortex diode. Not allowing for the pumping transients increases the apparent outlet flow coefficient. If the transient outlet line fill time is a significant fraction of the pumping time, then equation (17) should be modified to subtract out the transient pumping time from the total pumping time. The general equation (16) is always correct.

Three major points come from these data. The outlet line characteristics determine the outlet flow coefficient for a particular transfer system. The vortex diode size does not effect the outlet coefficient. Inclusion of the transient times produces a false higher outlet flow coefficient for the larger vortex diode jets. This error becomes significant with a vortex diode size of approximately $1 / 4^{\prime \prime}$ and larger. 


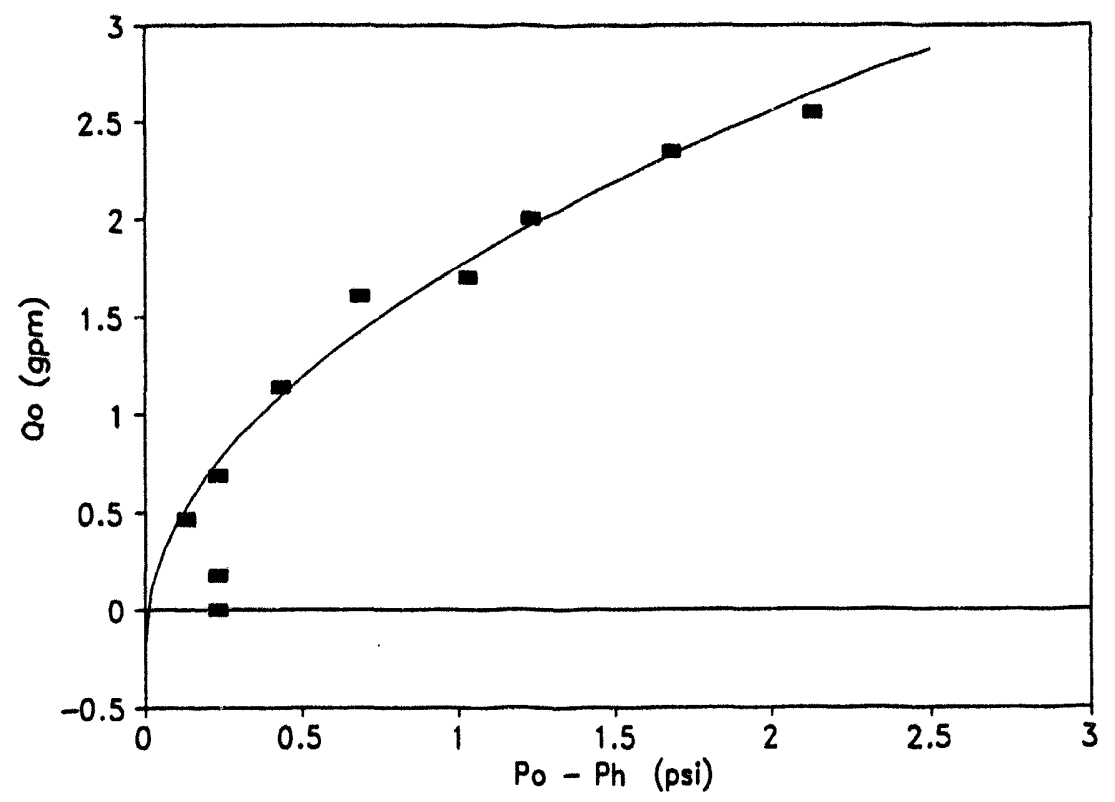

Figure 13. 1/4" VD - 1/2" Penberthy Vortex Diode Jet Outlet Flow

Table 8. Outlet Flow Coefficients

\begin{tabular}{|c|c|c|}
\hline Configuration & $\begin{array}{l}\text { Outlet Flow Coefficient } \\
\qquad\left(C_{0}\right)\end{array}$ & Intercept \\
\hline 1/2" Fox Jet & 1.72 & -0.254 \\
\hline $1 / 8^{\prime \prime}$ VD $\cdot 1 / 2^{n}$ Fox & 1.52 & 0.297 \\
\hline $1 / 4^{\prime \prime}$ VD $(t) \cdot 1 / 2^{\prime \prime}$ Fox & 1.47 & 0.282 \\
\hline $1 / 4^{n}$ VD (s) $\cdot 1 / 2^{n}$ Fox & 1.66 & -0.129 \\
\hline 1/2" Penberthy Jet & 1.52 & 0.253 \\
\hline 1/4" VD - 1/2" Pen. & 1.93 & -0.174 \\
\hline 3/8" VD - 1/2" Pen. & 2.20 & 0.178 \\
\hline 1/2" VD - 1/2" Pen. & 1.84 & -0.0733 \\
\hline
\end{tabular}


Table 9. $P_{0}$ Intercept and 95\% Confidence Interval

\begin{tabular}{|c|c|c|}
\hline Configuration & Intercept & 95\% Confidence Interval \\
\hline 1/2" Fox Jet & .0 .254 & $(-0.345) \cdot(-0.163)$ \\
\hline $1 / 8 "$ VD $\cdot 1 / 2^{\prime \prime}$ Fox & 0.297 & $0.222 \cdot 0.372$ \\
\hline $1 / 4^{\prime \prime}$ VD $(t) \cdot 1 / 2^{\prime \prime}$ Fox & 0.282 & $0.119 \cdot 0.445$ \\
\hline $1 / 4 "$ VD (s) - 1/2" Fox & -0.129 & $(-0.332) \cdot 0.074$ \\
\hline 1/2" Penberthy Jet & 0.253 & $0.175 \cdot 0.331$ \\
\hline 1/4" VD - 1/2" Pen. & -0.174 & $(-0.319) \cdot(-0.029)$ \\
\hline 3/8" VD $\cdot 1 / 2^{n}$ Pen. & 0.178 & $0.055 \cdot 0.301$ \\
\hline $1 / 2^{\prime \prime}$ VD $\cdot 1 / 2^{n}$ Pen. & -0.0733 & $(-0.398) \cdot 0.252$ \\
\hline
\end{tabular}

\subsection{Inlet and Outlet Pressure Relationship}

To complete the pumping cycle system modeling, some relationship between the inlet $\left(P_{1}\right)$ and the outlet $\left(P_{0}\right)$ pumping pressure is required. With this relationship a vortex diode jet's performance could be predicted for any application. Unfortunately, no simple relationship exists. This is because the outlet pressure is not only a function of the inlet pressure but also a function of the jet and the outlet line characteristics. This behavior is demonstrated by Figure 14 . Figure 14 also shows that the $P_{0}$ versus $P_{1}$ is a linear relationship.

The point where two regression lines cross is indicative of a change in behavior. This change in behavior in from no flow in the outlet line $\left(P_{0} \leq\right.$ $\left.P_{h}\right)$ to flow through the outlet line $\left(P_{0}>P_{h}\right)$. As expected this change takes place when $P_{0}=P_{h}$ which is the intercept of the two lines. As shown in Figure 14 the slope of $P_{0}$ versus $P_{1}$ is a function of the outlet line configuration, the base jet (slope is 0.071 for the $1 / 2^{\text {" }}$ Fox, 0.061 for the $1 / 2$ " Penberthy) and NOT on the vortex diode jet size or whether the jet being used is a vortex diode jet (Figure 15). 


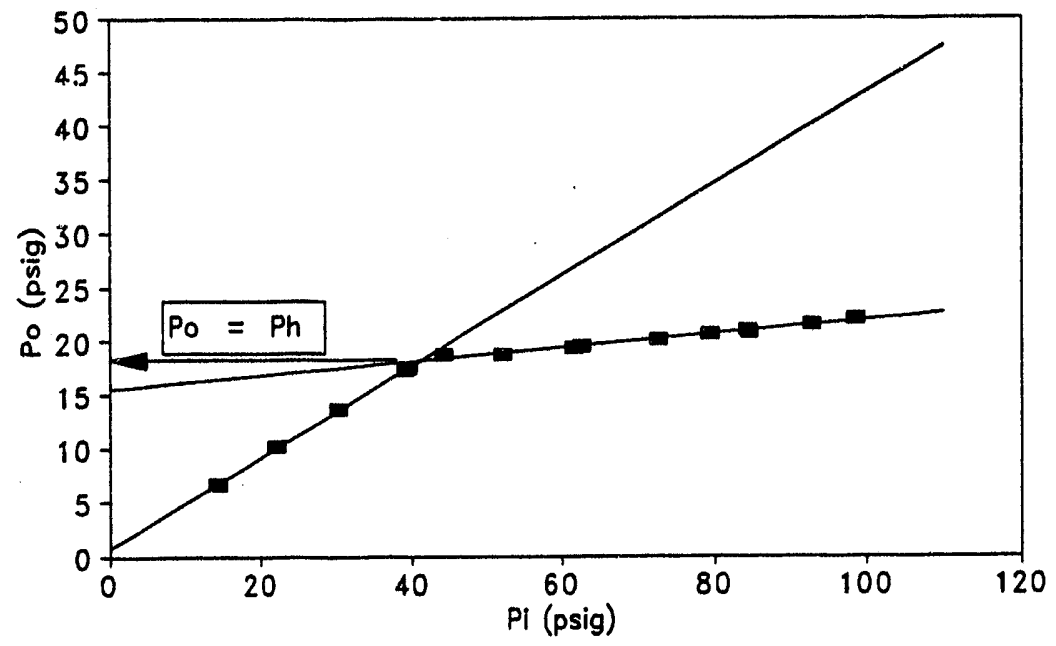

Trans. Coef. - Turb. Coef.

Figure 14. 1/8" VD - 1/2" Fox VDJ $P_{0}$ versus $P_{i}$ Relationship

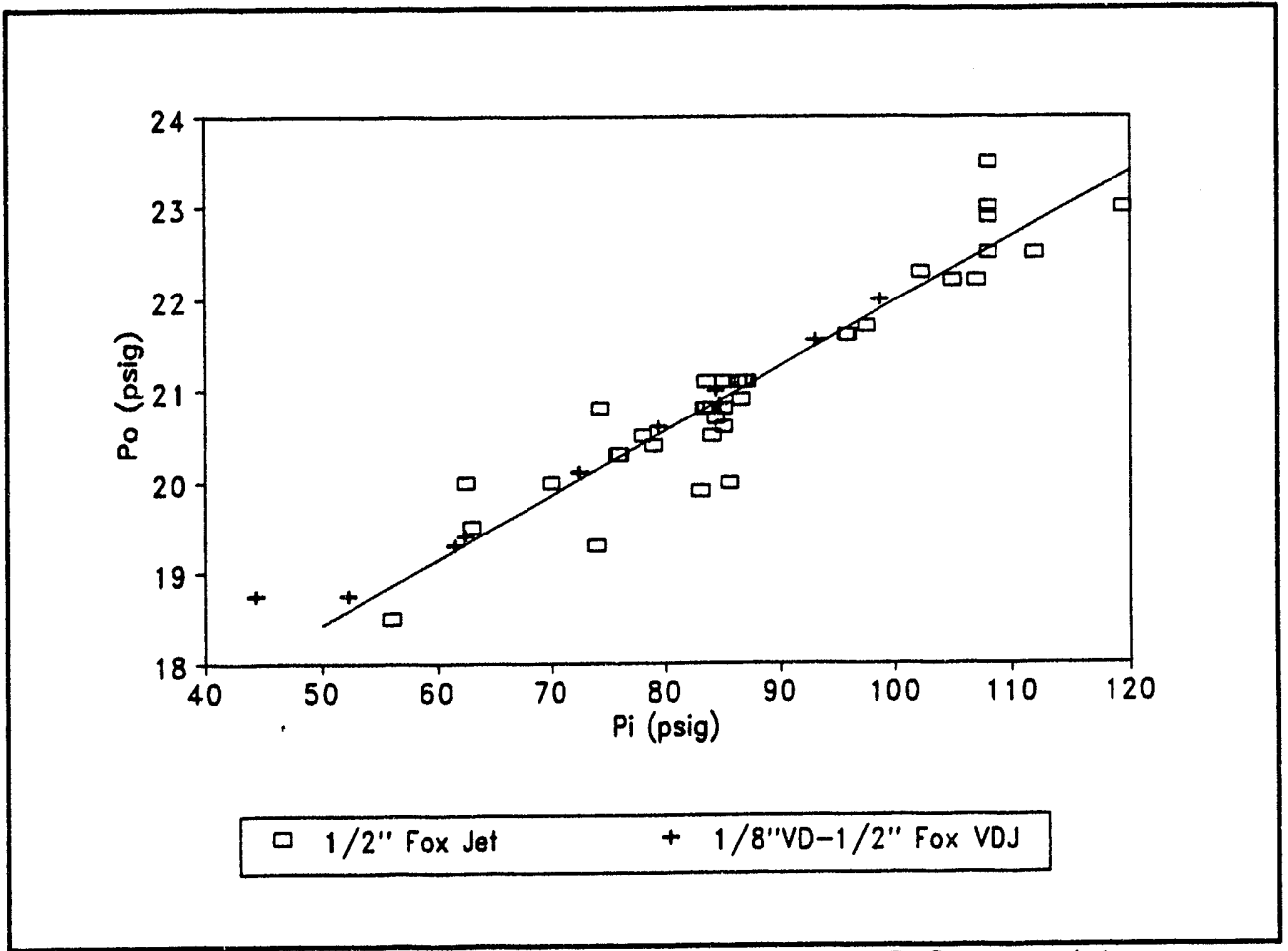

Figure 15. 1/8" VD - 1/2" Fox $P_{0}$ versus $P_{i}$ Relationship 
Therefore, the $P_{0} \cdot P_{1}$ relationship is given by:

$$
P_{0}=C_{p 10} * P_{1}+\text { Intercept }
$$

$C_{p i o}$ is a function of the sum of the resistance coefficients and $P_{h}$. $P_{h}$ is the intercept of the two lines in Figure 14. An additional resistance increases the $P_{0} \cdot P_{1}$ slope. Until flow starts, the $P_{0}-P_{1}$ slope is independent of the outlet flow resistance coefficient and only a function of the jet characteristics.

\subsection{Refill Flow}

The fourth major point of interest was the pumping chamber refill (Figure 16, and the Appendix). The results showed that this was a very repeatable function. For a particular head and feed tank leve1, the pumping chamber would refill to within a second or two of the same amount of time for each run. The refill rate was controlled by the pumping jet or vortex diode jet refill flow coefficient, with a smaller effect from the other flow path features (i.e. vent line orifice size). As expected, the larger the vortex diode, the faster the refill rate as shown by the VDJ and VD refill coefficients in Tables 10 (Fox) and Table 11 (Penberthy). However. increasing the vortex diode size produced only a small increase in the vortex diode refill coefficients. The refill rate regression fit to equation (12) was essentially linear for these systems. The offset in the refill lines was caused by a calibration error in the feed tank flowmeter (Appendix, Figure 40). For low flow rates a differential pumping chamber heights technique was used. For the higher flow rates the refill rate was directly read off of the feed tank (plenum) flow gauge. The offset caused by the different techniques was consistently $0.1 \mathrm{gpm}$.

In all tests series but one, the pumping chamber vent line entered the feed that at $4^{\prime} 1^{\prime \prime}$ which was below the solution level in the feed tank. This resulted in a constant tank pressure on the pumping chamber vent line regardless of the feed tank solution level. There was no difference in refill flow rate when the outlet vent line was moved up to $8^{\circ}$. 


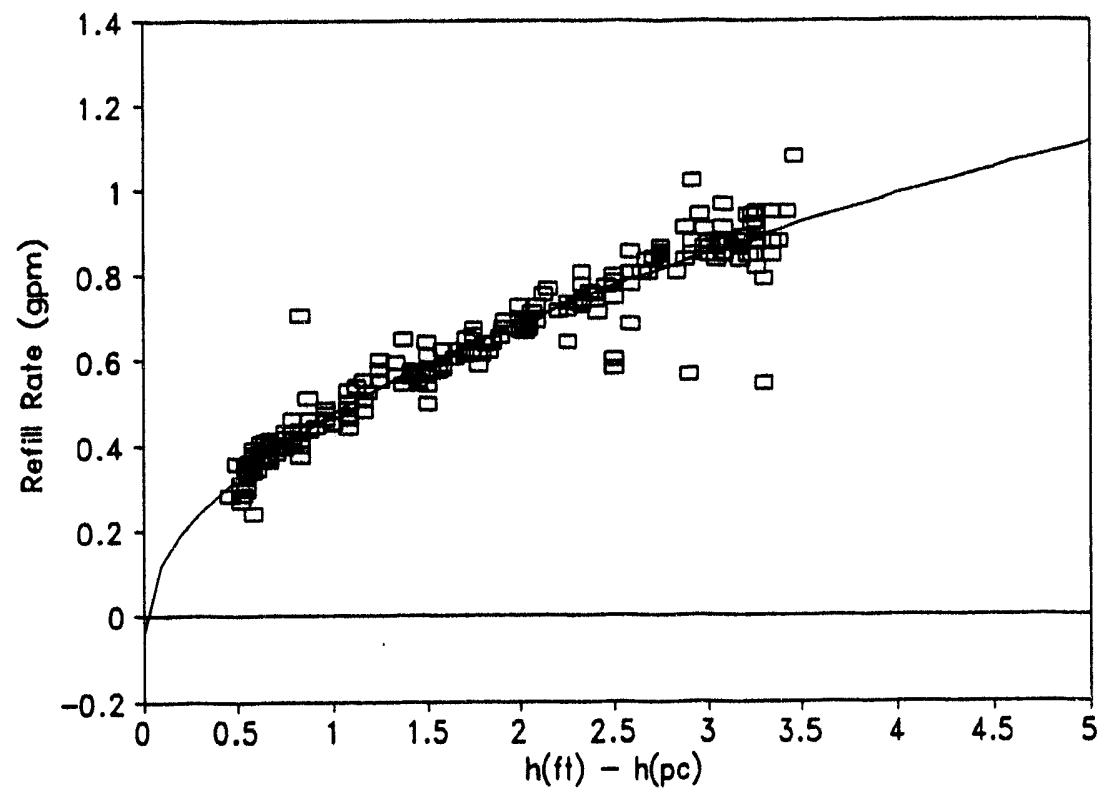

Figure 16. 1/4" VD(t) - 1/2" Fox Vortex Diode Jet Refi11 Time

Table 10. 1/2" Fox Refill Flow Coefficients

\begin{tabular}{|c|c|c|}
\hline Configuration & $\begin{array}{c}\text { VDJ Refill } \\
\text { Coefficient }\end{array}$ & $\begin{array}{c}\text { VD Refil1 } \\
\text { Coefficient }\end{array}$ \\
\hline \hline $\begin{array}{c}1 / 2^{\prime \prime} \text { Fox Jet } \\
\text { Orifice }=0.5^{\prime \prime}\end{array}$ & 0.211 & N/A \\
\hline Orifice $=0.125^{\prime \prime}$ & 0.120 & N/A \\
\hline Orifice $=0.032^{\prime \prime}$ & 0.330 & N/A \\
\hline $1 / 8^{\prime \prime}$ VD $\cdot 1 / 2^{\prime \prime}$ Fox & 0.511 & 0.300 \\
\hline $1 / 4^{\prime \prime} V(t) \cdot 1 / 2^{\prime \prime}$ Fox & 0.516 & 0.305 \\
\hline $1 / 4^{\prime \prime} \mathrm{V}(s) \cdot 1 / 2^{\prime \prime}$ Fox & 0.533 & 0.322 \\
\hline
\end{tabular}


Table 11. 1/2" Penberthy Refil1 Flow Coefficients

\begin{tabular}{|l|c|c|}
\hline \multicolumn{1}{|c|}{ Configuration } & $\begin{array}{c}\text { VDJ Refil1 } \\
\text { Coefficient }\end{array}$ & $\begin{array}{c}\text { Vortex Diode Refill } \\
\text { Coefficient }\end{array}$ \\
\hline \hline 1/2" Penberthy Jet & 0.258 & N/A \\
\hline 1/4" VD $-1 /$ " Penberthy $^{\prime \prime}$ & 0.465 & 0.207 \\
\hline 3/8" VD $-1 /$ " Penberthy $^{\prime \prime}$ & 0.455 & 0.197 \\
\hline 1/2" VD $-1 /$ " Penberthy $^{\prime}$ & 0.518 & 0.260 \\
\hline
\end{tabular}

At low flow and low differential refill heights, flow drops off sharply due to a transition to laminar flow change. This caused the calculated intercept to be lower that would be expected from the transition data alone. It also gave lower $R^{2}$ values $(0.92 \cdot 0.97)$.

Table 12 gives laminar-transition point Reynolds number and flow rate. The smal1 refill coefficient intercept, typically $0.01 \mathrm{gpm}$, is indicative of the nonlaminar refill regime. While the intercept is small, it is statistically significant in all cases except the 1/4" VD - 1/2" Penberthy with sampler configuration. Since only a laminar regime flow would have a zero intercept, the intercept is real and should be added to equation 11 to produce the best results.

One series of three tests were made with a $1 / 2$ " tube tee is stead of a vortex diode jet (Figure 2). Results of these tests are shown in Figure 43. The system with the tee had a refill coefficient of 0.501 . Since the refill coefficient for the vortex diode is of the same magnitude as the tee, the vortex diodes are the controlling factor in the refill of the pumping chamber. Increasing the size of the vortex diode did not improve overall system performance. A $1 / 8$ " vortex diode in a vortex diode jet doubles the refill coefficient of a base jet and achieves $80 \%$ of the $1 / 2$ " tubing tee refill coefficient. The 1/4" vortex diode achieved $90 \%$ of the 
Table 12. Refill Laminar.Transition Flow Transition Point

\begin{tabular}{|c|c|c|c|}
\hline Configuration & $\begin{array}{l}\text { Laminar- } \\
\text { Transition } \\
\text { Point } \mathrm{N}_{\mathrm{Re}}\end{array}$ & $\begin{array}{c}\text { Transition } \\
\text { Point Flow } \\
\text { Rate } \\
\text { (gpm) }\end{array}$ & $\begin{array}{c}\text { Experimental } \\
\text { Refill Flow } \\
\text { Rate Range } \\
\text { (gpm) }\end{array}$ \\
\hline $1 / 2$ " Fox (vent orifice $=0.5 "$ ) & $3.3 * 10^{3}$ & 0.090 & $0.07 \cdot 0.35$ \\
\hline 1/8" VD.1/2" Fox VDJ & $3.0 * 10^{3}$ & 0.26 & $0.22 \cdot 0.95$ \\
\hline $1 / 4^{\prime \prime}(t)$ VD.1/2" Fox VDJ & $3.0 * 10^{3}$ & 0.35 & $0.25 \cdot 1.1$ \\
\hline 1/4"(s) VD-1/2" Fox VDJ & $3.0 * 10^{3}$ & 0.35 & $0.30-0.95$ \\
\hline $1 / 2 "$ Pen. (Or. I.D. $\left.=0.066^{\prime \prime}\right)$ & $3.4 * 10^{3}$ & 0.063 & $0.1 \cdot 0.47$ \\
\hline $1 / 2 "$ Pen. (Or. I.D. $=0.27^{\prime \prime}$ ) & $3.0 * 10^{3}$ & 0.26 & $0.1 \cdot 0.47$ \\
\hline 1/4" VD-1/2" Penberthy VDJ & $3.0 * 10^{3}$ & 0.35 & $0.26 \cdot 1.2$ \\
\hline 3/8" VD-1/2" Penberthy VDJ & $3.0 * 10^{3}$ & 0.47 & $0.27 \cdot 1.0$ \\
\hline 1/2" VD-1/2" Penberthy VDJ & $3.0 * 10^{3}$ & 0.52 & $0.24 \cdot 1.0$ \\
\hline
\end{tabular}

tee refill coefficient, 3/8" vortex diode achieved 105\%, and the 1/2" vortex diode achieved $110 \%$ of the tee refill coefficient. As expected other flow path restrictions effect the refill rate.

Vent line orifices have measurable effects but are still not the primary controlling feature refill rate. The vortex diode jet is the primary controlling feature. The total resistance coefficient is the sum of the resistance flow coefficients, equation (8) (Reference 6). Adding large resistance to the refill path will lower the refill rate for both jet and vortex diode jet systems. The base system used in this work, with two flow gauges, two pressure gauges, two valves, nine elbows, and a tee in addition to the jet or VDJ was a high resistance system. Therefore in any well designed system the VDJ advantage should be greater that the results reported here. 


\subsection{Overal1 Flow Rate}

For three typical cases: $h_{f t}=4.083^{\circ}, h_{\text {inttiol }}=0.4167^{\circ}, h_{\text {final }}=3.75^{\circ}$, for Case 1: $P_{1}=60.1 \cdot 62.5$ psig, $P_{p}=2.0 \cdot 2.6$ psig, $P_{0}=19.21$ psig, Case 2: $P_{1}$ $=80-84.4$ psig. $P_{p}=2.0-2.6$ psig, $P_{0}=20.22$ psig, and Case $3: P_{1}=94.98 .5$ psig, $P_{p}=2.0-2.6 \mathrm{psig}, P_{0}=21.23 \mathrm{psig}$, the overall flow rates are calculated from actual data using Equation 16 and shown in Tables 13, 14, and 15.

Table 13. Overal1 Pumping Rates for a Typical Case $\left(P_{1}=62 \mathrm{psig}\right)$

\begin{tabular}{||c|c|c|c|c||}
\hline $\begin{array}{c}\text { Vortex Diode } \\
\text { Size }\end{array}$ & $\begin{array}{c}\text { Fox Jet } \\
\text { Flow Rate } \\
\text { (gpm) }\end{array}$ & $\begin{array}{c}\text { Relative Flow } \\
\text { Rate (Fox Jet } \\
=100)\end{array}$ & $\begin{array}{c}\text { Penberthy } \\
\text { Jet Flow } \\
\text { Rate (gpm) }\end{array}$ & $\begin{array}{c}\text { Relative Flow } \\
\text { Rate (Pen. Jet } \\
=100)\end{array}$ \\
\hline \hline N/A & 0.11 & 100 & 0.00 & N.A. \\
\hline $1 / 8^{\prime \prime}$ & 0.19 & 173 & N.A. & N.A. \\
\hline $1 / 4^{\prime \prime}$ (twist) & 0.16 & 145 & N.A. & N.A. \\
\hline $1 / 4^{\prime \prime}$ (slant) & 0.18 & 163 & 0.14 & N.A. \\
\hline $3 / 8^{\prime \prime}$ & N.A. & N.A. & 0.22 & N.A. \\
\hline $1 / 2^{\prime \prime}$ & N.A. & N.A. & 0.18 & N.A. \\
\hline
\end{tabular}


Table 14. Overall Pumping Rates for a Typical Case $\left(P_{1}=84 \mathrm{psig}\right)$

\begin{tabular}{||c|c|c|c|c||}
\hline $\begin{array}{c}\text { Vortex Diode } \\
\text { Size }\end{array}$ & $\begin{array}{c}\text { Fox Jet } \\
\text { Flow Rate } \\
\text { (gpm) }\end{array}$ & $\begin{array}{c}\text { Relative Flow } \\
\text { Rate (Fox Jet } \\
=100)\end{array}$ & $\begin{array}{c}\text { Penberthy } \\
\text { Jet Flow } \\
\text { Rate (gpm) }\end{array}$ & $\begin{array}{c}\text { Relative Flow } \\
\text { Rate (Pen. } \\
\text { 100) }\end{array}$ \\
\hline N/A & 0.18 & 100 & 0.063 & 100 \\
\hline $1 / 8 "$ & 0.30 & 167 & N.A. & N.A. \\
\hline $1 / 4^{\prime \prime}$ (twist) & 0.27 & 150 & N.A. & N.A. \\
\hline $1 / 4^{\prime \prime}$ (slant) & 0.29 & 161 & 0.25 & 397 \\
\hline $3 / 8 "$ & N.A. & N.A. & N.A. & N.A. \\
\hline $1 / 2 "$ & N.A. & N.A. & N.A. & N.A. \\
\hline
\end{tabular}

Table 15. Overall Pumping Rates for a Typical Case $\left(P_{1}=96\right.$ psig $)$

\begin{tabular}{|c|c|c|}
\hline Vortex Diode Size & $\begin{array}{c}\text { Fox Jet Flow Rate } \\
\text { (gpm) }\end{array}$ & $\begin{array}{c}\text { Relative Flow Rate } \\
\text { (Fox Jet = 100) }\end{array}$ \\
\hline \hline N/A & 0.21 & 100 \\
\hline $1 / 8^{\prime \prime}$ & 0.33 & 157 \\
\hline
\end{tabular}

Figure 17 shows the effect of changing $P_{1}$ on the overall flow rate for several different outlet heads and feed tank height. Figure 18 shows the effect transfer height for $P_{1}=80$ psig. All tests were for the $1 / 2$ " Fox

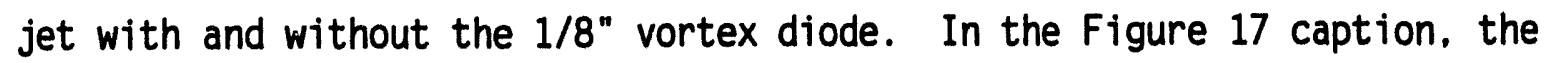
first number is transfer height and the second is the feed tank height $\left(h_{p}\right)$. These figures were generated using equation (17), the experimental coefficients, and intercepts. The average error in the estimated values is one to seven percent overestimation of the flow rate for the 1/8" VD - 1/2" Fox vortex diode jet and sixteen to twenty-une percent overestimation of the flow rate of the $1 / 2^{n}$ Fox jet. 


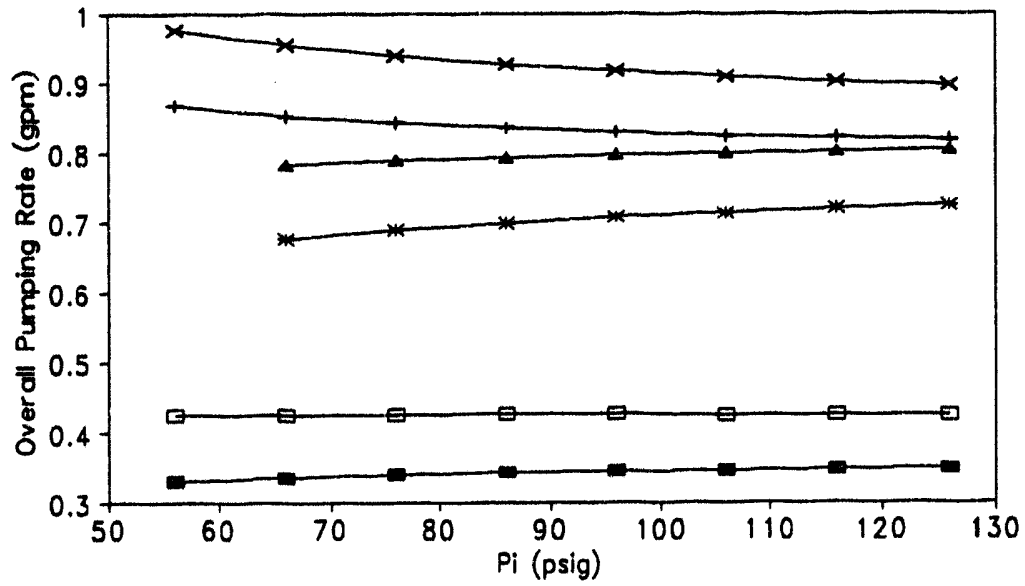

$\rightarrow$ Fox, 36, 4' $\rightarrow$ Fox, 31', 9' $\rightarrow$ Fox, 36, 9'

$\rightarrow 1 / 8^{\prime \prime} \mathrm{VJ}, 36^{\prime}, 4^{\prime} \rightarrow-1 / 8^{\prime \prime} \mathrm{VJ}, 31^{\prime}, 9^{\prime} \rightarrow-1 / 8^{\prime \prime} \mathrm{VJ}, 36^{\prime}, 9^{\prime}$

Figure 17. Overal1 Pumping Rate for the 1/2" Fox Jet and the $1 / 8$ " VD- $1 / 2$ " Fox VDJ versus $P_{1}$

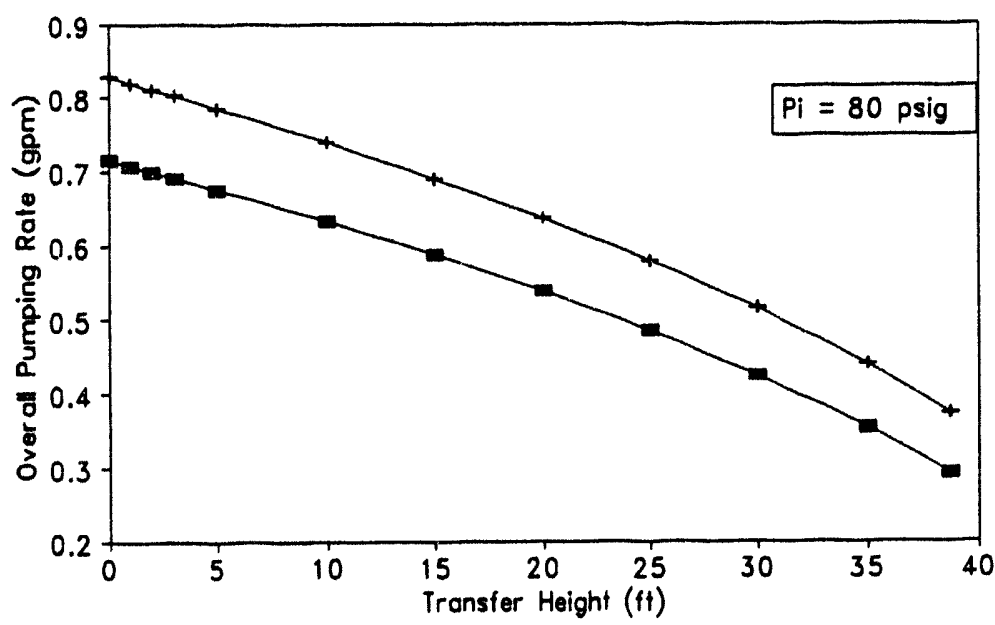

$\rightarrow-1 / 2^{\prime \prime}$ Fox Jet $\rightarrow 1 / 8^{\prime \prime} \mathrm{VD}-1 / 2^{\prime \prime}$ Fox VDJ

Figure 18. Overall Pumping Rate for the 1/2" Fox Jet and the 1/8" VD - 1/2" Fox VDJ versus Transfer Height 
Therefore, while these figures accurately predict the relative behavior of the systems they should be used for comparison only because they significantly overstate the $1 / 2$ " Fox jet overall pumping rate. However, the following trends can be seen:

1) Larger outlet heads increase the relative vortex diode jet advantage. It has a very large effect on the overall pumping rate (equation (4)).

2) The effect of the $P_{1}$ is small on the relative performance between the jet and the vortex diode jet. However, it also has a large effect on the overall pumping rate (equations (1), (4), (7), (17), and (18)).

3) The effect of the refill head is: the smaller the refill head the larger the vortex diode jet advantage. This effect is sma11. A decrease of five feet in the refill height increased the vortex diode jet advantage by five percent. The small refill heads make the vortex diode more important by increasing the refill rate in cases.

\subsection{Construction Effects}

Two construction details were investigated (Table 1), the orientation of the vortex diode, and the length of the vortex diode inlet and outlet line. The outlet line for the $1 / 4^{\prime \prime}$ VD(s) - 1/2" Fox vortex diode jet was 0.75 " shorter than the $1 / 4 " V D(t) \cdot 1 / 2^{\prime \prime}$ Fox vortex diode jet. The results indicate that the slant version pumps better (higher $C_{1}$ ), does not pump to the destination quite as well (lower $C_{0}$ ), and does not refill quite as fast (lower $\mathrm{C}_{3}$ ), however, the slant version's overall pumping rate is slightly higher. All of these effects were small and consistent with the shorter flow path of the slant version. Since there is no theoretical reason for the orientation to effect the vortex diode jet performance, the shorter flow path is concluded to be the cause. A longer flow path improves the pumping efficiency at a cost to the refill rate. Balancing the pumping efficiency with the refill rate would optimize the vortex diode jet design. The overall pumping rate for the $1 / 8^{\prime \prime}$ vortex diode jet can be expected to be improved with a longer vortex diode outlet line. 


\subsection{Use With a Fluidic Sampler}

Many runs were performed with fluidic samplers (Reference 7). With a fluidic sampler, primary flow was into the feed tank and not through the outlet line. The outlet flow rate decreased by a factor of eight to ten because of the very high head loss through a fluidic sampler. As expected, the refill coefficient was not effected. In this configuration, with the very high friction head loss in the outlet line, neither the jet or VDJs produced induced flow. However, both the jet and VDJ systems transfer higher than the standard jet assisted air lift sample systems. Further, the VDJ had an overall pumping rate over fifty percent faster than the standard fluidic jet configuration so even in this extreme application the VDJ is still clearly superior to a jet. An optimized fluidic sampler (large samples. low flow resistance) would operate in the induced flow pumping regime. 


\subsection{Counclusions}

1. Vortex diode jets greatly increase the overall pumping rate of similar standard pumping fluidic transfer systems. Vortex diode jets have 2.5-3.0 times the refill rate of the base jet. The smallest vortex diode jet gave the highest overall pumping rate. Overall pumping rates were $173 \cdot 157$ percent of the system with the jet alone. The larger the vortex diode the higher the required inlet pressure to induce the flow. Moreover, the most efficient use of pumping air favors the smaller diode vortex diode jets.

2. The design equations with the experimental coefficients work very well for modeling the pumping inlet, outlet (and thus the plenum), and refill behavior. A slight improvement can be obtained with the use of laminar. transient, and turbulent experimental flow coefficients.

3. The poorly performing Penberthy jet (lower $C_{1}$, lower $C_{p 10}$ ) required large vortex diodes to overcome the jet's characteristics. A vortex diode jet can compensate for a poor base jet. The $3 / 8$ " vortex diode was optimal for the Penberthy based vortex diode jets, producing 80 percent of the Fox based vortex diode jet performance.

4. Equation (17) is a useful tool for design and comparison. However, inclusion of the intercepts for the transient and turbulent flow coefficients is required to accurately predict the overall flow rates of jet and VDJ systems.

5. The three major determinants in absolute and relative overall pumping rate are: a) refill head, b) pumping pressure, and c) outlet line characteristics.

6. The inlet and outlet line characteristics of the vortex diode jet's vortex diode are important. Three 1/4" vortex diode with different outlet line lengths were tested. These tests showed that the vortex diode jet overall pumping rate could be optimized by finding the outlet line length that balances the pumping and refill rates. 
7. The orientation of the vortex diode did not significantly change the vortex diode jet performance.

8. Inclusion of a vortex diode does not change the jet equation $\left(P_{1} \cdot P_{0}\right.$ relationship). so the standard jet equations can be used with a vortex diode jet system. 


\subsection{Recommendations}

1. The intercepts for the transient and turbulent flow coefficients should be used to determine the inlet, outlet, refill, and overall flow rates.

2. The vortex diode size should be optimized to the base jet. Fox jet optimum was $1 / 8$ " while the Penberthy optimum size was $3 / 8$ ".

3. All fluidic jet transfer systems should be operated with a high inlet pressure as possible. The higher pumping pressure also minimizes the pumping time without increasing the refill time, thus reducing the cycle time and increasing the overall pumping rate.

4. The vortex diode jet (or any fluidic jet) performance (overall pumping rate) should be maximized by minimizing the outlet and refill flow resistances.

5. The vortex diode inlet and outlet line length affect the vortex diode jet overall pumping rate, this relationship should be determined and optimized.

6. When using an in-line fluidic sampler, optimal VD size and pumping (high) pressure are especially important for optimal overall pumping rate. The fluidic sampler should be optimized before it is used with a VDJ fluidic transfer system. 


\subsection{References}

1. C. Etherington, "Power Fluidics and Its Application in the Nuclear Industry." Nuclear Energy, 1984, 23, No. 4, pg. 227-235.

2. M. G. Deshpande and Prof. Subir Kar. "Analysis for Flow Prediction of Vortex Amplifier, "Journal of the Institute of Engineers (India). Vol. 58, pg. 200-202. March 1978.

3. S. M. Robinson. Development of a Continuous.Flow Fluidic Pump, Martin Marietta Energy Systems. Inc., Oak Ridge National Laboratory report ORNL/TM-9564, August 1985.

4. James R. Welty, Charles E. Wicks, and Robert E. Wilson, Fundamentals of Momentum. Heat and Mass Transfer, Second Edition, John Wiley \& Sons, copyright 1976, pages 84-88, 132-134, 187.219.

5. G. V. Smith and B. E. Lewis, Design of a Pulsed-Mode Fluidic Pump Using a Venturi.Like Reverse Flow Diverter, Martin Marietta Energy Systems. Inc. . Oak Ridge National Laboratory report ORNL/TM-10281. February 1987.

6. Crane Co., Flow of Fluids through Valves. Fittings, and Pipe, Technical Paper No. 410, Twenty-First Printing, 1982.

7. E. D. Houck letter EDH-1.91 to T. A. Todd, "Fluidic Sampler Mock-Up Report," dated June 27, 1991. 


\subsection{Nomenclature}

$A_{a}$ - vent line orifice cross sectional area, $\mathrm{ft}^{2}$

$A_{1}$ - jet nozzle inlet cross sectional area

$A_{n}$ - equivalent jet nozzle outlet-diffuser inlet cross sectional area

$A_{o}$ - vortex diode outlet port cross sectional area

$C_{d} \cdot$ jet discharge coefficient

$C d_{d, d}$ - the vent line orifice coefficient for air

$\mathrm{Cd}_{\mathrm{o}, 1}$ - the vent line orifice coefficient for liquid

$C_{\text {head }}$ - the experimental intercept for equation 3

$C_{i}$ - inlet flow coefficient in general, specifically for a vortex diode jet

$C_{i j}$ - inlet flow coefficient, jet specific

$C_{\text {ivd }}$ - inlet flow coefficient; vortex diode specific

$C_{0}$ - generic outlet flow coefficient (jet, VD, or VDJ)

$C_{o j}$ - outlet flow coefficient for a jet diffuser

$C_{o v}$ - flow coefficient for vortex diode outlet orifice

$C_{p}$ - pressure recovery coefficient.

$C_{p i o}$ - conversion factor between the inlet and outlet pressure for a jet or

a VDJ as defined by equation 17

$C_{1}$ - vortex diode outlet flow coefficient

$C_{2}$ - jet outlet flow coefficient

$C_{3}$ - vortex diode jet outlet flow coefficient

$D_{p}$ - the vent line pipe inside diameter, in feet

$f_{j, 1}$ - jet liquid friction factor during pumping chamber refill

$f_{p . d}$ - the vent line air friction factor during pumping chamber refill

$f_{p .1}$ - the vent line liquid friction factor during pumping chamber refill

g - gravitational acceleration, $32.2 \mathrm{ft} / \mathrm{s}^{2}$

$h$ - the head of solution in a tank

$h_{\text {factor }}$ - average refill head over a refill cycle as defined by equations 13 and 14

$h_{\text {final }}$ - the final head of solution at the pumping chamber outlet (bottom) during the refill cycle

$h_{h}$ - the equivalent head applied by a column of solution between the outlet line height and the feed tank solution upper surface

$h_{1}$ - the head of solution at the pumping chamber outlet (bottom)

$h_{\text {initial }}$ - the initial head of solution at the pumping chamber outlet 
(bottom) during the refill cycle

$h_{p}$ - the head of solution in the jet plenum (or the VD of the feed tank outlet)

$K$ - resistance coefficients for valves and fittings

$K_{a}$ - vent line orifice $K$

$K_{f} \cdot K$ for forward flow through the vortex diode

$K_{j, 1}$ - the jet $K$, for liquid during pumping chamber refill

$K_{r} \cdot K$ for pumping chamber refill through the vortex diode

$\mathrm{N}_{\mathrm{Re}}$ - Reynolds number (diameter*density*velocity/viscosity, dimensionaless)

$P$ - pressure

$P_{h}$ - the equivalent pressure applied by a column of solution between the outlet line height and the feed tank solution upper surface

$P_{1}$ - inlet pressure, general

$P_{\text {inlet }}$ - inlet pressure to the fluidic sampler

$P_{n} \cdot$ jet nozzle exit pressure

$P_{0}$ - outlet pressure, general

$P_{p}$ - the jet plenum (suction) or feed tank outlet pressure

$Q$ - the volumetric flow rate

$Q_{f}$ - vortex diode forward flow rate

$Q_{1}$ - inlet liquid flow rate in general, specifically for a vortex diode jet

$Q_{i j} \cdot$ jet inlet liquid flow rate

$Q_{0}$ - outlet line (jet outlet) flow rate, general

$Q_{p} \cdot$ jet plenum (suction) flow rate

$Q_{r j}$ - pumping chamber refill rate through a jet or jet reverse flow rate

$Q_{r v}$ - pumping chamber refill rate through a VD or the VD reverse flow rate

$Q_{r f}$ - pumping chamber refill rate through a VDJ or VDJ reverse flow rate

$Q_{t}$ - flow rate from (pos.) the feed tank, general (for a jet system $Q_{t}=Q_{p}$ )

$T$ - turndown ratio, $K_{r} / K_{f}$

$V_{f p}$. volume transferred to (negative) or from the feed tank during pumping

$V_{f r}$ - volume transferred from the feed tank during refill

$V_{p} \cdot$ volume pumped from the pumping chamber

$V_{t}$ - volume transferred from the feed tank which equals the volume

transferred to the destination (hold-up tank)

$\rho$ - fluid density, $1 \mathrm{~b}_{\mathrm{a}} / \mathrm{ft}^{3}$

$\rho_{\mathrm{a}} \cdot$ air density, $1 \mathrm{~b}_{\mathrm{a}} / \mathrm{ft}^{3}$

$\rho_{1} \cdot$ liquid or water density, $1 b_{a} / \mathrm{ft}^{3}$ 


\subsection{Appendix}

\section{Test Result Figures}

The following figures show the results of tests, data from these figures are summarized in Tables $3 \cdot 15$. Figures $19 \cdot 26$ show the inlet flow results. Figures $27 \cdot 34$ show the outlet flow results. Figures $35 \cdot 43$ show the refill flow results.

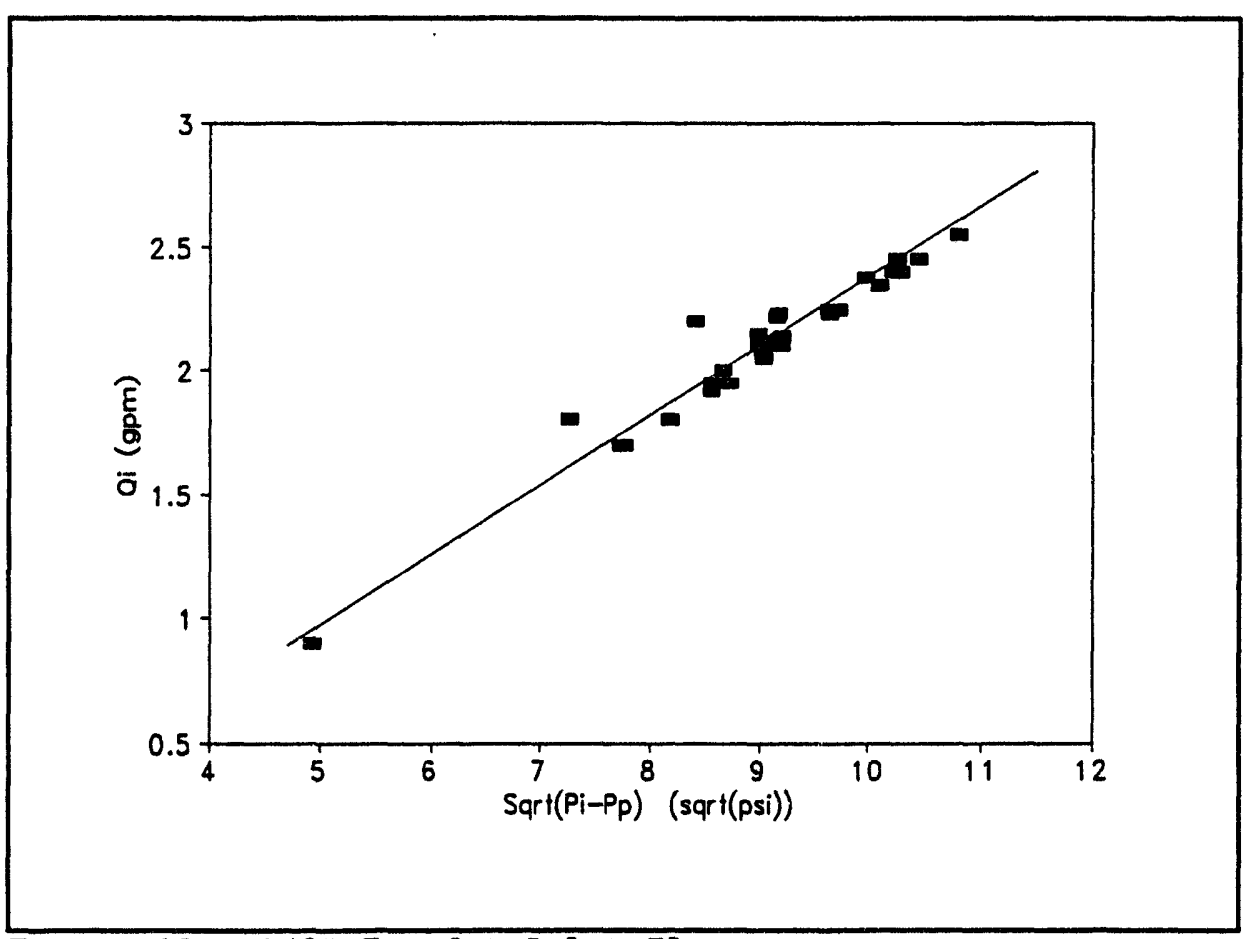

Figure 19. 1/2" Fox Jet Inlet Flow 


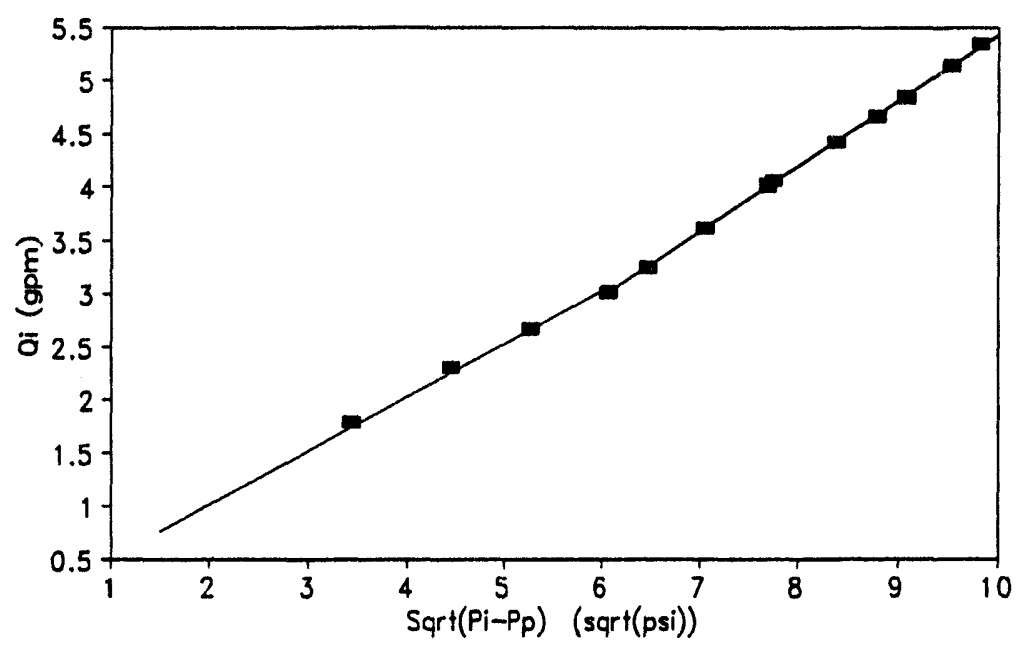

- Trans. Coef. - Turb. Coef.

Figure 20. 1/8" VD - 1/2" Fox Vortex Diode Jet Inlet Flow

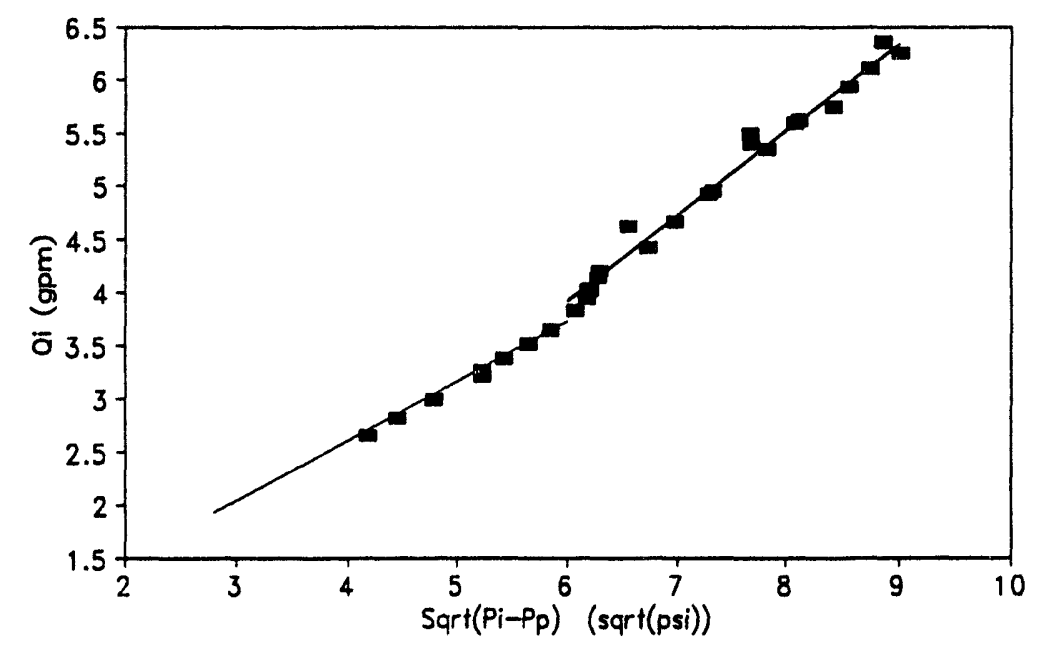

- Trans. Coef. - Turb. Coef.

Figure 21. 1/4" VD(t) - 1/2" Fox Vortex Diode Jet Inlet Flow 


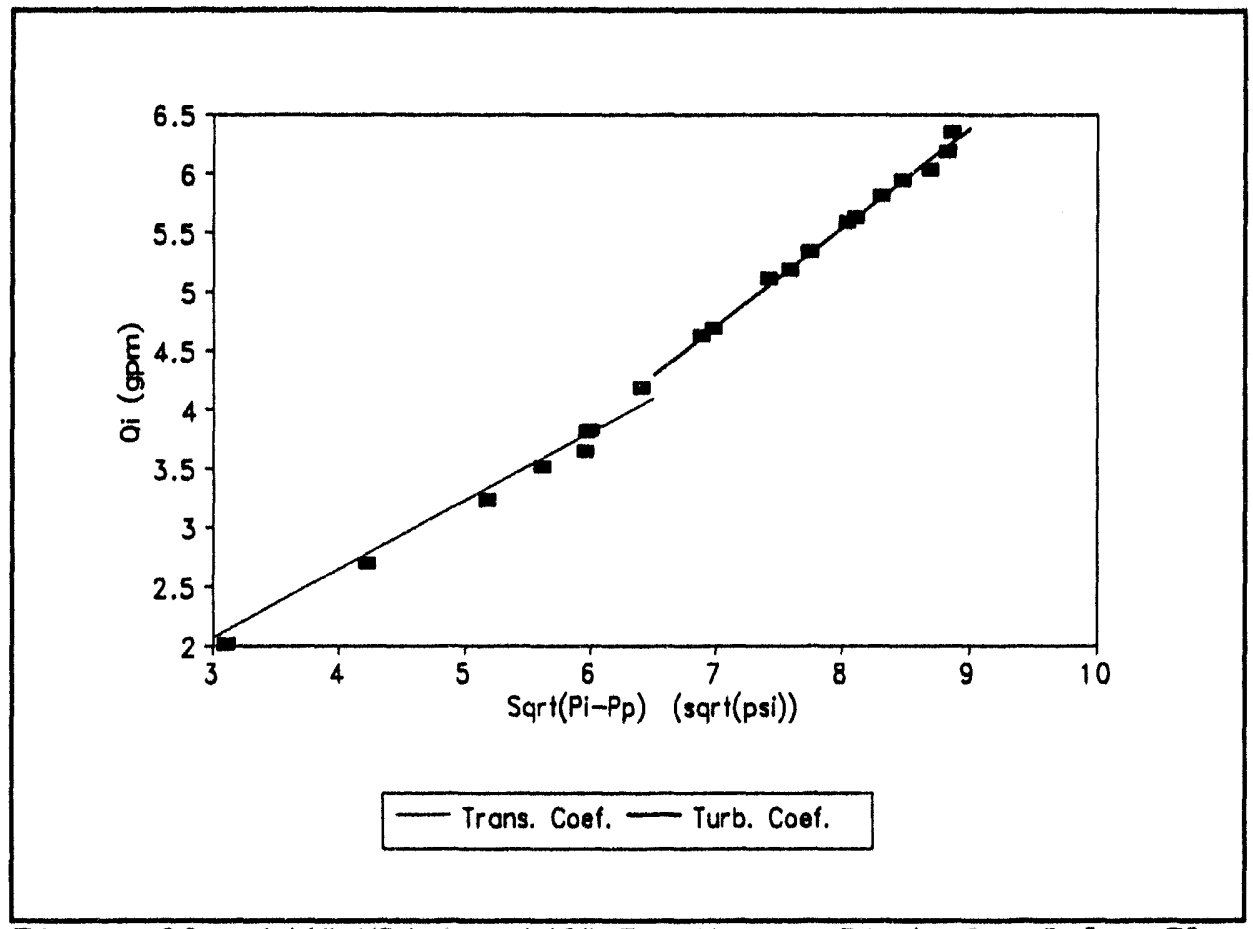

Figure 22. 1/4" VD(s) - 1/2" Fox Vortex Diode Jet Inlet Flow

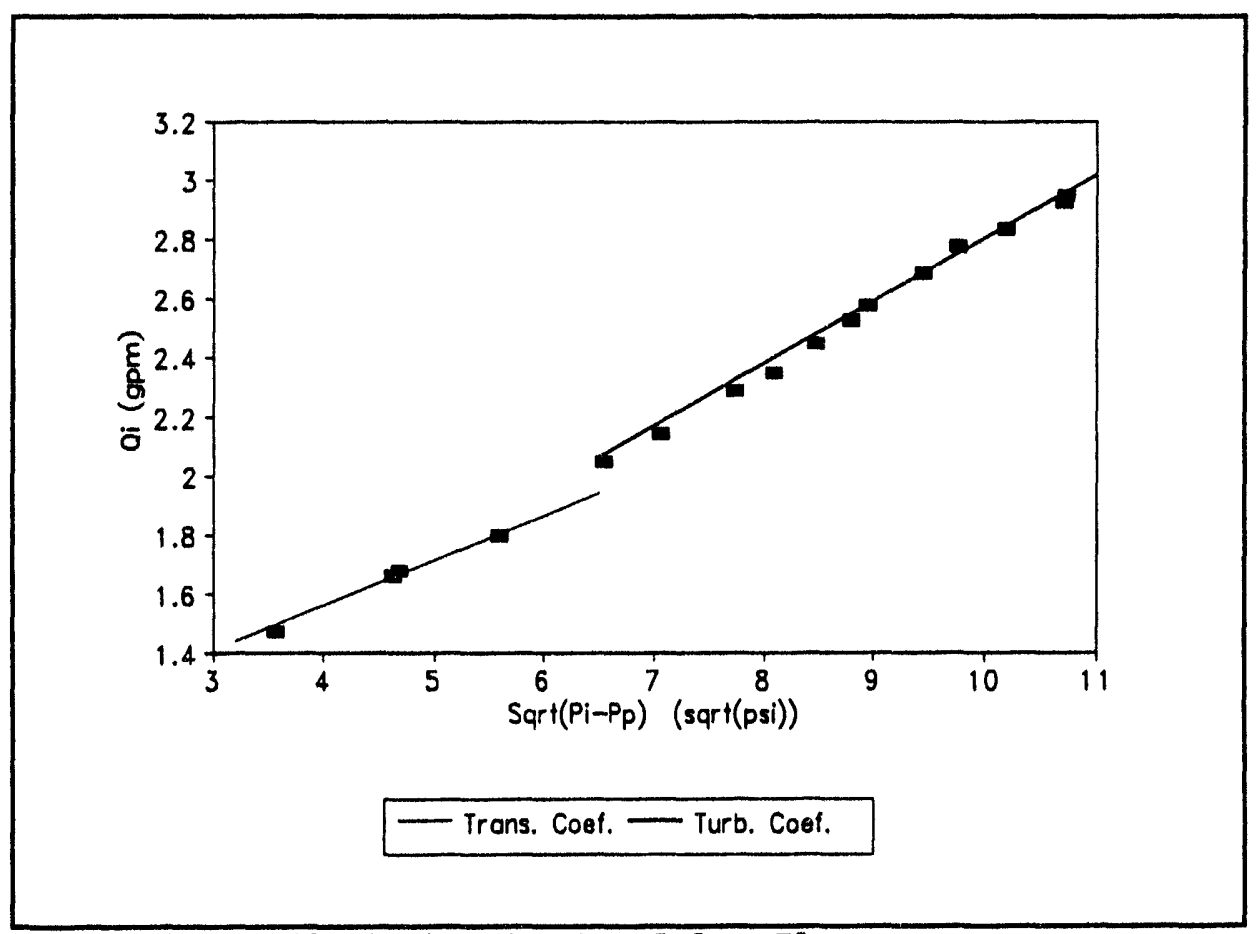

Figure 23. 1/2" Penberthy Jet Inlet Flow 


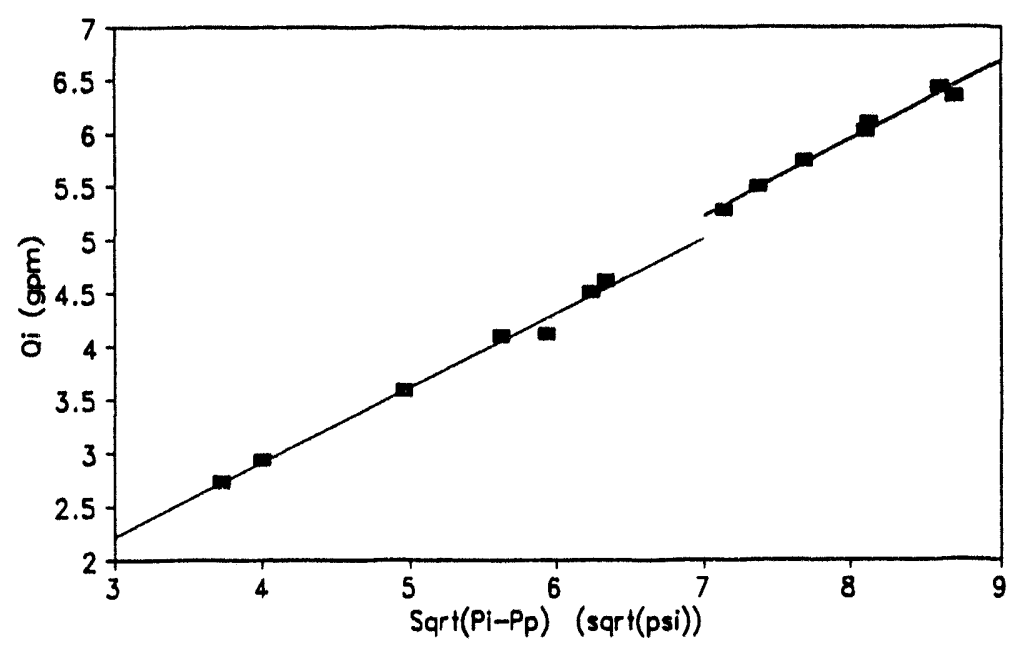

Trans. Coef. - Turb. Coof.

Figure 24. 1/4" VD - 1/2" Pen. Vortex Diode Jet Inlet Flow

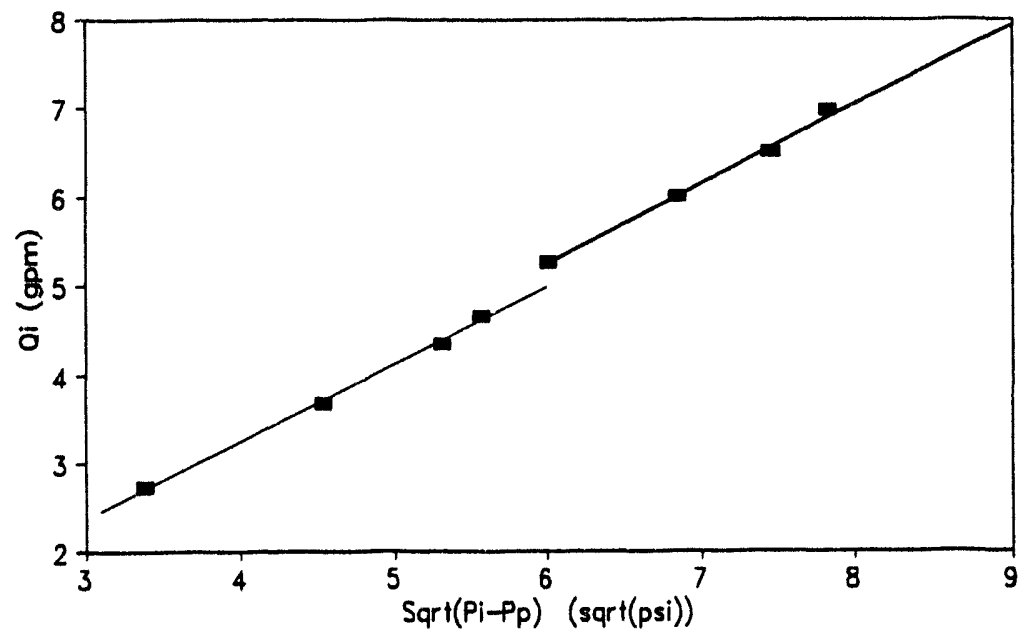

- Trans. Coef. - Turb. Coef.

Figure 25. 3/8" VD - 1/2" Pen. Vortex Diode Jet Inlet Flow 


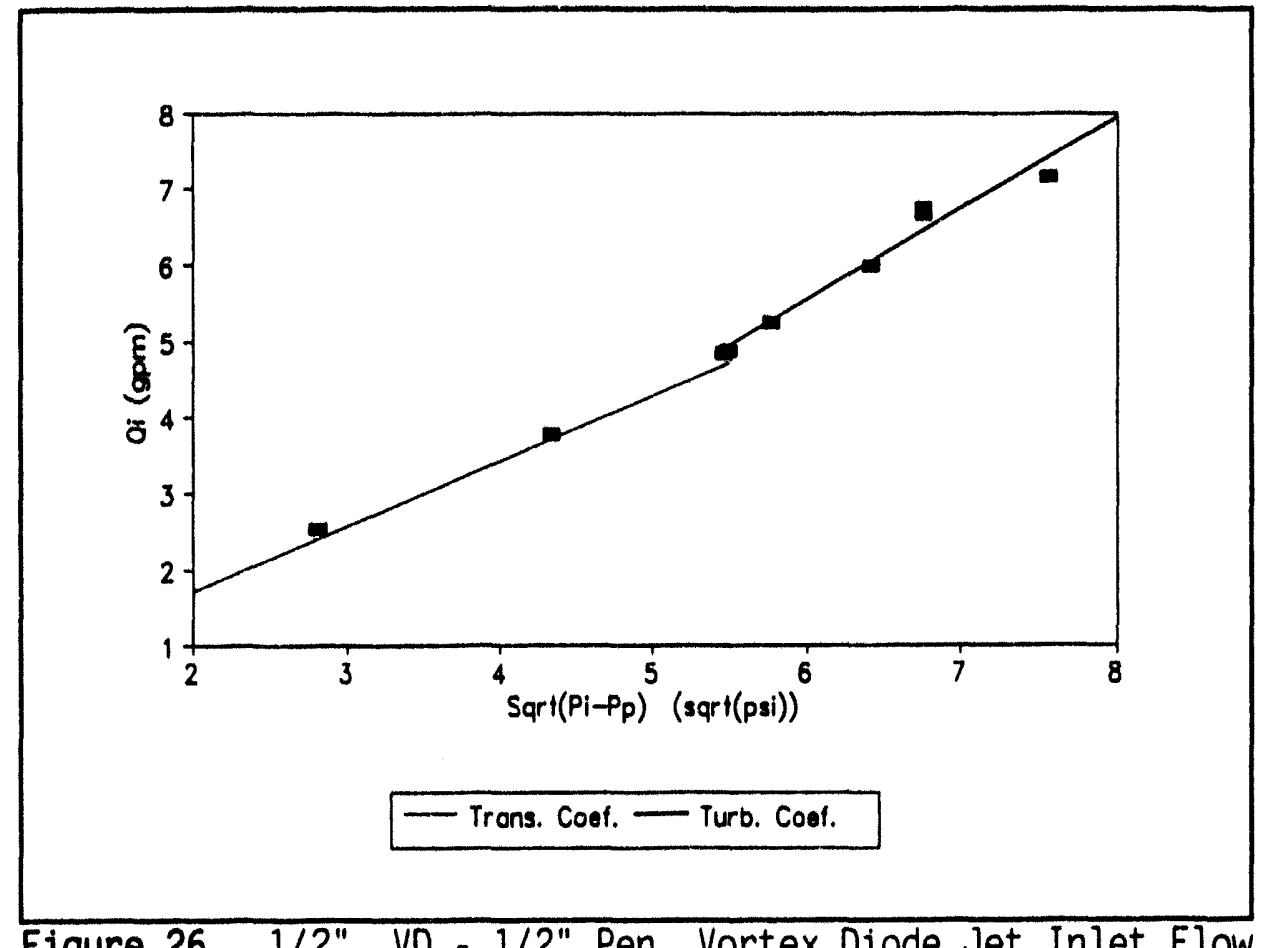

Figure 26. 1/2" VD - 1/2" Pen. Vortex Diode Jet Inlet Flow

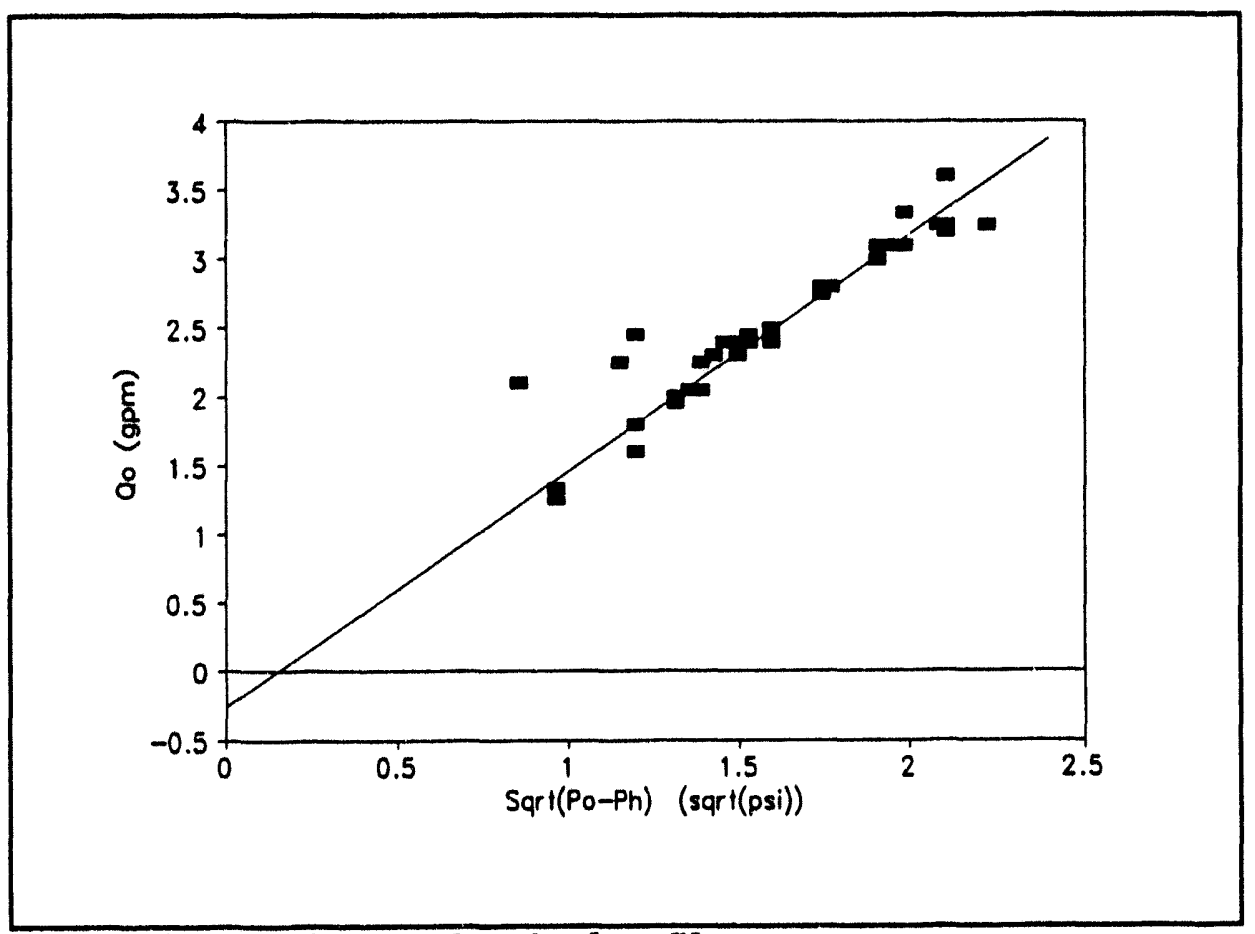

Figure 27. 1/2" Fox Jet Outlet Flow 


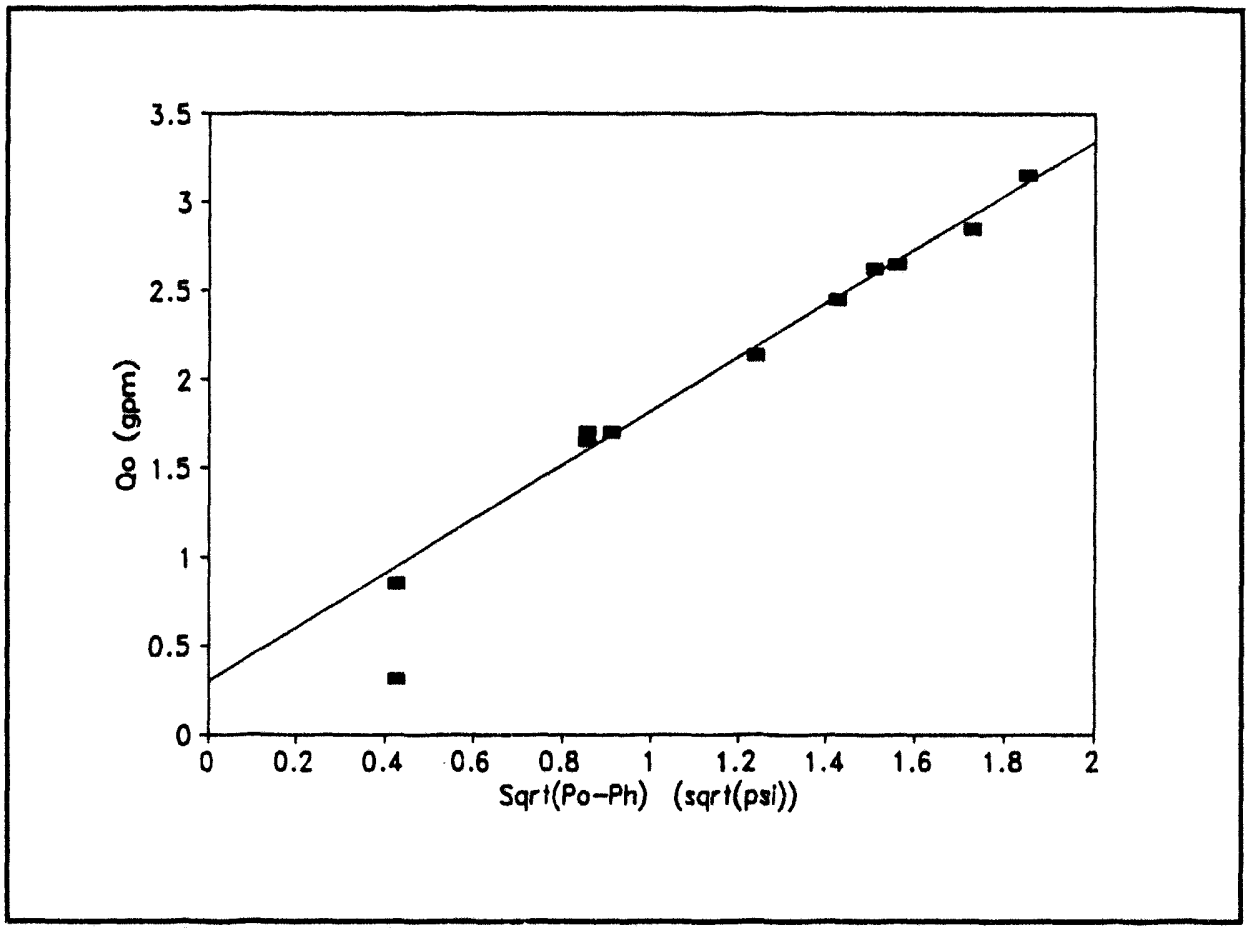

Figure 28. 1/8" VD - 1/2" Fox Vortex Diode Jet Outlet Flow

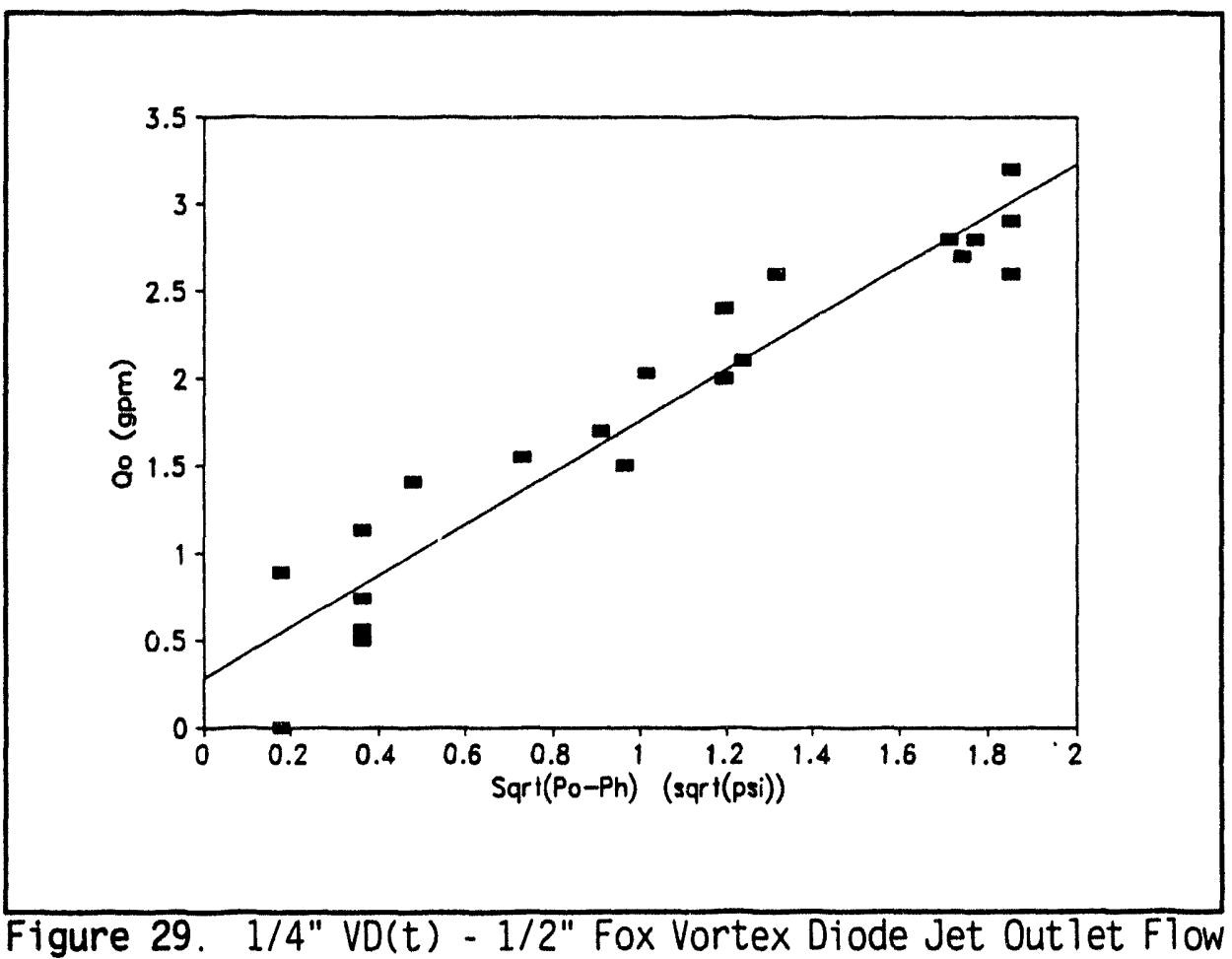




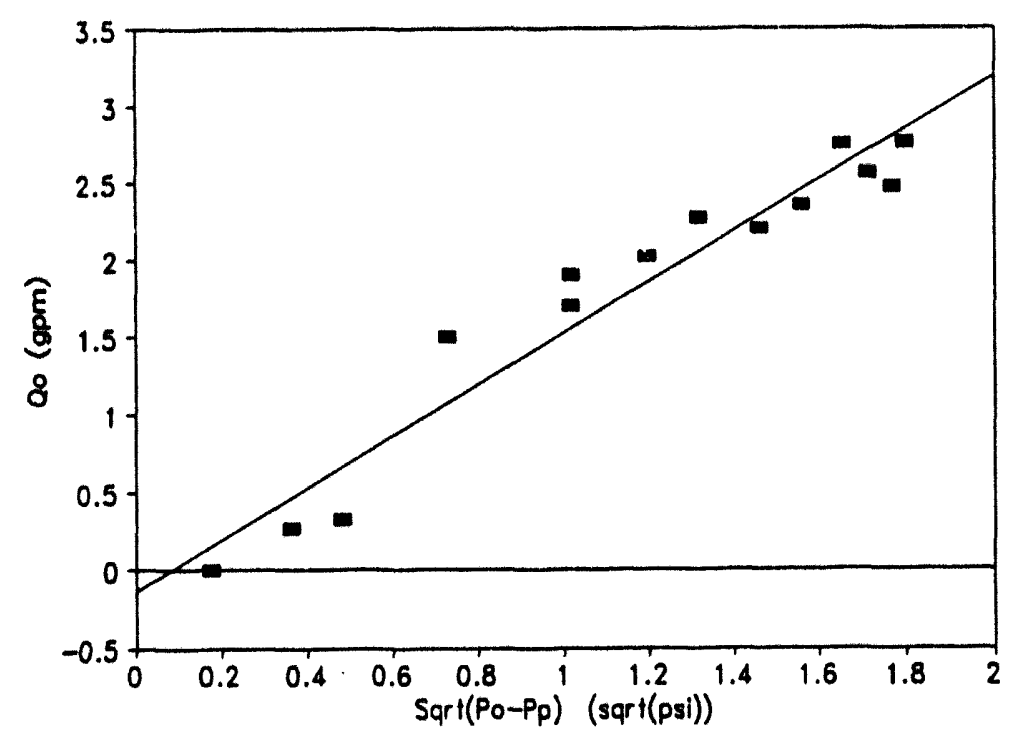

Figure 30. 1/4" VD(s) - 1/2" Fox VDJ Out let Flow

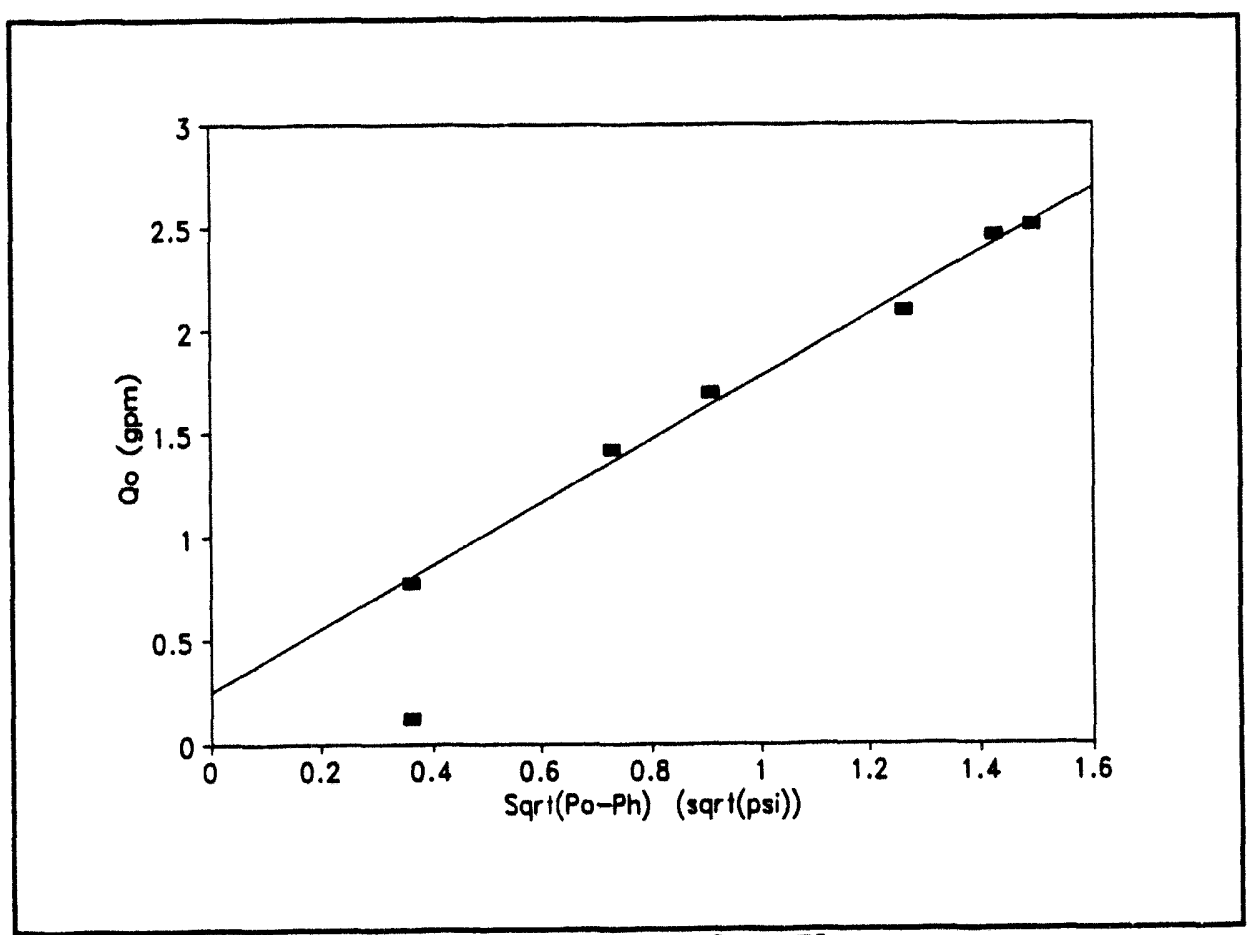

Figure 31. 1/2" Penberthy Jet Outlet Flow 


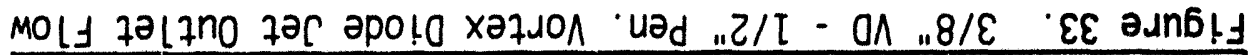

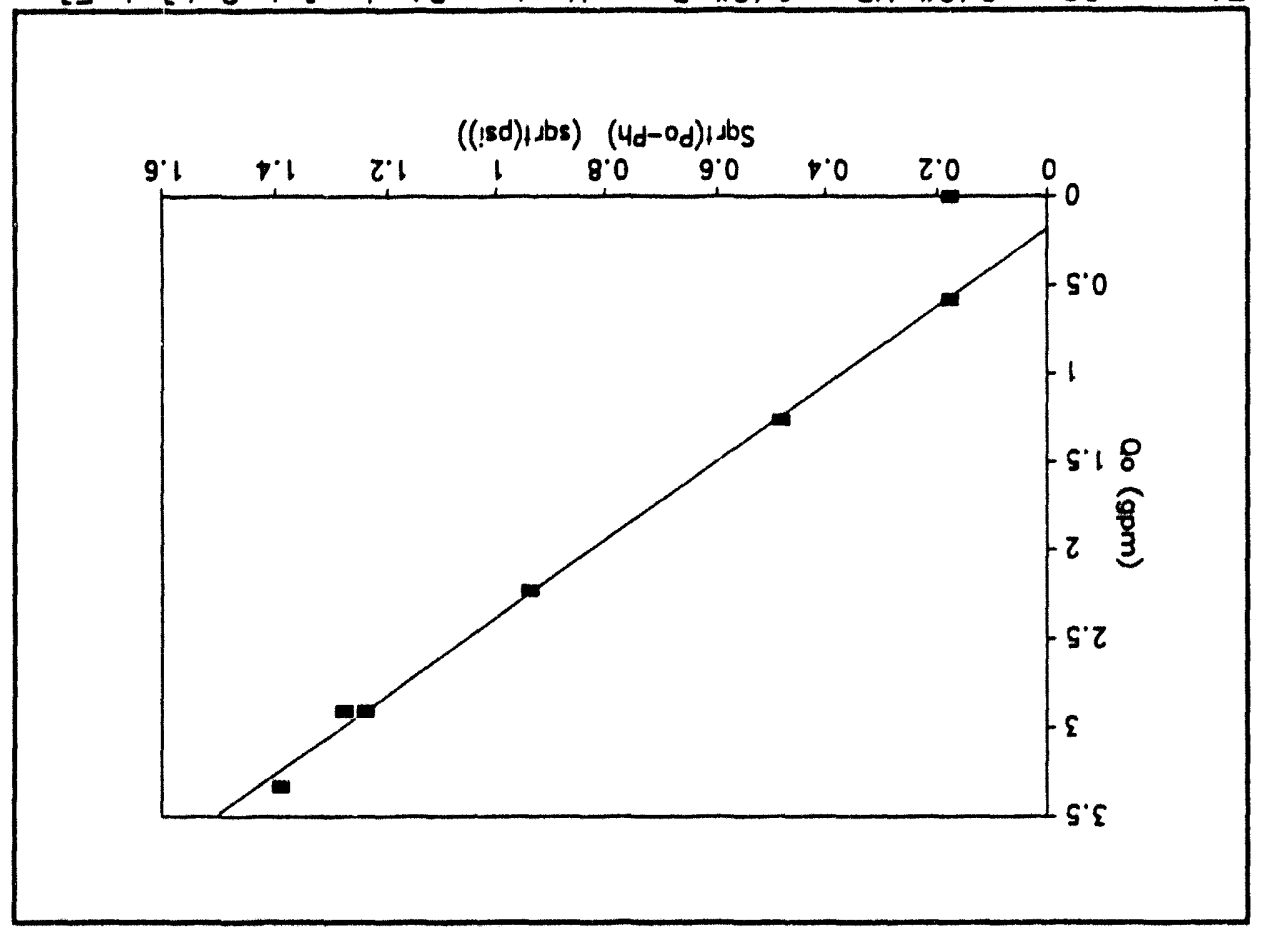

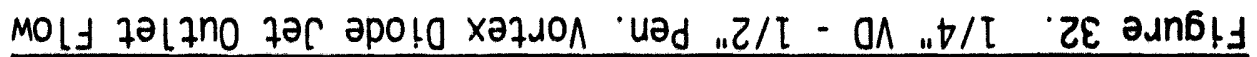

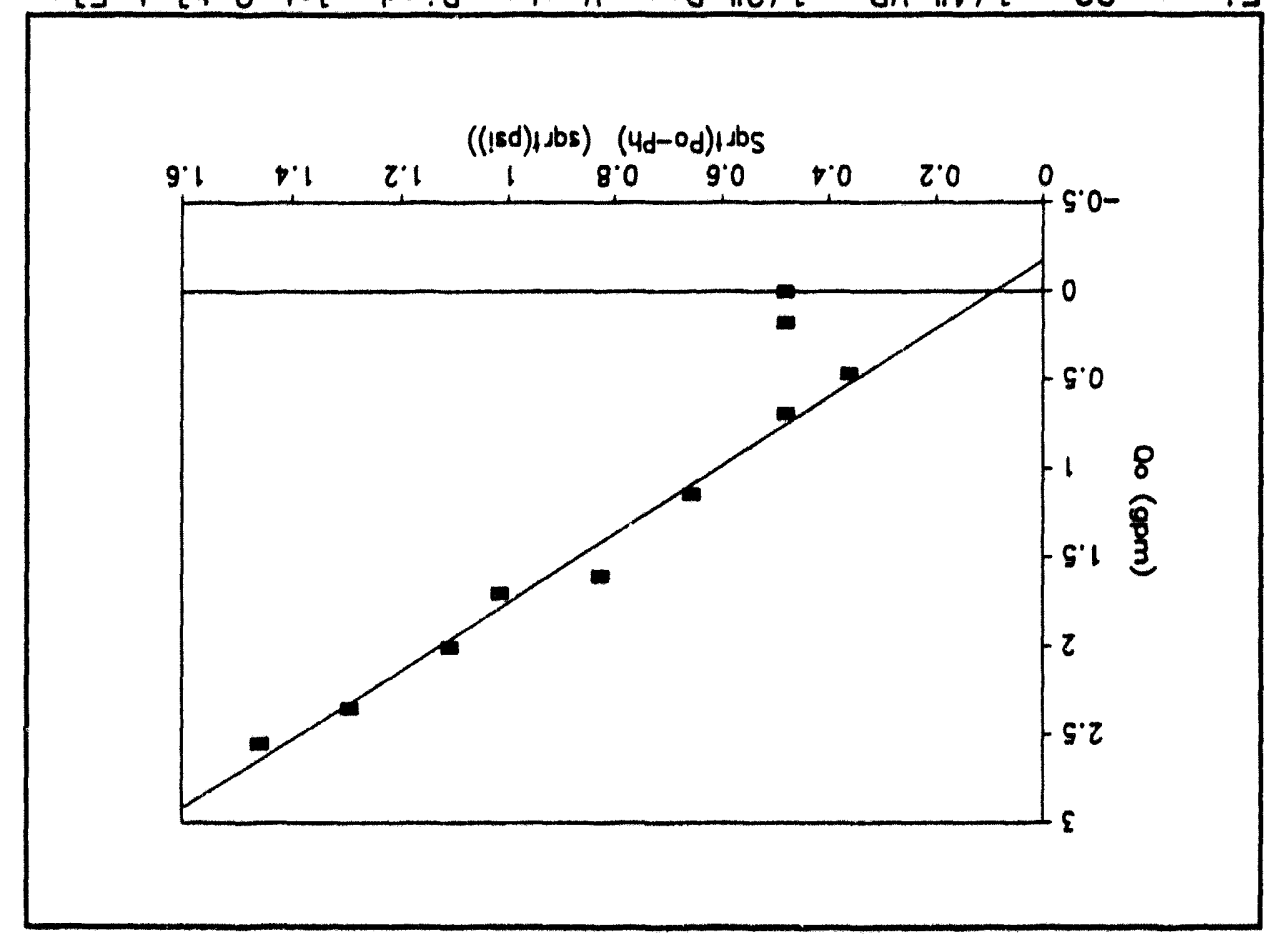




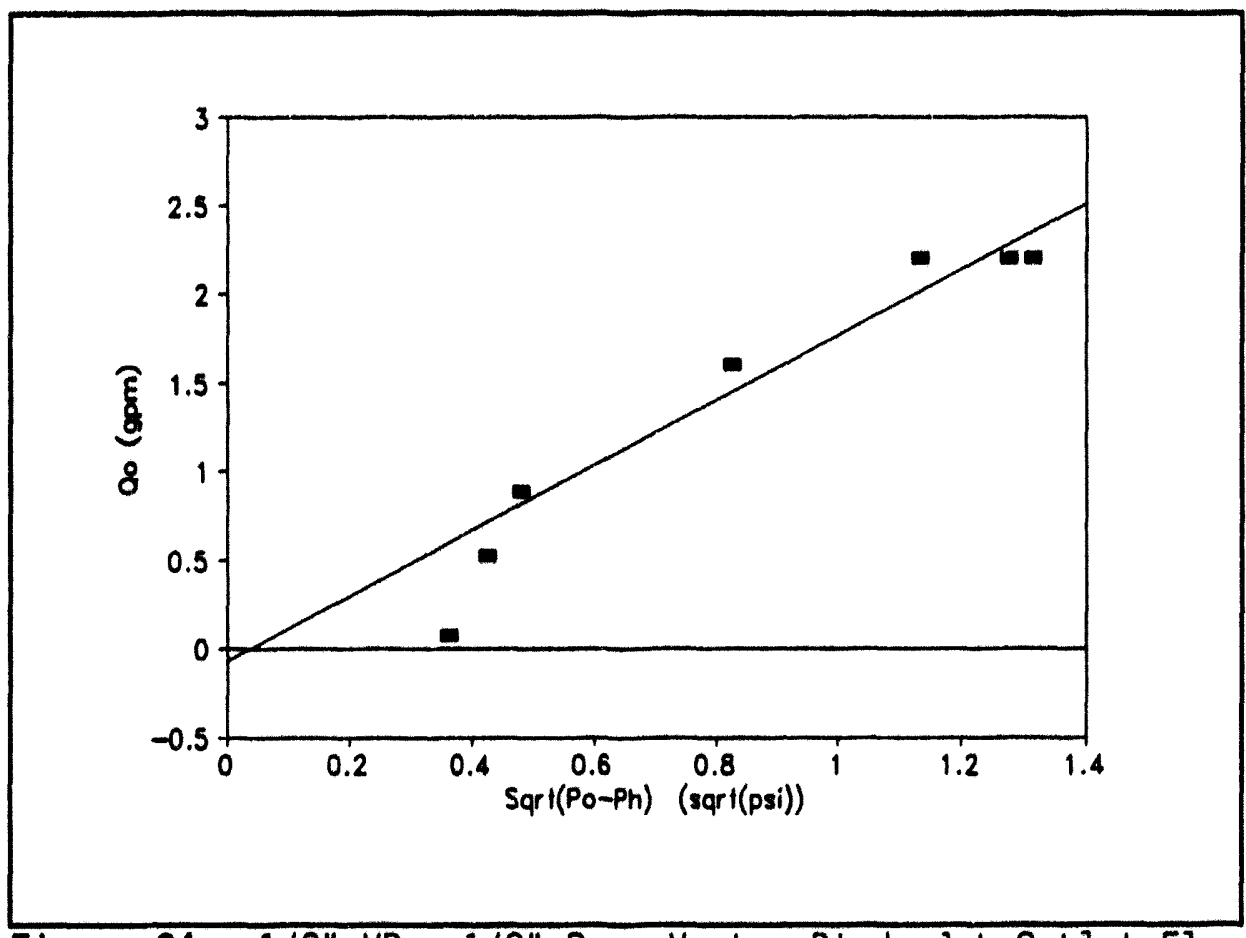

Figure 34. 1/2" VD - 1/2" Pen. Vortex Diode Jet Outlet Flow

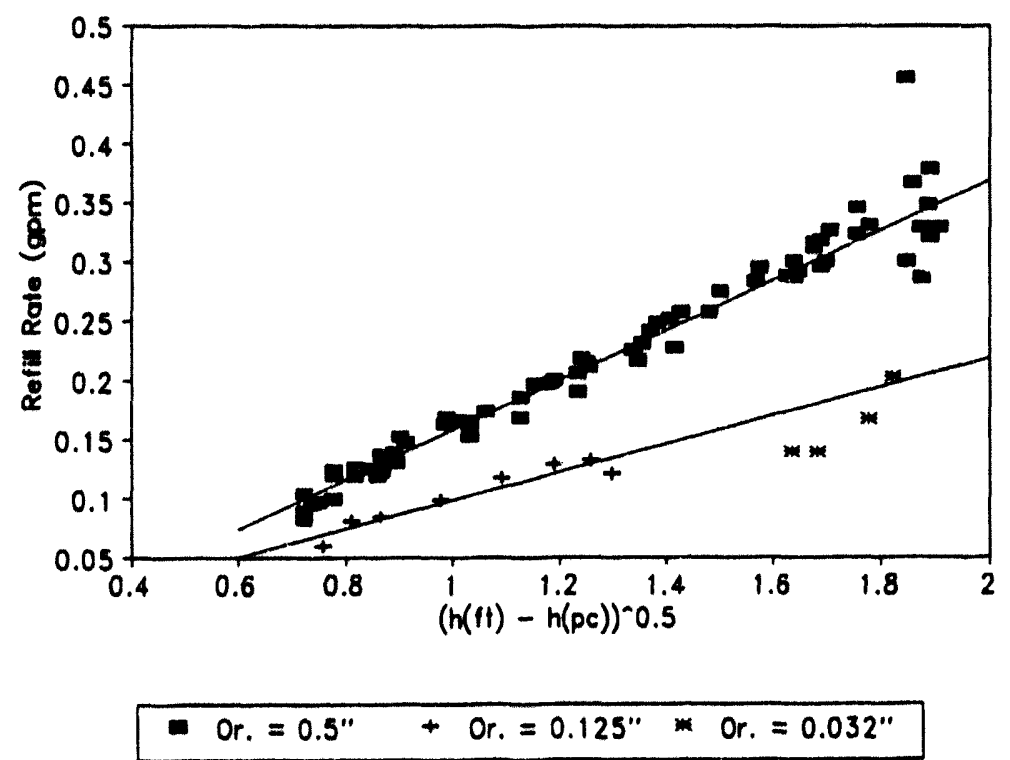

Figure 35. 1/2" Fox Jet Refill Flow 


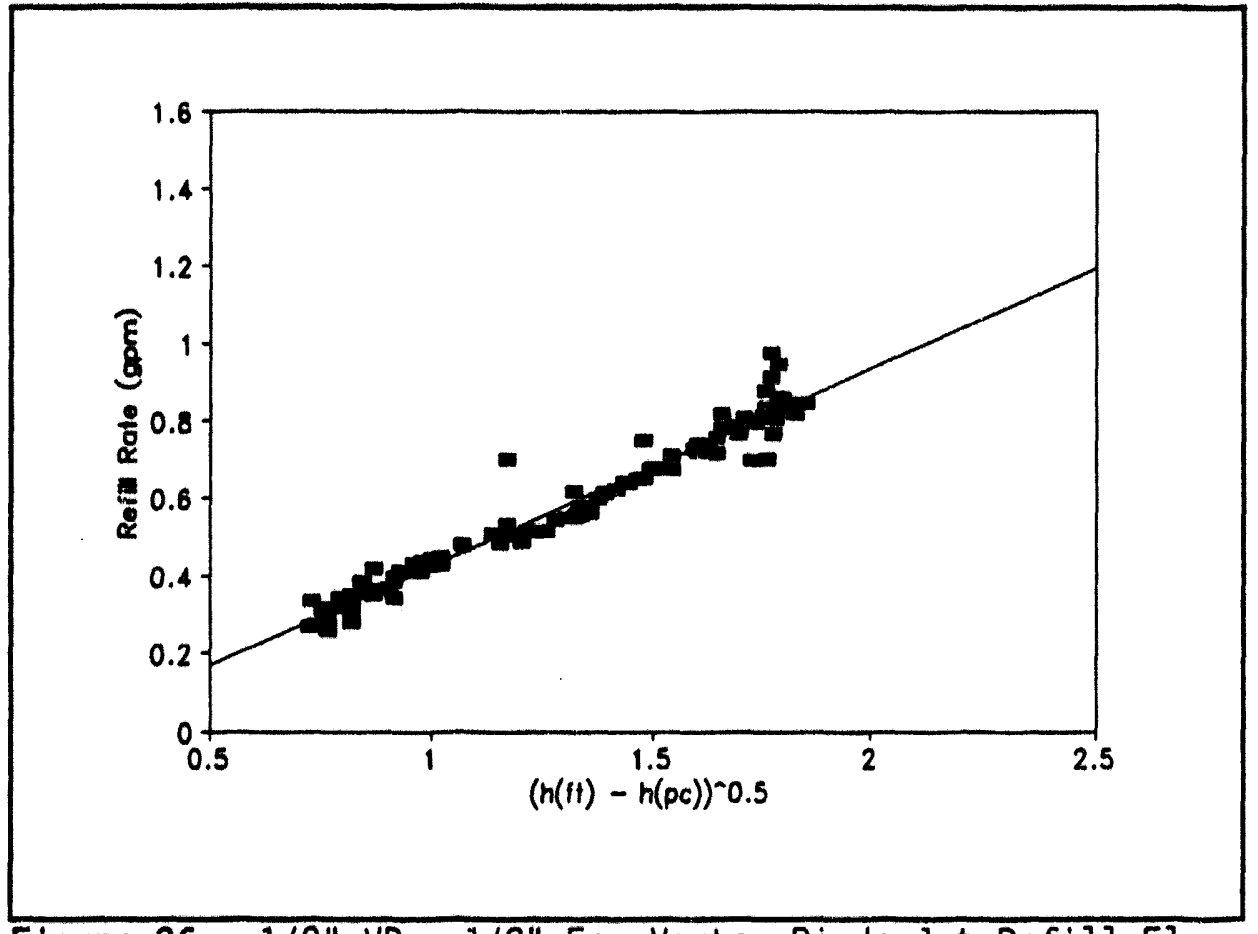

Figure 36. 1/8" VD - 1/2" Fox Vortex Diode Jet Refill Flow

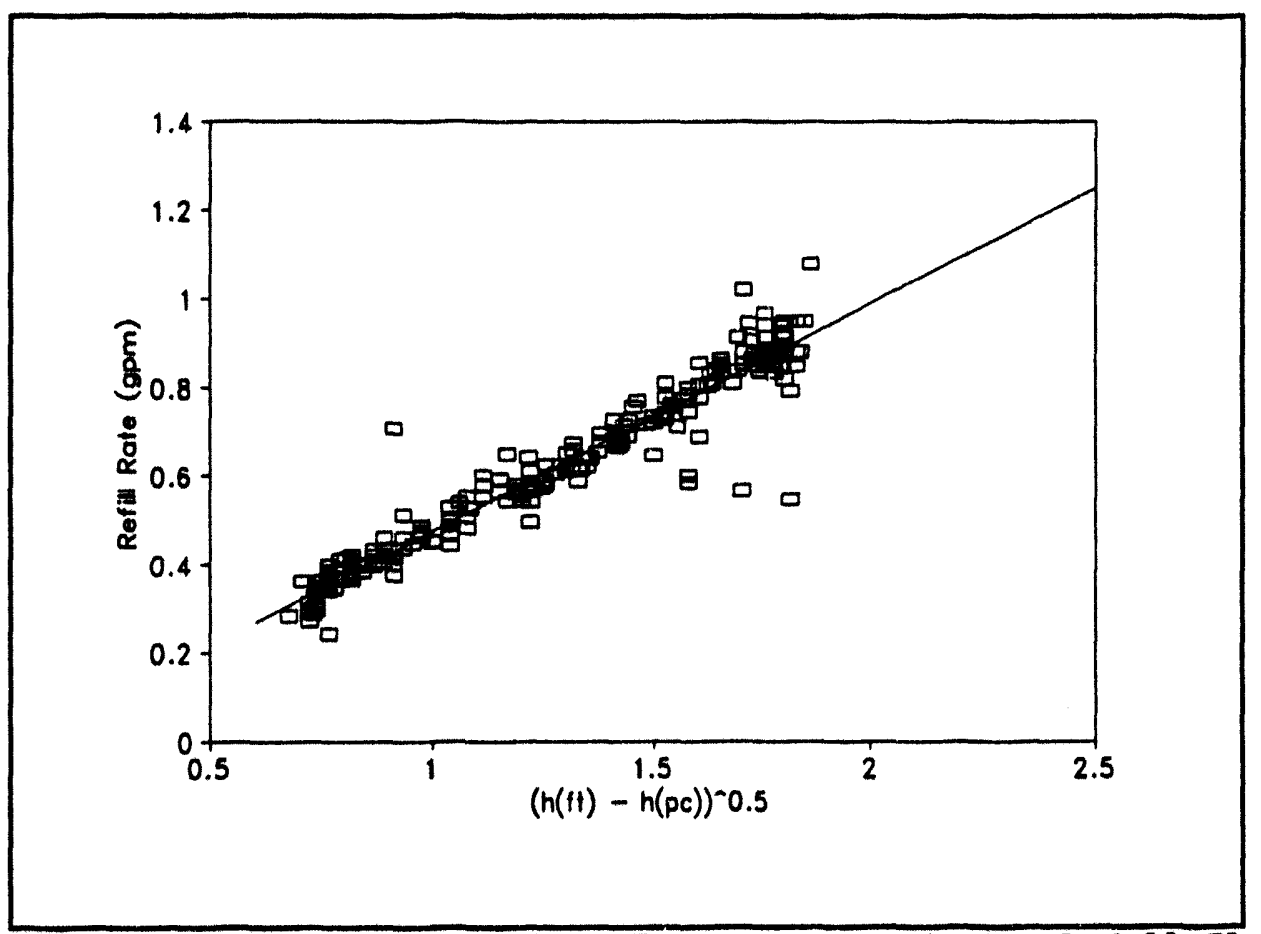

Figure 37. 1/4" VD(t) - 1/2" Fox Vortex Diode Jet Refi11 Fl ow 


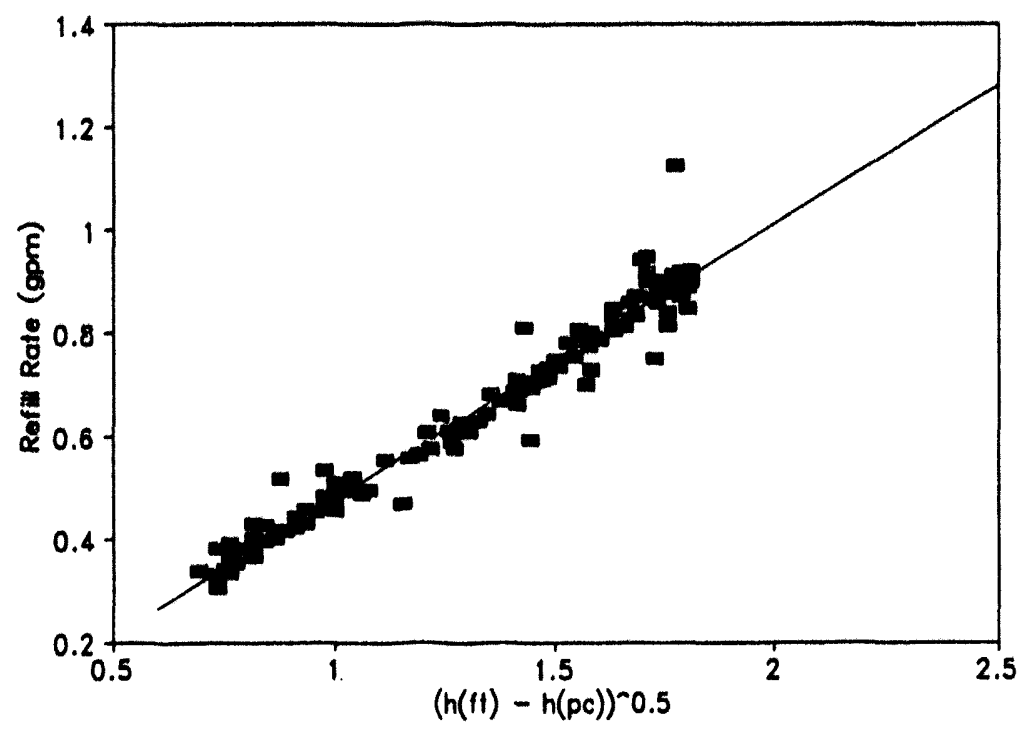

Figure 38. 1/4" VD(s) - 1/2" Fox Vortex Diode Jet Refil1 F1 ow

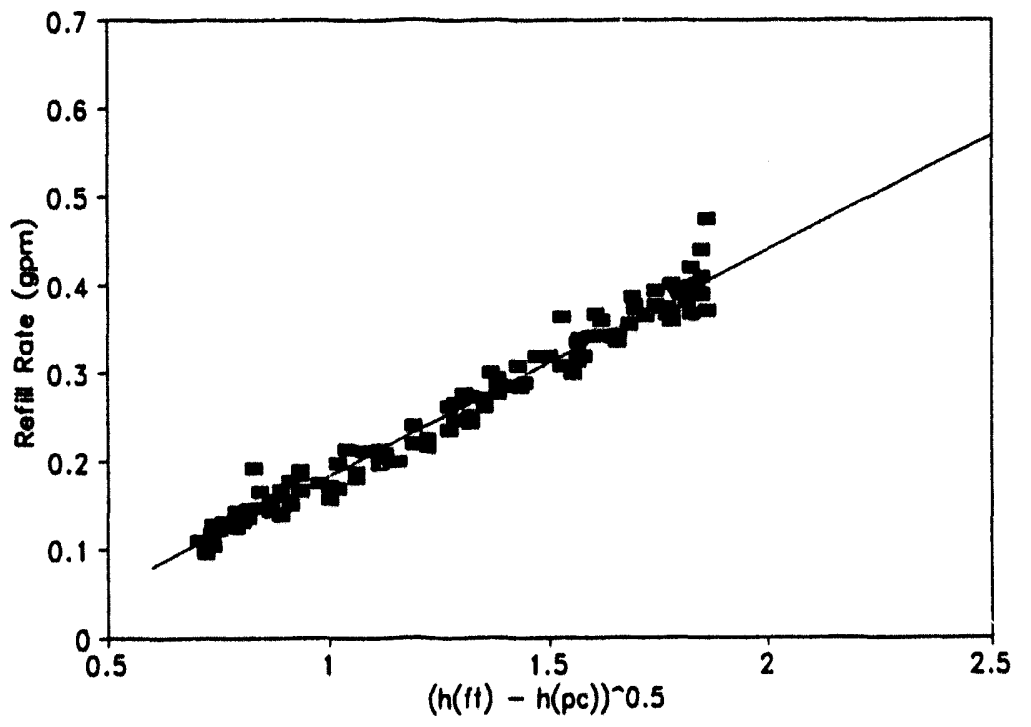

Figure 39. 1/2" Penberthy Jet Refil1 Flow 


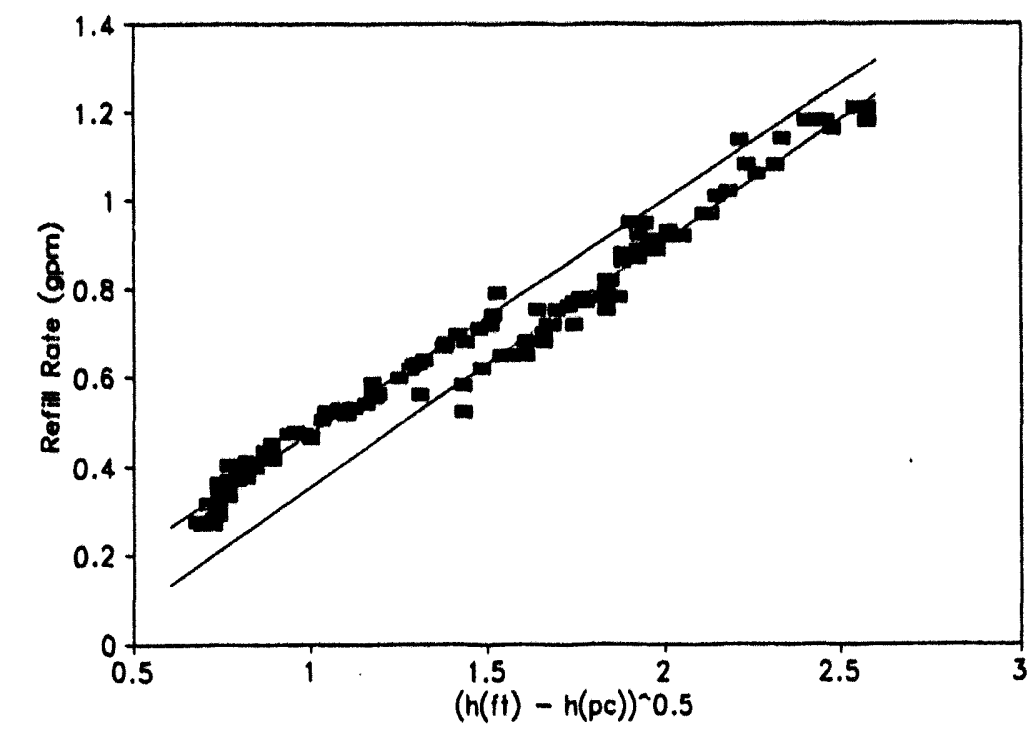

Figure 40. 1/4" VD - 1/2" Pen. Vortex Diode Jet Refill Flow

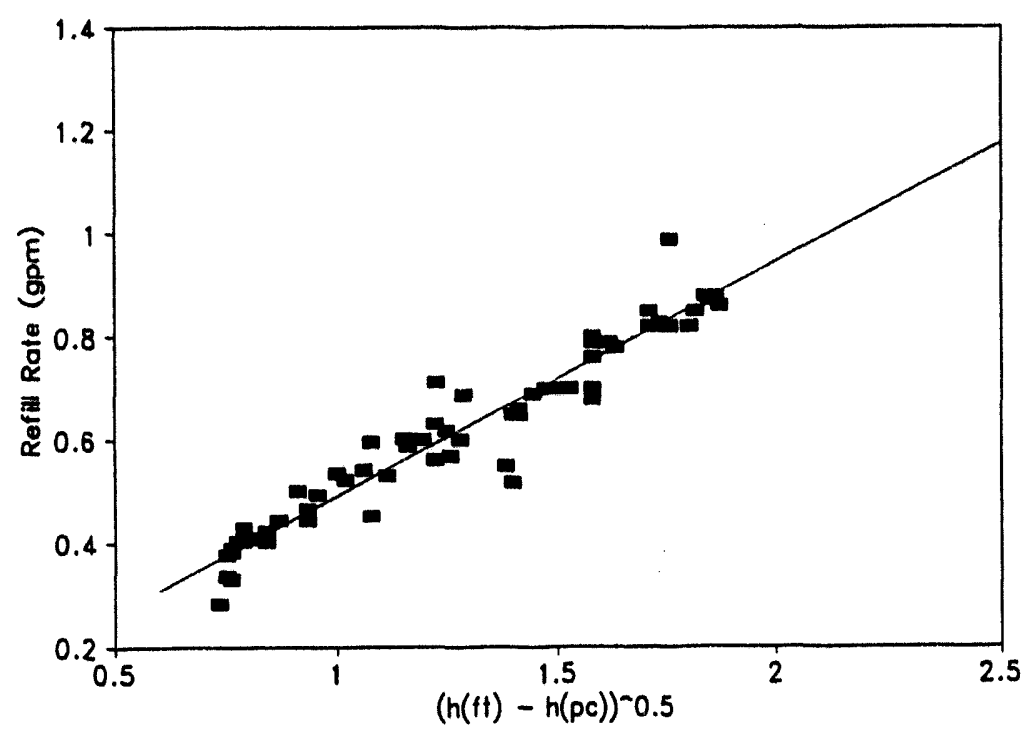

Figure 41. 3/8" VD - 1/2" Pen. Vortex Diode Jet Refill Flow 


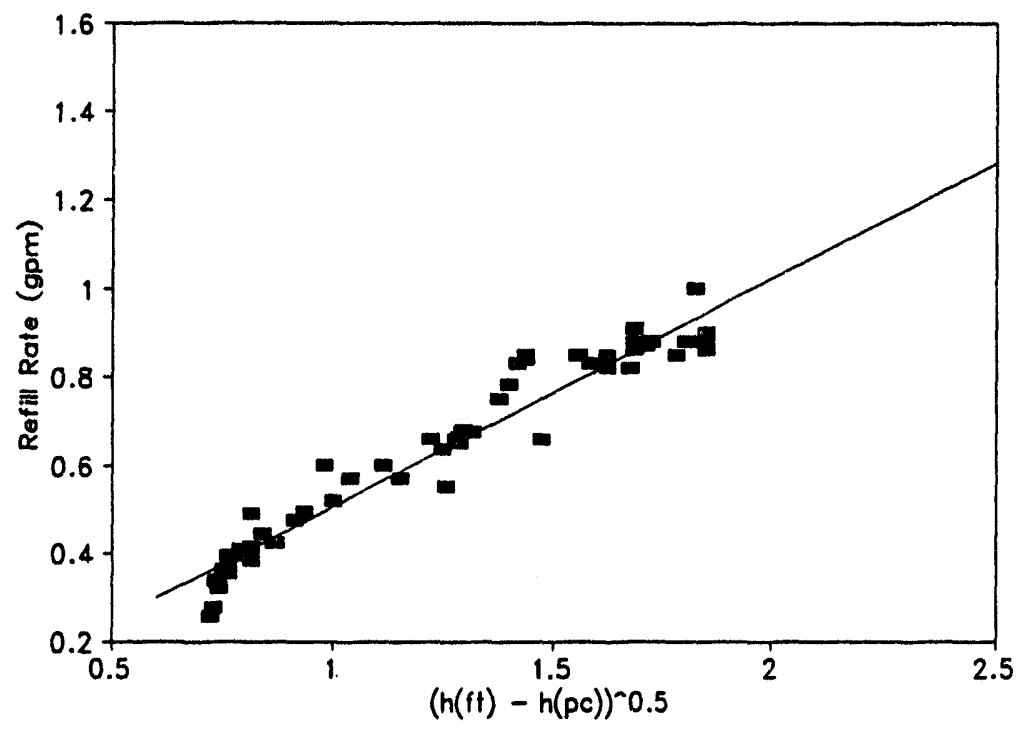

Figure 42. 1/2" VD - 1/2" Pen. Vortex Diode Jet Refil7 Flow

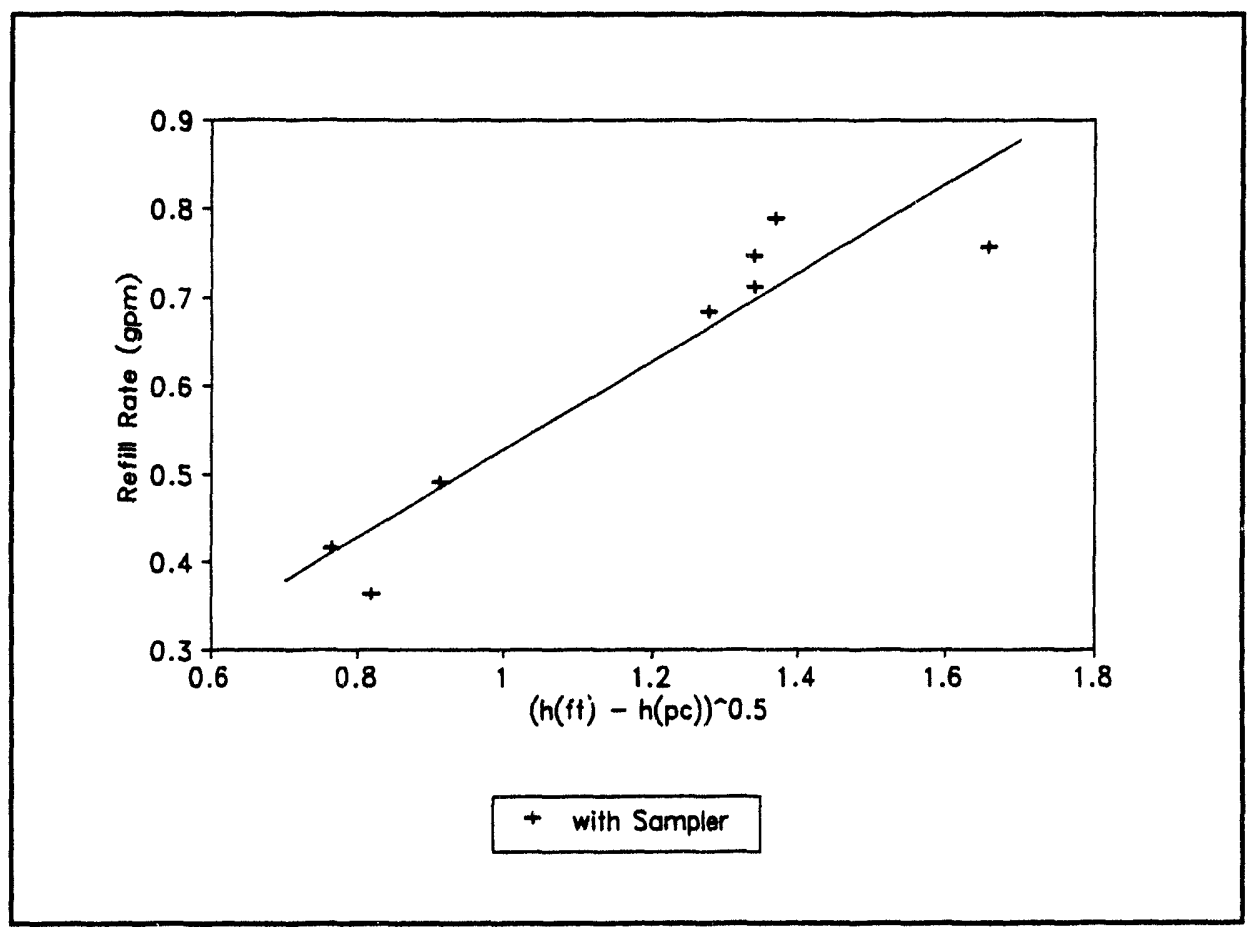

Figure 43. Jetless Refill Flow 

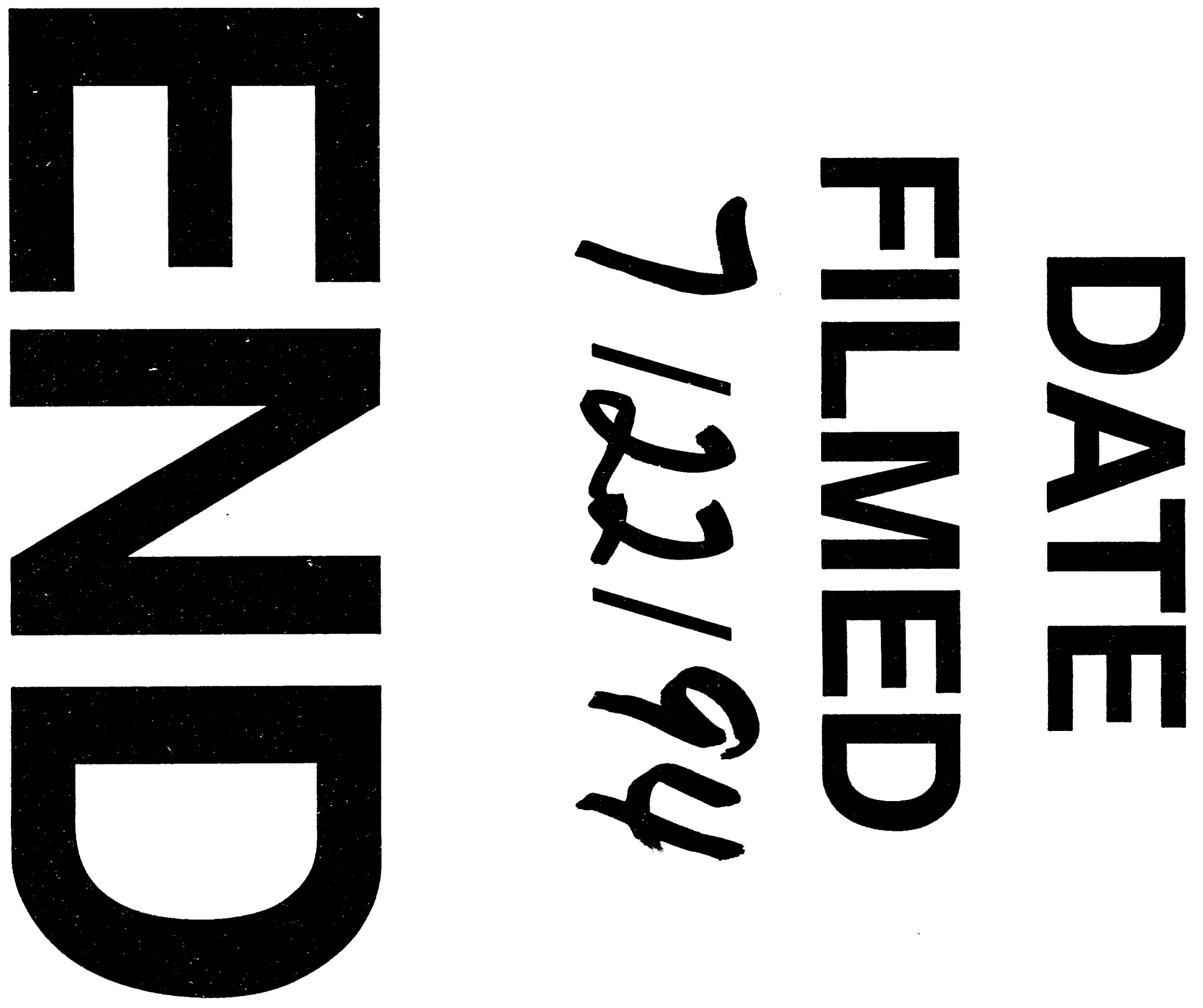
